\title{
A STUDY OF THE OPERATIVE TREATMENT FOR LOSS OF NERVE SUBSTANCE IN PERIPHERAL NERVES.
}

\author{
G. CARL HUBER, M.D.,
}

Assistant Professor of Histology and Embryology in University of Mrchigan.

THE far-reaching pathological changes which result from loss of continuity in peripheral nerves, and the relative frequency of such injuries, have for many years aroused the attention of physiologists and surgeons. The very voluminous literature bearing on this subject is rich in experimental and clinical observations.

All the evidence, experimental and clinical, goes to show that the function of a divided nerve (peripheral) can be restored if the severed ends are brought together, and retained in close apposition by means of a suture or otherwise; that a careful coaptation of the divided ends favors return of function; and that the results are more hopeful if only a short time intervenes between the injury to the nerve and the application of the suture. The underlying principle in all operations for the repair of a divided nerve is, therefore, to obtain as rapid and as accurate approximation of the divided ends as possible.

That return of function may take place even though the divided ends are not carefully adjusted and retained in position, has been shown experimentally and clinically. Surgeons regret the fact, that, after dividing and even resecting a nerve, to alleviate neuralgic pains, the pain may return again, in a longer or shorter time.

Notta, Langenbeck and Hueter, and Weir Mitchell report cases where spontaneous return of function occurred after loss of nerve substance.

In 1827 Tiedemann cut the nerves in the branchial plexus of a dog, and removed IO- 12 centimeters. Complete loss of sensation and motion occurred. Within the next two years these were restored, and in 1829 , when the dog was killed, the defect was completely healed. 
These cases must, however, be looked upon as exceptions, and not considered as disproving the general principle laid down.

In the great majority of cases the surgeon will have no difficulty in bringing the divided ends of a nerve together and applying a suture. The injuries to which peripheral nerves are exposed (among which may be mentioned cuts with sharp instruments, glass or saws, gunshot wounds, etc.) are of such a nature that not much nerve tissue is removed. This is, however, not always the case. In laceration wounds of an extremity several inches of a nerve may be destroyed; in removing tumors involving nerves the resected ends may be far apart, and again, in cases where inflammation and suppuration follow injury to a nerve, the stump may become so imbedded in a mass of cicatricial tissue that without long and tedious dissection the severed ends cannot be found : at such times the surgeon cannot resort to nerve suture.

A number of methods have from time to time been suggested to obviate the difficulties arising in such cases. To try these methods experimentally, and to establish if possible their comparative value, has been the object of this investigation. Much experimental work dealing with these questions has already been done. A review of this work, with a table giving some clinical cases, will form the first part of this paper. The record of the author's experiments, and the physiological observations made, will be presented in the second part; and the results of the microscopical examinations in the third part. It is hoped that the subject may be more clearly and completely presented in this form.

\section{Part I. - Review of Literature.}

The various methods which have been employed in the treatment of nerve injuries with loss of nerve substance may best be grouped under the following heads :-

(a) Nerve stretching (Schüller).

(b) Implantation of a nerve segment removed from a recently amputated limb or from one of the lower animals.

(c) Tubular sutures (Vanlair). 
(d) Union of ends with catgut threads, or a bundle of catgut threads (suture à distance, Assaky).

(e) Nerve flap from central stump, or a flap from both central and peripheral stumps (autoplasie nerveuse à lambeaux, Létiévant).

$(f)$ Grafting of the central end of the peripheral stump of a divided nerve to an accompanying nerve trunk (greffé nerveuse, Létiévant).

$(g)$ Cross-suturing the long central and peripheral stump, in cases where two accompanying nerves are cut obliquely, and grafting the central short stump to central long one, and peripheral short stump to peripheral long one (Létiévant, Tillmanns).

(h) Resecting the bone or bones in the extremity and suturing the nerve (Löbker).

(a) Nerve Stretching. - Schüller does not mean to be understood as advising actual stretching of a divided nerve, but states that a nerve can be drawn out from the loose connective tissue surrounding it, and then, by placing the extremity in a position which relaxes the nerve, the separated ends can often be brought together. The force should be applied to the longer end. Kölliker estimates that a separation of 2 to $3 \mathrm{ctm}$. may in this way be overcome. Schüller has shown that, in some instances at least, the ends may be brought together after a separation of 4 to $5 \mathrm{ctm}$. He reports the case of a man aged I9, who, nearly six months before Schüller saw him, had injured one of his median nerves under the annular ligament. Sensation in the median area of the hand was lost, and the muscles of the ball of the thumb had atrophied. After exposing the nerve and vivifying the ends, they were $5 \mathrm{ctm}$. apart. He was able to draw down the central end, and suture it to the peripheral stump. The report records a return of sensation in the part of the hand supplied by the median, and also a return of function in the thumb muscles.

Quite recently Von Hacker reports the case of a boy aged 9, who, about three months before the nerve suture was made, had fallen while carrying a glass pitcher, and had completely divided the left median a little above the elbow. Soon after 
the injury the bleeding was controlled, and the wound closed. After the dressing was removed, actual loss of sensation and motion in the hand was observed. At the time of the operation, the ends of the divided median were found to be 4 to 5 ctm. apart. They were drawn out as far as possible, and, after flexing the arm, he was able to bring them together and apply sutures. Function began to return several months after the operation.

It will be noticed that in neither of the above cases was there any loss of nerve tissue at the time of the injury. The separation of the ends seems to have been due to their retraction, and probably also to the contraction of the cicatricial tissue of the wound. I may suggest this as a reason why the separated ends could, in these cases, be brought together, while this was not possible in some of the cases where loss of nerve tissue occurred.

This method is by far the simplest and most natural, and should in all cases be tried; care being exercised to use no unnecessary force in attempting to bring the ends together.

(b) Implantation. - The first attempt at transplantation of a nerve trunk was made as early as 1869 . Philippeaux and Vulpian, in a series of experiments, resected the hypoglossal to the extent of $2 \mathrm{ctm}$. A segment of equal length was removed from the lingual of the same side, and implanted between the ends of the divided hypoglossal, and retained in place by sutures. Their aim seems to have been to determine whether a segment removed from a sensory nerve like the lingual, implanted between the resected ends of a motor nerve (in their experiment, the hypoglossal) would carry afferent impulses. This was tried on seven dogs. In only two of these experiments did the transplanted nerve unite with the resected ends of the hypoglossal. In one of the successful cases, stimulation of the central end excited movements of the tongue, which were more vigorous when the peripheral end was stimulated. On histological examination the transplanted lingual segment was found to consist largely of fibrous tissue and a few medullated nerve fibres. In the other experiment 
where union was obtained, the dog lived only twenty-four days, and there was no evidence of regeneration.

This operation was first tried on the human subject in 1878 . At this time Albert reported the case of a servant from whom he had removed a sarcoma, about as large as a hazel nut, from the median and with it so much of the nerve that the resected ends were $3 \mathrm{ctm}$. apart. Before closing the wound, he implanted a segment of a nerve taken from an amputated foot, and sutured the same to the ends of the median. The case was observed for ten days, at the end of which time the wound had healed. No further history is given.

To Glück must be given the credit of again trying implantation of nerves experimentally (apparently without knowledge of any earlier experiments of this nature), and of drawing attention in a number of published articles to the feasibility of this procedure as a legitimate operation in surgical practice.

We are told by Tschirschwitz that Glück, while investigating regeneration of divided nerves, was led to cut a peripheral nerve at two places, and found that, after suturing, regeneration was complete. He next resected a nerve and united the peripheral end of the resected segment to the central nerve stump and vice versa; in these experiments the results were also successful. A fowl and rabbit were then chloroformed, and $3 \mathrm{ctm}$. removed from the sciatic of the fowl, and $3 \frac{1}{2} \mathrm{ctm}$. exsected from the same nerve of the rabbit, transplanted, and sutured above and below with silk sutures. On the eleventh day after the operation, the wound, having healed by first intention, was again opened. The union was found to be "ideal"; only by its slight wavy appearance, and by the position of the sutures could the transplanted segment be localized. After isolating the nerve, it was pinched with forceps above the implanted segment and violent muscular movements ensued. The sciatic was then divided above the transplanted piece, and the peripheral end stimulated with the same result. In all, eighteen experiments were made, in some of which the results were equally favorable, in others not so satisfactory.

Glück states, "that a mixed (sensory and motor) implanted nerve unites by first intention, not only when the nerve is 
taken from the same, but also when taken from other species; the ends of the implanted segments must, however, be carefully sutured if this result is to be hoped for." Primary union of divided nerves is brought about through the agency of special cells, known, according to Glück, as "specific nerve granulation cells." These are large protoplasmic cells with long processes, and are developed from the nuclei of the sheath of Schwann. They assume a gray-green tinge when stained with osmic acid. The cells anastomose with each other, and unite the central and peripheral end of the divided nerve within the first few days. At the end of six to eight days this investigator notes the finding of young nerve fibres between the spindle-shaped cells. In the course of these young fibres are observed swellings, produced by large nuclei possessing prominent nucleoli, the nuclei resembling the nuclei of the "nerve granulation tissue cells" from which the new fibres are thought to have been developed.

The possibility of union of divided nerves by first intention, i.e., without degeneration of the peripheral end, finds only a few advocates among the many writers who have given thought to this question. Of these, the views enunciated by Gliick, based on his interpretation of the experiments above mentioned, are the most outspoken, and most frequently quoted. With him are to be identified Wolberg and Bruch. The former reports one experiment in which primary union took place; this was after partial section of a cat's sciatic. The latter describes one experiment on a kitten where this favorable result was obtained.

The observations of Glück, Wolberg, and Bruch are, however, so at variance with the results obtained by other investigators, that it is difficult to find a suitable explanation for them, or to accept them without further corroboration. In proof of this, I may be allowed to quote from a number of the more recent writings dealing with nerve de- and regeneration.

Bünger states "that every nerve severed from its center undergoes degeneration. The possibility of union by first intention, as upheld by Glück and Wolberg, is for this reason not tenable." Howell and Huber, while admitting Glück's 
results as "positive and unmistakable," draw attention to a failure on his part to make a thorough histological examination of the peripheral nerves. In all their experiments, section of a nerve was followed by complete degeneration of the peripheral end.

Stroebe, in a very comprehensive and able research, expresses himself as follows: "Aus allen meinen Experimenten geht hervor, dass die durch Compression von ihrem 'trophischen' Centrum, den Ganglion-Zellen im Central Nervensystem oder Spinal-Ganglion, abgetrennten Nervenfasernabschnitte des Ohrnerven und Ischiadicus jeweils regelmässig der Degeneration anheimfallen, welche sowohl den Axencylinder als die Markscheide ergreifen. Eine Wiedervereinigung der gequetschten Faser an der Druckstelle per primam intentionem, welche zu einer physiologischen und morphologischen Restitution der Nerven führen würde, bevor und ohne dass die Degeneration in der peripheren Strecke zur Ausbildung kommt, giebt es nicht."

In Notthaft's article we read: "Nach jeder Verletzung (Verbrennung, Quetschung, Durchschneidung), welche die Nervensubstanz an irgend einer Stelle total zerstört, kommt es zu einer Degeneration des ganzen Peripher von der Verletzungsstelle gelegenen Nervenabschnittes und eines kleineren etwa $I-5 \mathrm{ctm}$. betragenden Centralen-Stückes. Eine Heilung durch prima intentio im Sinne Schiff's giebt es nicht."

The accumulated evidence of nearly all workers in this field coincides with the above statements. In the experiments to be recorded in the second part of this paper, fifty in number, peripheral degeneration followed every nerve section.

Transplantation of nerves has further been tried experimentally by Johnson. His experiments, three in number, were on fowls. In two he resected the sciatic on one side, and transplanted a segment taken from the opposite sciatic. The animals were killed, the one twenty-eight, the other thirtyfour days after the operation. In the third experiment he implanted a segment removed from a rabbit's sciatic between the resected ends of a fowl's sciatic. This animal was allowed to live twenty-three days after the operation. In each case 
the implanted segment was found to be united to the resected ends of the nerve, but the transplanted portion possessed no conductivity. Tillmanns, in referring to Johnson's experiments, calls attention to the short interval intervening between the operation and the date of the examinations, and correctly assumes that regeneration might have taken place if a longer time had elapsed.

In a series of fifteen experiments recorded by Assaky, dealing with the operative treatment of " nerve defects," transplantation of a nerve was made in four.

(Exp. 3.) A rabbit's sciatic was resected $3 \mathrm{ctm}$; a segment $3 \frac{\mathrm{y}}{2} \mathrm{ctm}$. long, taken from the sciatic of a turkey, was implanted, and sutured above and below with fine catgut. The animal was examined thirty-five days after operation. On pinching the nerve above the implanted segment slight flexion of the foot was observed. The same result when stimulated with the induction coil. On histological examination a few nerve fibres were found in the implanted and peripheral nerve.

(Exp. 12.) The operation was the same as above. The animal was killed sixty-eight days after operation, and the abdominal aorta injected with gelatine and Berlin blue. The operated leg was seized with clonic convulsions. However, these were not as vigorous as on the well side. No new-formed fibres were found in the implanted segment.

(Exp. I 4.) The median of a dog was resected $3 \mathrm{r} / 2 \mathrm{ctm}$., and a piece of equal length, taken from a rabbit's sciatic, was implanted. The dog was killed thirty-eight days after operation. A cord of fusiform shape was found to unite central and peripheral stump of the median. On cutting into this it was found to contain a "pus-like" substance. No histological examination was made.

(Exp. 15.) Implantation of a segment from rabbit's sciatic between the resected ends of a dog's sciatic. The operation was a failure.

The rapid return of function, obtained by Assaky in the first of the four experiments just quoted, would seem to show that regeneration occurs more speedily in rabbits than in dogs, the animals used by the author in his experiments.

Bünger gives the result of one experiment in which he exsected I ctm. from the right sciatic of a dog, and transplanted a segment from the other sciatic. Fifty days after the operation the nerve was examined; at this time he was not able to state what had become of the implanted segment, as in its place were found newly formed nerve fibres. He is, how- 
ever, of the opinion that the elements of the transplanted nerve furnished the material for the newly formed fibres. He traces the development of the new axis cylinders from the mitotically increased nerve nuclei and proliferated protoplasm of the sheath of Schwann belonging to the nerve fibres of the implanted segment. Before dissenting from Bünger's interpretation of this experiment, it is necessary and just to explain what his position is concerning degeneration and regeneration of divided nerves. In the first place, he states that there is no time interval separating degeneration and regeneration; regeneration begins soon after the former is initiated, and goes on while degeneration is drawing to a close.

In the guinea pigs used for experimentation the axis cylinder and myelin disintegrate soon after injury to the nerve. At the beginning of the third day the nuclei of the sheath of Schwann begin to divide karyokinetically, and at the same time a proliferation of the protoplasm is noticed. The increase of the nuclei and protoplasm marks the beginning of the regenerative process. This increase continues while the myelin and old axis cylinders are degenerating. Toward the end of the second week the proliferated nuclei begin to arrange themselves in one or two (very seldom more) rows, parallel to the long axis of the nerve ; and the protoplasm, which up to this time has been homogeneous, begins to be longitudinally striated. "The fibrillar striation is the anlage of the new axis cylinder, and is developed from the protoplasmic contents of the nerve fibres." This is first observed near the wound. By the end of the second week the new axis cylinders have developed centrifugally some distance away from the seat of injury, and are richly beset with nuclei. In the third week a thin continuous layer of myelin surrounds the axis cylinder. Later another sheath of myelin developing in segments blends with the continuous sheath. The nerve fibres developing in the periphery unite with newly formed fibres, which have their origin in proliferated nuclei and protoplasm of the peripheral end of the nerve fibres in the central nerve stump. These observations were made on degenerating and regenerating nerves hardened in Flemming's solution and stained in safranin, a method 
which, with Stroebe, I must condemn as unsuitable for axis cylinder differentiation. I am, furthermore, in accord with this writer in believing that neither Bünger's illustrations nor the description of his section sustain him in his statements. The unequivocal results obtained by the anilin blue-safranin method, as first employed by Stroebe, a stain which gives an axis cylinder differentiation far clearer than when safranin alone is used, leads me to say that the proliferated nuclei of the sheath of Schwann of a degenerating peripheral nerve, or of a degenerating implanted segment, play no part in the development of the axis cylinder. It is an outgrowth of the axis cylinder of the nerve in the central end, as was first clearly shown by Ranvier, later held by Vanlair, Howell and Huber, Stroebe, and Notthaft.

It may further be stated that a number of embryological observations show that the sheath of Schwann and its nuclei, as also the medullary layer, are of mesoblastic origin, while nerve cells and axis cylinders are developed from the epiblast. The axis cylinders are outgrowths from nerve cells ; the naked axis cylinders constitute, at one stage in the development, the entire peripheral nerve. Mesenchymal cells apply themselves to the outside of bundles of naked axes, and grow in between them, and from these the medullary and sheath of Schwann are developed. Minot states "that each cell is the anlage of a medullary segment, the junction of two adjacent cells is the anlage of a node of Ranvier, and the nucleus becomes the internodal nucleus of the sheath of Schwann." (See, also, His, Vignal, and Kölliker.)

In the three experiments of transplantation mentioned by Notthaft only $1 / 2 \mathrm{ctm}$. was removed from the sciatic of a rabbit. In one instance the exsected segment was again inserted; in the other two a portion was removed from the opposite sciatic, implanted, and fixed with sutures between the resected ends. After fifty days there was regeneration through the implanted piece. Notthaft's experiments can be of little practical importance, as the distance between the resected ends could easily have been overcome by stretching the nerves and applying a suture in the ordinary way. 
Quite recently Dr. De Forest Willard, in a communication ciealing with nerve sutures, reports fourteen experiments, two of which have to do with implantation.

In one of these $3 / 4$ of an inch was removed from the left sciatic of a dog. The segment was reinserted and sutured with fine catgut. Twenty days later the right side was operated upon in the same way. The dog was killed forty-four days after the first operation. On the left side the sciatic was bulbous at the seat of operation, the bulbs being united by a bridge about half the size of the nerve. On the right side there was a thickening of connective tissue which included the graft. In the other experiment $3 / 4$ of an inch was removed from the sciatic of a dog, and a segment of nerve $\backslash 7 / 8$ of an inch was taken from the sciatic of another dog, implanted, and sutured. The dog was killed on the thirtieth day. A small bridge united the divided ends of the sciatic. Physiological and histological examinations, if made, were not reported.

The results obtained in the experiments reviewed may be summed up in the table on the following page.

Excluding the experiments of Glück (for reasons already given), we find only one instance where, after the removal of a segment more than $3 \mathrm{ctm}$. long, followed by implantation, recovery is reported.

The above table also shows that Glück is the only experimenter that has obtained union by first intention.

The large number of failures and "doubtful" cases would not speak encouragingly for the adoption of this method in surgical practice. That much more favorable results may be hoped for, if the animals are observed for a time long enough to admit of regeneration, I hope to show in the experiments recorded later on.

(c) Tubular Suture. - Glück experimentally tried implantation of substances other than nerve tissue, using bands of Danish leather, a bundle of catgut threads, strips of muscle and skin, and finally inserting the resected ends of a nerve into a "Neuber's bone drain." In these experiments the implanted substance now and then made "connective tissue union" with the pineurium of the nerve. However, it was usually absorbed or mummified. In no instance did regeneration of the peripheral end occur. 
TABLE No. I.

\begin{tabular}{|c|c|c|c|c|c|c|c|c|}
\hline \multirow[b]{2}{*}{ EXPERIMENTER. } & \multirow[b]{2}{*}{$\begin{array}{l}\text { ANumal } \\
\text { UsED. }\end{array}$} & \multirow{2}{*}{ 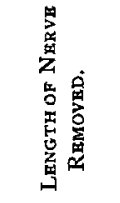 } & \multirow{2}{*}{ 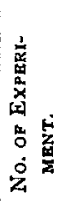 } & \multicolumn{4}{|c|}{ Results. } & \multirow[b]{2}{*}{ Remarks. } \\
\hline & & & & 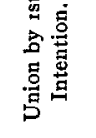 & 离 & 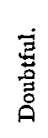 & 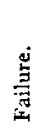 & \\
\hline $\begin{array}{l}\text { Philippeaux } \\
\text { \& Vulpian }\end{array}$ & Dogs. & $\begin{array}{c}\text { About } 2 \\
\text { ctm. }\end{array}$ & 7 & $\ldots$. & I & $\ldots$. & 6 & \\
\hline Glück . . . & Fowls. & $\begin{array}{c}\text { About } 3 \\
\mathrm{ctm} .\end{array}$ & 18 & $\begin{array}{l}\text { In } \\
\text { some } \\
\text { cases. }\end{array}$ & $\ldots$ & $\ldots$ & $\ldots$. & $\begin{array}{l}\text { A full report } \\
\text { not given. }\end{array}$ \\
\hline Johnson. . . & Fowls. & $\cdots$. & 3 & $\ldots$. & $\ldots$ & $\ldots$. & 3 & $\begin{array}{l}\text { Animals ob- } \\
\text { served } 23-34 \\
\text { days after } \\
\text { operation. }\end{array}$ \\
\hline Assaky ... & $\begin{array}{l}\text { Rabbits } \\
\text { \& Dogs. }\end{array}$ & $2-3 \mathrm{ctm}$ & 4 & $\ldots$. & I ? & I & 2 & \\
\hline Bünger ... & Dog. & I $\mathrm{ctm}$. & I & $\ldots$ & $\mathrm{I}$ & $\ldots$ & $\ldots$ & \\
\hline Notthaft .. & Rabbits. & $1 / 2 \mathrm{ctm}$. & 3 & $\ldots$. & 3 & $\ldots$. & $\ldots$. & \\
\hline Willard ... & Dogs. & $3 / 4$ in. & 2 & $\ldots$. & $\ldots$ & 2 & $\ldots$. & $\begin{array}{l}\text { Neither histo- } \\
\text { logical nor } \\
\text { physiological } \\
\text { examination } \\
\text { reported. }\end{array}$ \\
\hline
\end{tabular}

Soon after Glück's results were made known Vanlair instituted a series of control experiments, using bone drains as a means of uniting the ends of the resected nerve. The sciatic of a young dog was exposed, $3 \mathrm{ctm}$. removed, and the central and peripheral ends were placed into a decalcified bone tube, and retained in position by catgut sutures. After four months the dog was killed, and the operated nerve laid bare. With the naked eye nothing was seen of the bone tube. The nerve was removed and hardened, and after sectioning, two small fragments of bone were found imbedded in the tissue uniting the resected nerve stump. This tissue contained many newformed nerve fibres, some of which were even found in the 
Haversian canals of the unabsorbed bone. In the peripheral end new fibres were found between the degenerated old sheaths. Other experiments of a similar character have from time to time been reported by Vanlair. He recognizes in "bone drain suture" a group of mechanical condition most favorable for aiding regeneration of nerves after loss of substance, and has gained the conviction that, experimentally, one could reproduce a nerve segment which in length had no limit other than that of the member containing the injured nerve. He was further able to change the course of a nerve by placing the peripheral end of the central stump of a resected sciatic into a bone drain and imbedding the other end of the bone tube in a long, deep incision made in the muscular tissue of the leg, where it was retained by catgut sutures. The wound was then closed. The animal died $6 \frac{x}{2}$ months after the operation. $U p$ to that time no return of function had been observed in the leg and foot operated upon. At the post-mortem examination the end of the central sciatic was found bulbous, and from this enlargement could be traced a small cord ending in the muscle; this consisted of nerve fibres, the bundle becoming smaller and the fibres less numerous the further away from the central sciatic the observation was made. Vanlair was able to trace the new fibres $6 \mathrm{ctm}$. from the bulbous enlargement, and states that he might no doubt have followed them still farther had not the scalpel cut them. The peripheral sciatic was degenerated. This experiment seems to me to offer most convincing evidence that the nerve fibres are an outgrowth from the fibres of the central end; any other explanation seems to me untenable. The peripheral end could in no way take part in the development of the new fibres, and it can hardly be believed that the elements of a decalcified bone tube, or the connective tissue or muscle surrounding it, could furnish any material from which new nerve fibres might have been developed.

Bünger, in two instances, united the resected ends of a dog's sciatic, from which I ctm. of nerve tissue had been removed, with a human brachial artery. At the end of forty-three days the space which separated the nerve ends was filled with new fibres. They were arranged in parallel order within the 
lumen of the artery, the elastic tissue of which had not been fully absorbed. A number of small branches left the artery through small openings in its wall, and were lost in the surrounding tissue. Before removing the nerves they were tested with an induction current and showed conductivity. Bünger concludes : "Dass die Regeneration grösserer Nervenstrecken nach Resection unter der Bedingung leicht zu Stande kommt, wenn denen von beiden Enden neugebildeten Fasern der Weg und die Richtung gewiesen wird." It is not necessary at this place to again discuss the question whether or not regeneration of the peripheral end from the peripheral nerve fibre can occur. Bünger has, as far as I am able to ascertain, not studied experimentally the fate of the peripheral end after resection. He would have us believe, basing the assumption on observations made by him on degenerating and regenerating nerves after simple section, that, after resection, there is regeneration of the fibres in the peripheral portion from the proliferated protoplasm and nuclei of the degenerating nerves. In four of the author's experiments, where five, ten, twenty-two, and fifty-four days elapsed between the operation and examination, the peripheral stump was in process of degeneration or completely degenerated ; nothing that would point to a regenerative process in the peripheral nerves was observed. I therefore believe that I am justified in hesitating to accept Bünger's conclusions until they receive further corroboration.

The literature bearing on this subject is further enriched by experiments reported by Notthaft and Willard.

The former in two cases exsected $1 / 2 \mathrm{ctm}$. from the sciatic of a rabbit, and united the ends with a segment taken from the aorta of a rabbit. No regeneration was observed after fifty days. The latter resected the sciatic of an old Newfoundland dog for $3 / 4$ of an inch, and inserted $1 / 3$ of an inch of the two resected ends into a decalcified bone tube, retaining the same in position by catgut sutures. In ten days the dog was killed, and it was found that the tube had entirely disappeared, and no regeneration had taken place.

The early absorption of an implanted bone tube was also noticed by me in experiments of short duration, and is, of course, an objection to this method. The tubes used in the 
author's experiments were decalcified in a one per cent solution of hydrochloric acid, and thoroughly washed in flowing water. It may be that this rapid absorption could in some degree be retarded by decalcifying in chromic acid; no practical test was, however, made of this.

(d) Suture à Distance. - Believing that a divided peripheral nerve is regenerated through axis cylinders budding from the central end, and recognizing the fact that it is necessary to make it mechanically possible for the down-growing central fibres of a resected nerve to reach the peripheral end, Assaky tried experimentally to create such suitable mechanical conditions by uniting the ends of a resected nerve with catgut threads, expecting that these would guide the regenerating fibres, and thus aid them in reaching the peripheral part of the nerve. Assaky's experiments were of the following nature :-

In an adult dog he resected 35 millimeters from the left sciatic, and united the ends, which were fixed at a separation of $3 \mathrm{ctm}$., with four threads of No. 3 catgut. The wound was closed with silver sutures, and a drain was placed into the dependent part of the wound. The dog was killed thirty-five days later. The nerve stumps were found united with a cord somewhat smaller than the nerve itself. After cutting the nerve above the seat of section and rubbing across the distal end, no contractions were noticed. Compression of the nerve excited a single movement. When stimulated electrically, the muscle would contract slowly, "contracting as with regret." Histological examination revealed newly formed fibres in the cord uniting the resected ends, some of which possessed a thin sheath of myelin, others were naked. In the peripheral stump the old degenerated sheaths were found accompanied by fibres newly formed and as yet without a medullary sheath. Six experiments were made, four on dogs, two on rabbits. The length of time intervening between the operation and the examination varied in experiments on the dogs from thirty-five to eighty days, on the rabbits from sixty-seven days to four months. The distance at which the nerve ends were sutured varied from 3 to I $1 / 2 \mathrm{ctm}$.

A review of these experiments shows a favorable termination in each case; in all, nerve fibres were found in the band uniting the central and peripheral nerve; conductivity of nerve impulses had been established, as was shown by contraction of the muscle when stimulating the sciatic above the seat of injury, and this after the nerve had been cut some distance above the place of resection. 
The rapid return of function obtained in the first of the above four experiments is rather surprising. There would, however, seem to be no reason why Assaky's interpretation should not be accepted. In one of my own experiments, where an ulnar nerve was resected to the extent of $6 \mathrm{ctm}$., and a "suture à distance" applied, there was no regeneration at the end of thirty-nine days. This may be owing to the fact that in my experiment the down-growing axis cylinders met with greater resistance, as no doubt the connective tissue developing around the catgut threads had an opportunity to become more firmly organized before the developing axes could reach the peripheral end. By way of explanation, I may state that, in all cases of division of a peripheral nerve, the regeneration of the peripheral end depends on the outcome of a struggle between the down-growing axis cylinders and the developing connective tissue between the severed ends, a fact which I hope to show later on in this paper.

This method has further been experimentally tried by Willard, by whom four operations are reported. The results are as follows :-

From the right sciatic of a black pup $1 / 4$ inch was removed. The divided ends were stitched with fine chromatized catgut, purposely leaving them $1 / 4$ inch apart. After forty-six days the dog was killed. The site of operation upon the nerve was distinguishable only by a slight enlargement, and to the naked eye there apparently had been union. The microscope showed that only one bundle of the nerve trunk had been severed. The ends of the divided portion had separated $1 / 2$ inch, and were united by fibrous tissue, scattered through which were found many nerve fibres. Judging from the figure (No. 2) given by Willard, the new fibres do not seem to have reached the peripheral end of the nerve. The left side of the same dog was operated upon the day following the first operation ; 3/4 of an inch was removed from the sciatic, and a bundle of catgut strands was stitched between the ends. Microscopical examination showed the upper fragment ending in a bulb of fibrous tissue containing numerous nerve fibres, these radiating from the termination of the nerve fibres. The peripheral fragment was degenerated, the new fibres not having penetrated it. (See Fig. I of Willard's article, which represents a longitudinal section of the nerve operated upon in the second experiment. The central fibres of the stump are shown in the process of growing down toward the peripheral end; it would seem safe to assume that in time regeneration would have been complete.) In two other experiments of implantation of 
a catgut bundle, one was observed fourteen, the other thirty-five days after the operation; no regeneration was noticed.

No physiological examination was made in any of the above experiments.

(e) Nerve Flaps. - Létiévant has recommended three operations which may be performed when there is loss of nerve substance. Of these the making of a flap from the central or peripheral stump, or both, is the one more generally known, and is one of the procedures usually mentioned in surgical text-books. With a sharp knife or bistoury the nerve is split for a distance equal to about the length of the nerve segment lost; the division beginning a short distance from the end of the stump. One of the halves is cut free at its central end (if the flap is made from the central portion), turned down, and stitched to the peripheral stump. Létiévant reports a case where the method was employed (see case No. I7 of table). The simplicity of the method has no doubt done much to win for it approval. It must not, however, be forgotten that it is open to a number of objections. In the first place, assuming that regeneration of the peripheral end takes place through the agency of axis cylinders, which bud from the nerves of the central stump, and remembering that all experimental work shows that it is necessary to create favorable mechanical conditions for these down-growing axes; I must call attention to the fact that, after turning a flap on its base, the lower end of the nerve fibres of the central segment are not in line with the fibres in the flap, but are rather bent from the course of the nerve at an angle of about $90^{\circ}$, an observation which can easily be made after this portion of the operation has been concluded. The down-growing axis cylinders are, therefore, not guided toward the flap and thence to the peripheral end of the nerve, but bud into the connective tissue surrounding the peripheral end of the central stump, as is clearly shown in longitudinal sections through this region. In the second place, the flap degenerates completely (its connection with the central end in no way retarding this) with a result that we have a condition similar to the one where a nerve is implanted, except that in the latter case a more favorable approximation 
with the central end may be attained, and the central nerve segment is not subject to further mutilation.

Three experiments of Willard are interesting in this connection. In these $1 / 2$ in., $3 / 4$ in., and $I / 2$ in., respectively, were removed from the sciatics of three dogs. The ends were split longitudinally, the flaps turned on their base, and united with chromatized catgut. The animals were killed on the tenth, twenty-eighth, and forty-seventh days. The flap and the peripheral part of the nerve were found degenerated. If I understand Willard correctly, regeneration of the peripheral end was not observed, although in the first experiment, the fibres coming from above, separated into a fan-like expansion, but did not reach the peripheral nerves.

(f) Nerve Grafting. - Létiévant further recommended that the central end of the peripheral segment of a divided nerve, in case it cannot be sutured to the central portion of the same nerve, be fixed by means of sutures to an accompanying nerve. He suggested that the uninjured nerve be denuded of its epineurium at the site of suture. This method can, of course, only give favorable results if, while the epineurium is being removed from the uninjured nerve, some of its fibres are divided. These, in regenerating, we can assume, may grow into the grafted nerve.

As far as I have been able to ascertain, the only experimental observations bearing on this method are reported by Moses Gunn. At his request, Dr. W. H. Sheldon made a series of operations on dogs, which involved the removal of a segment from the ulnar nerve, and the grafting of its peripheral portion to the accompanying median. He states, "that the operations were generally successful, and apparently indicate that through the engrafted connection the parts supplied by the ulnar received their innervation." In another experiment made by Dr. Sheldon, where the ulnar was resected and not grafted, sensation or motion in the parts supplied by this nerve were, after the healing of the wound, in no way impaired. Gunn concludes that this experiment destroys entirely the value of the other. 
We are again indebted to Létiévant for the suggestion of cross-suturing the long stump of two divided nerves in cases where the injury is of such a nature that the nerves are cut at a different level. This suggestion admits of adoption only when the injured nerves lie in close proximity, as, for instance, the median and ulnar. That it is possible to obtain return of function after suturing the central end of one nerve to the peripheral end of another, has been shown experimentally by Flourens, Bidder, Gluge and Thiernesse, Philippeaux and Vulpian, Rawa, Gunn, and Howell and Huber. It is evident that only one of the divided nerves can in this way be regenerated, the peripheral end of the other degenerating.

Tillmanns recommends that, after cross-suturing, the short central segment should be grafted on to the long central, and the short peripheral to the long peripheral. This modification does not seem to me to enhance the value of Létiévant's operation. In one experiment by the author, the peripheral short segment was found to be completely degenerated, and the central short stump ended in a large bulb, beyond which no nerve fibres could be traced.

$(g)$ Resecting the Bones in the Extremity, and Suturing the Injured Nerves, - As a very extreme measure may finally be mentioned a method by Löbker, that of subperiosteal resection of the bone or bones in the extremity to such an extent that the separated nerve stumps can be brought together and sutured. The possibility of want of union between the ends of the resected bones, and the fact that regeneration of the peripheral end has been attained after the employment of measures less formidable, should cause hesitation before this method is determined upon.

\section{Report of Surgical. Cases.}

Nothing like a complete tabulation of the surgical cases in which a defect in a peripheral nerve was treated by operative means, has, as far as I am aware, been made. Damer Harrison has given us a list of ten cases of nerve implantation. This, I think, is the largest number yet collected. 


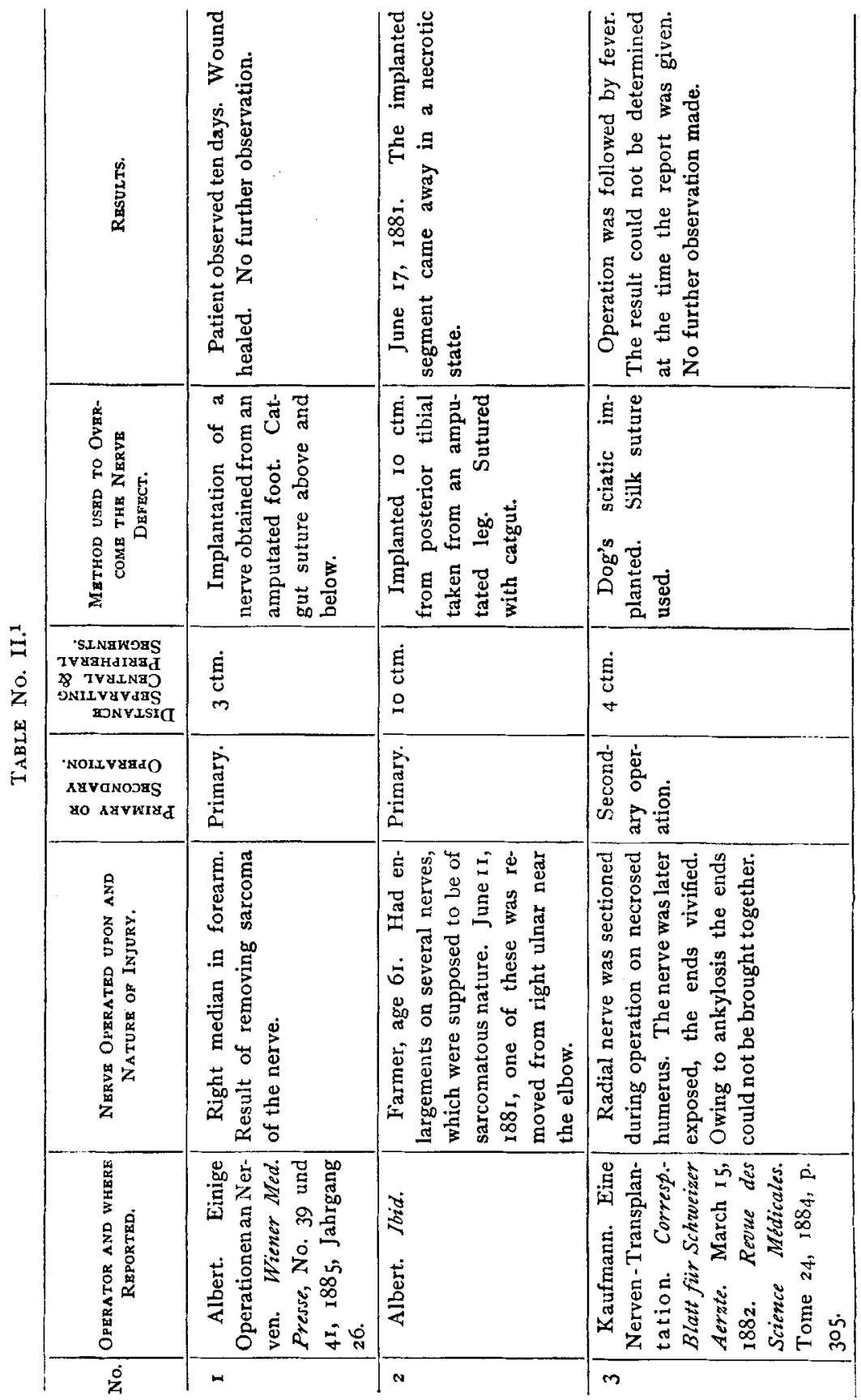




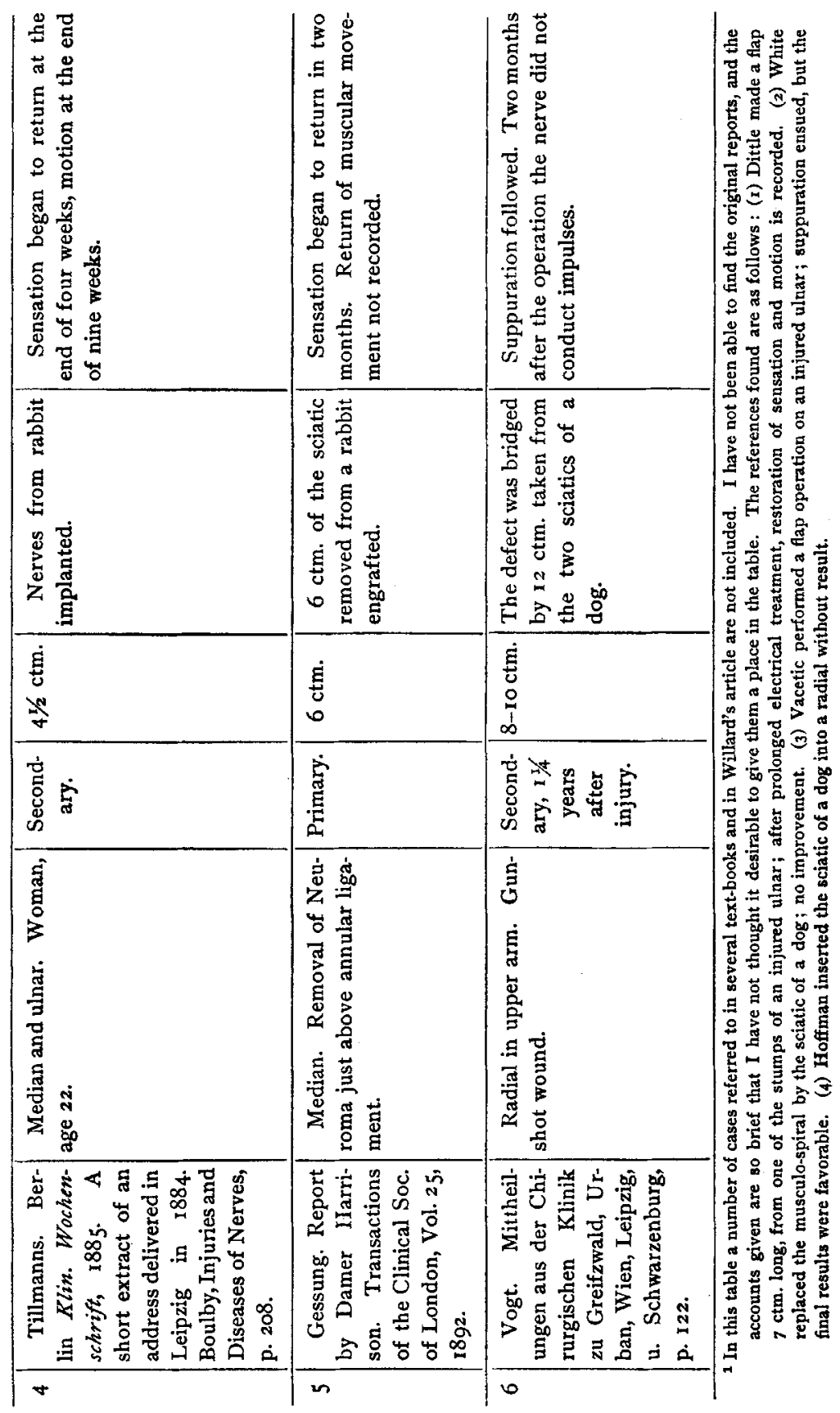


No. 3.]

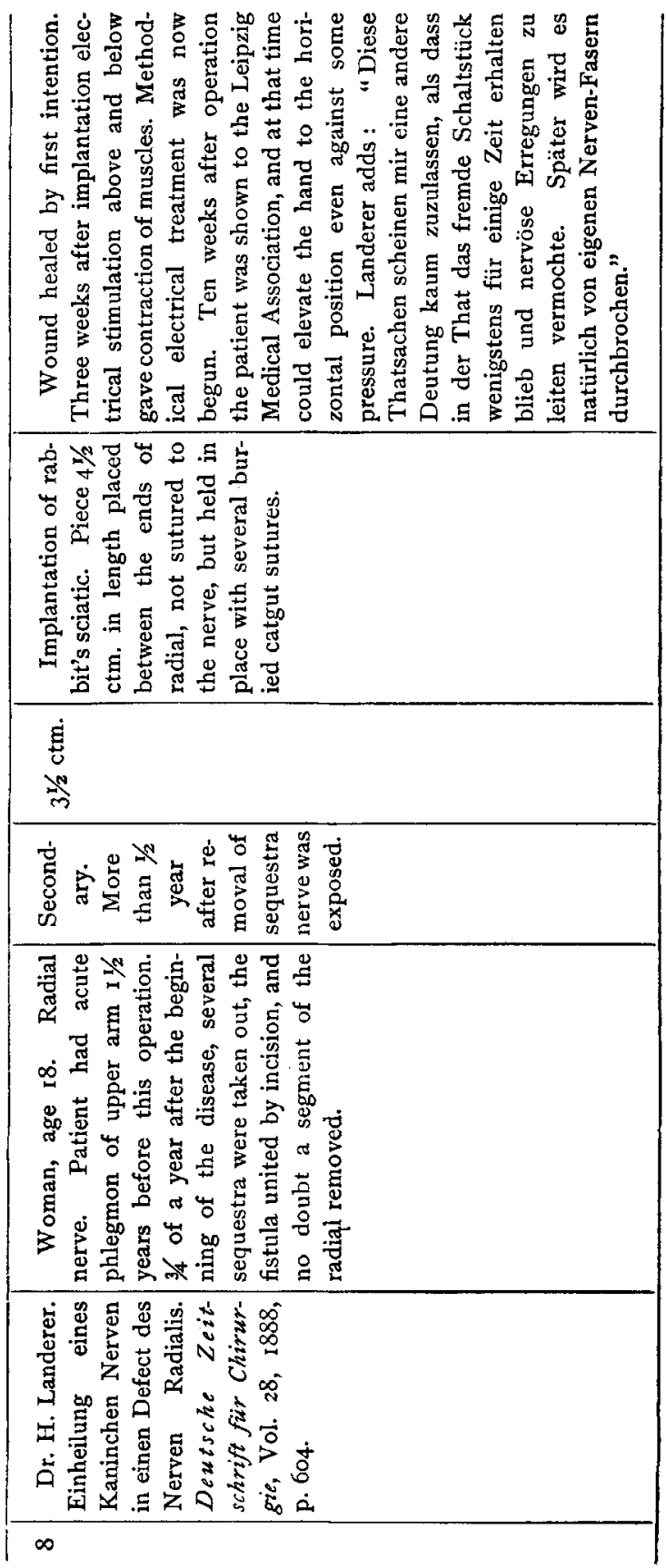




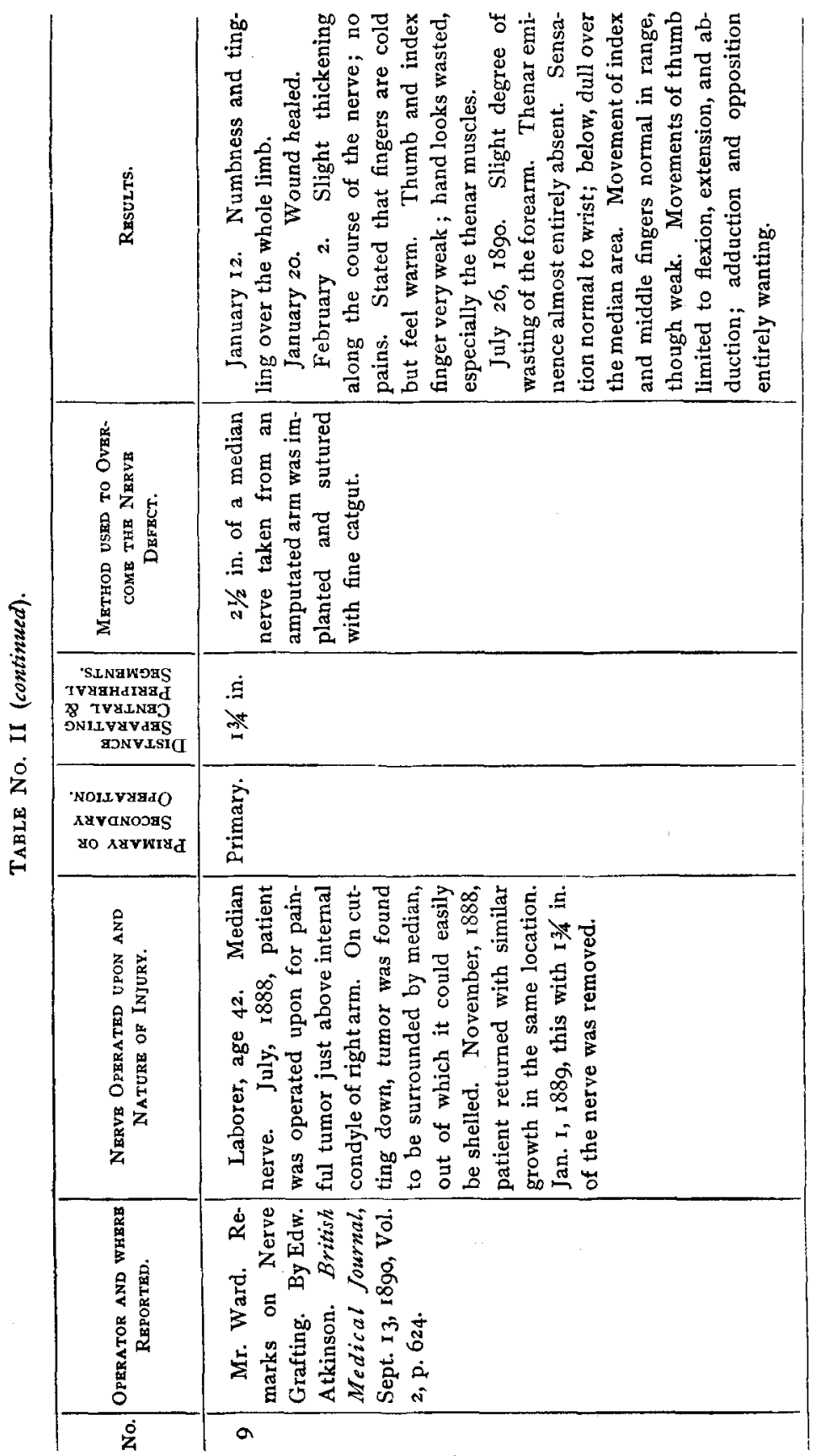




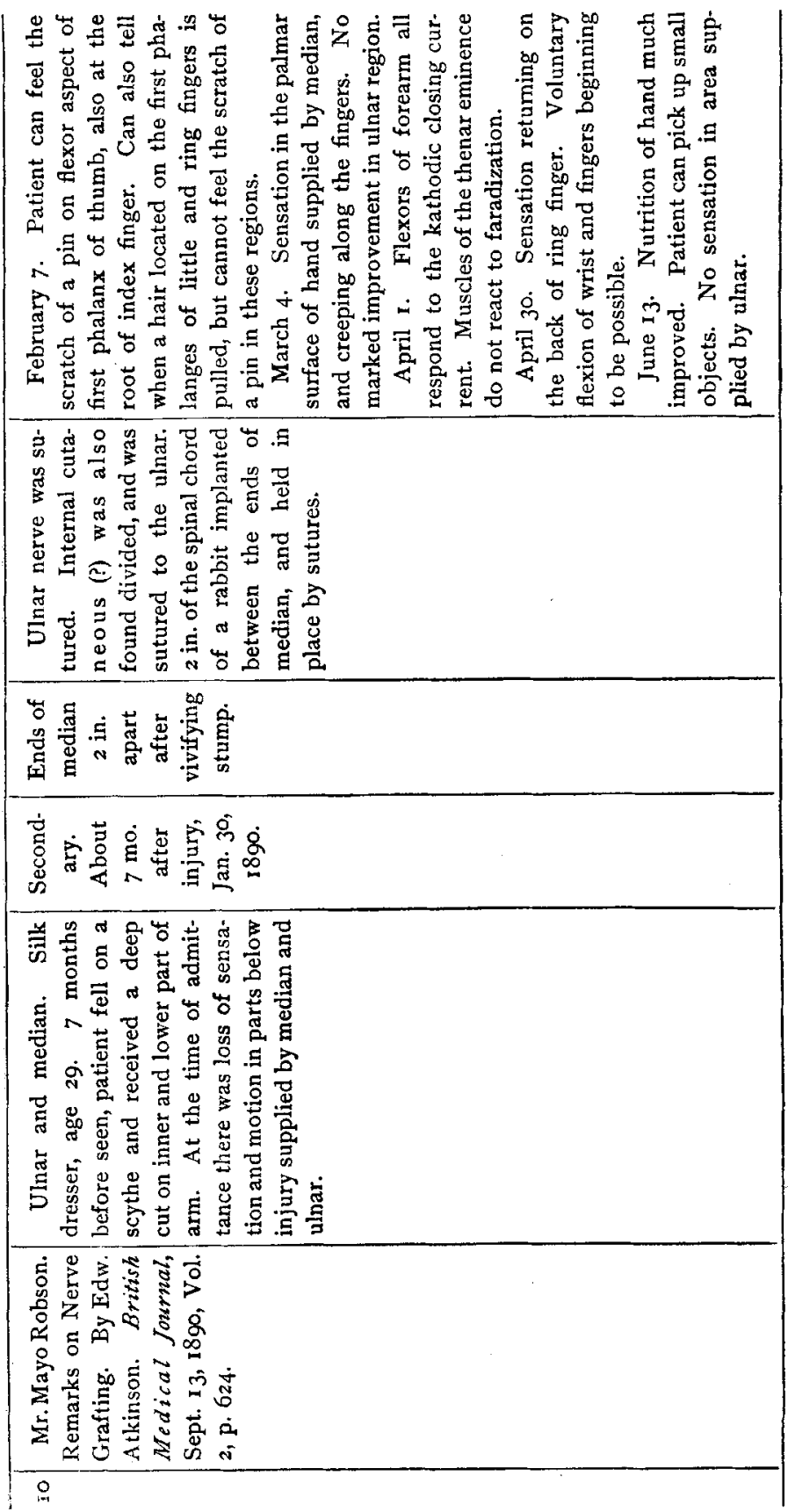




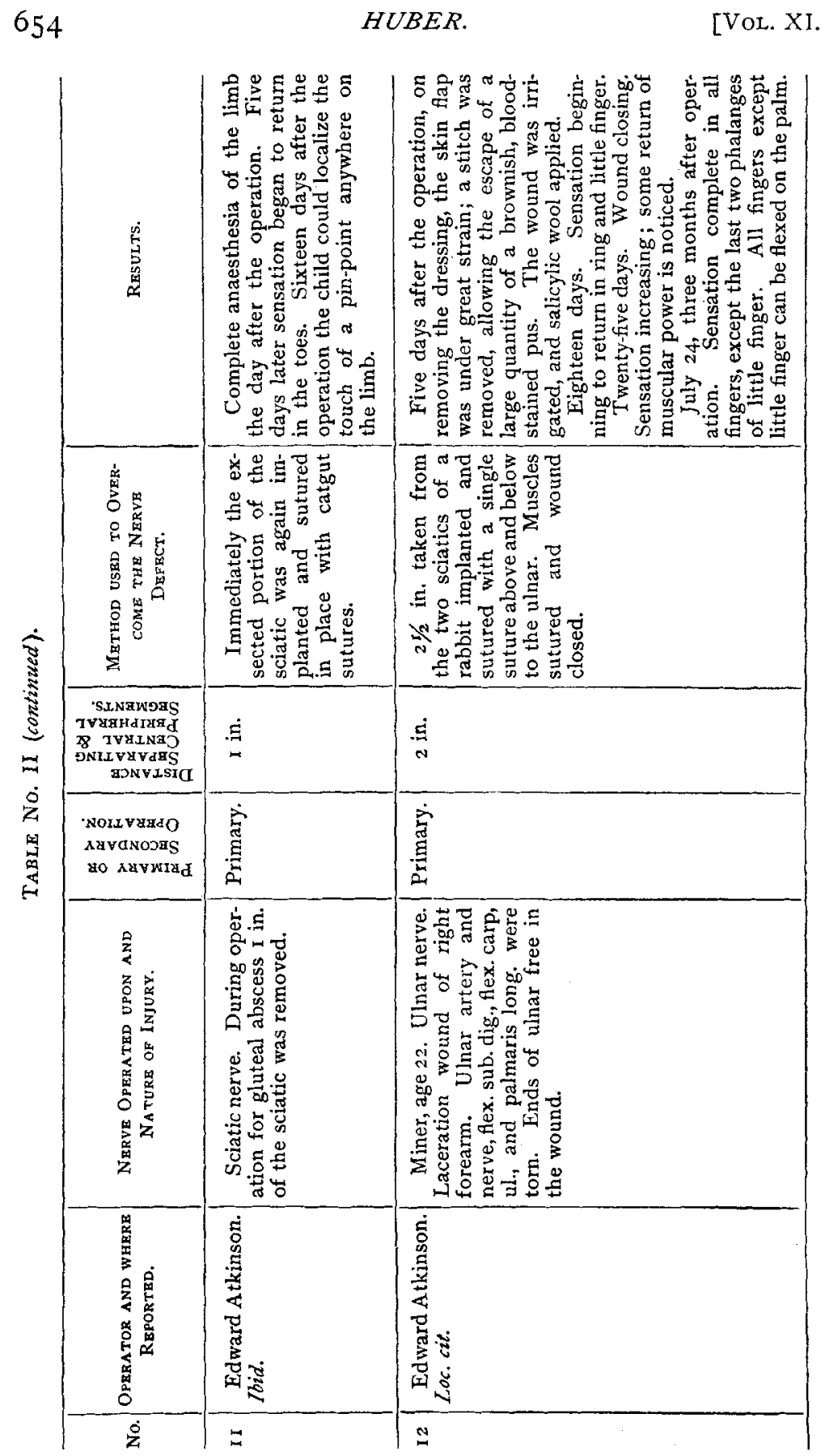




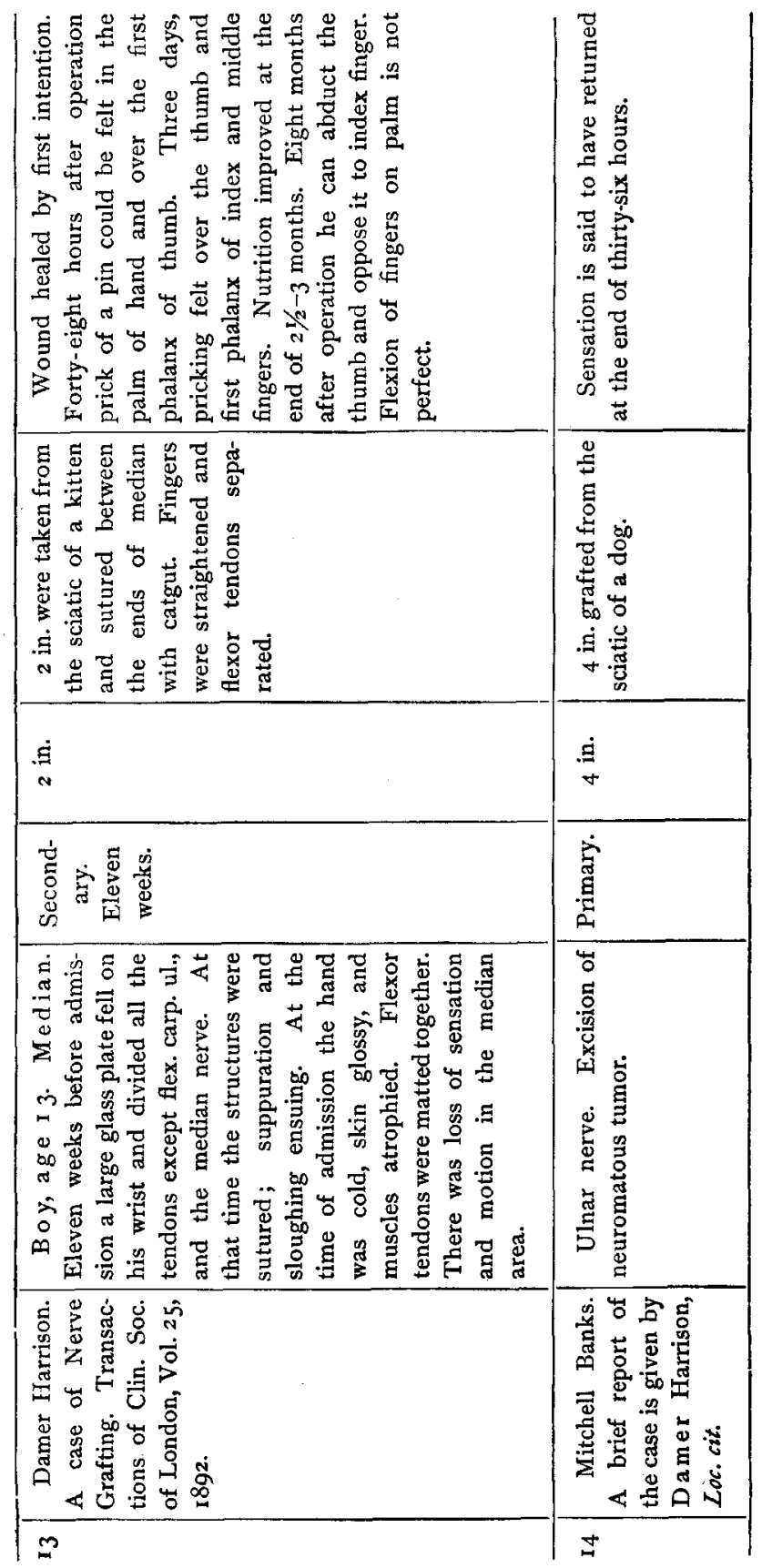



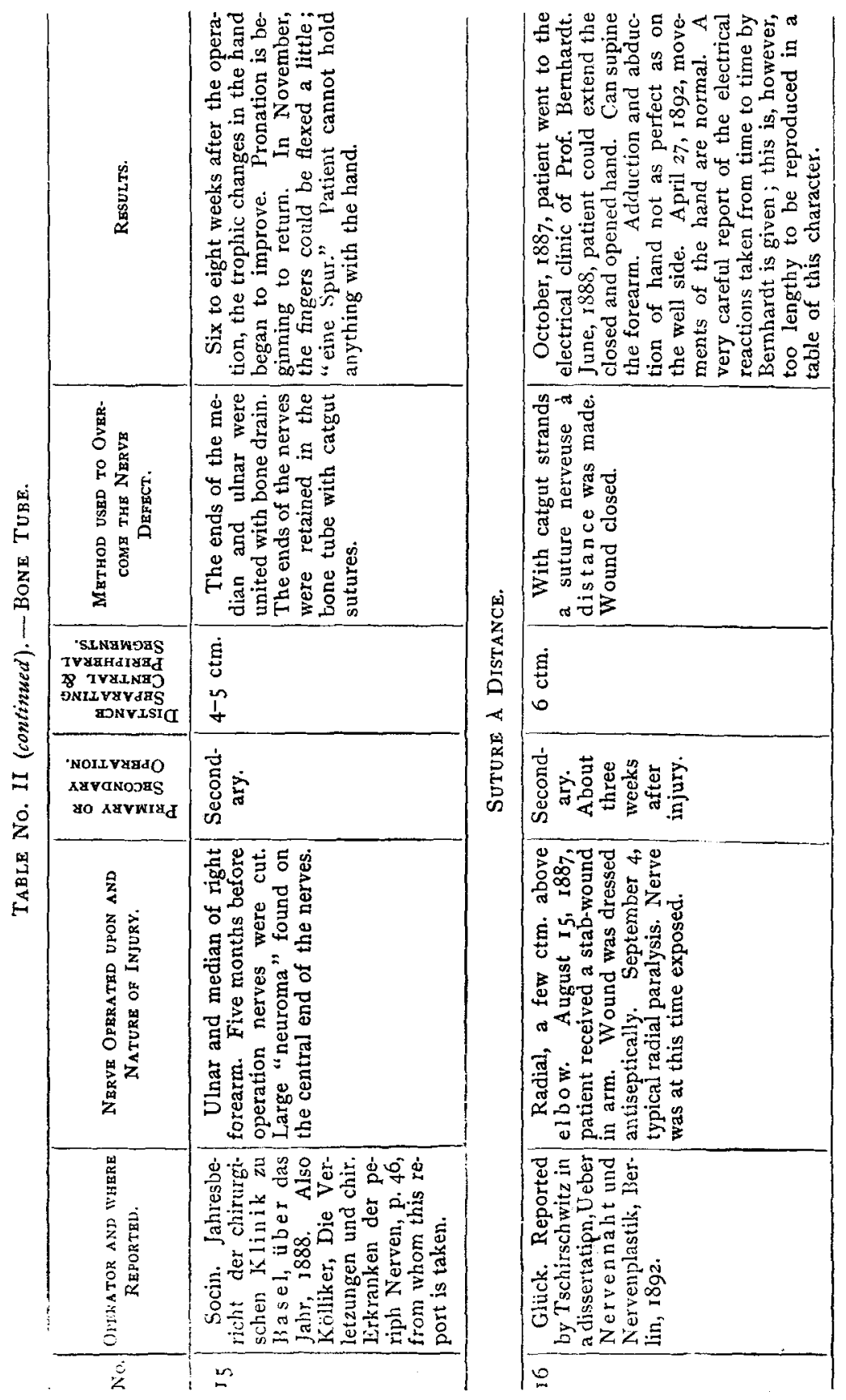


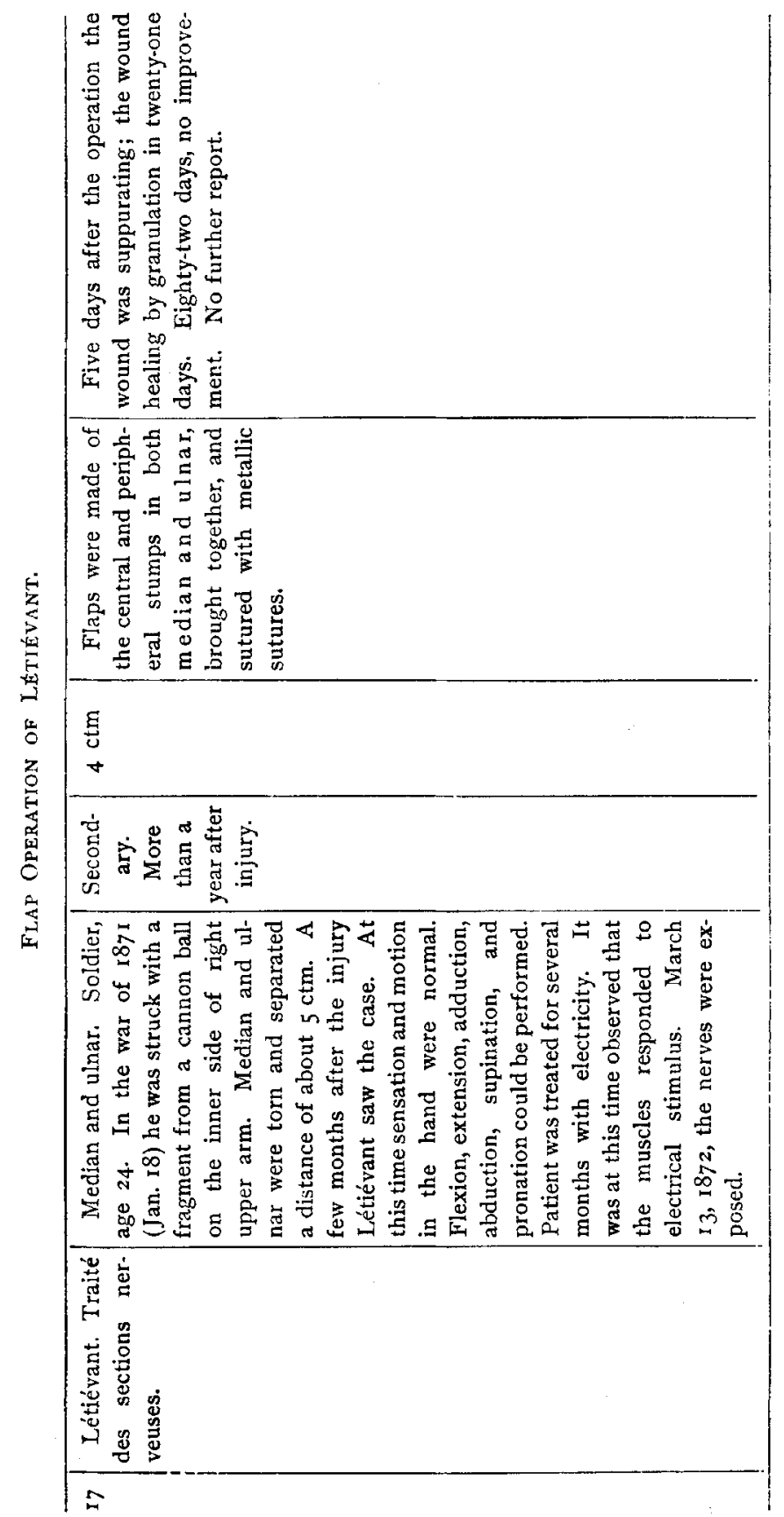




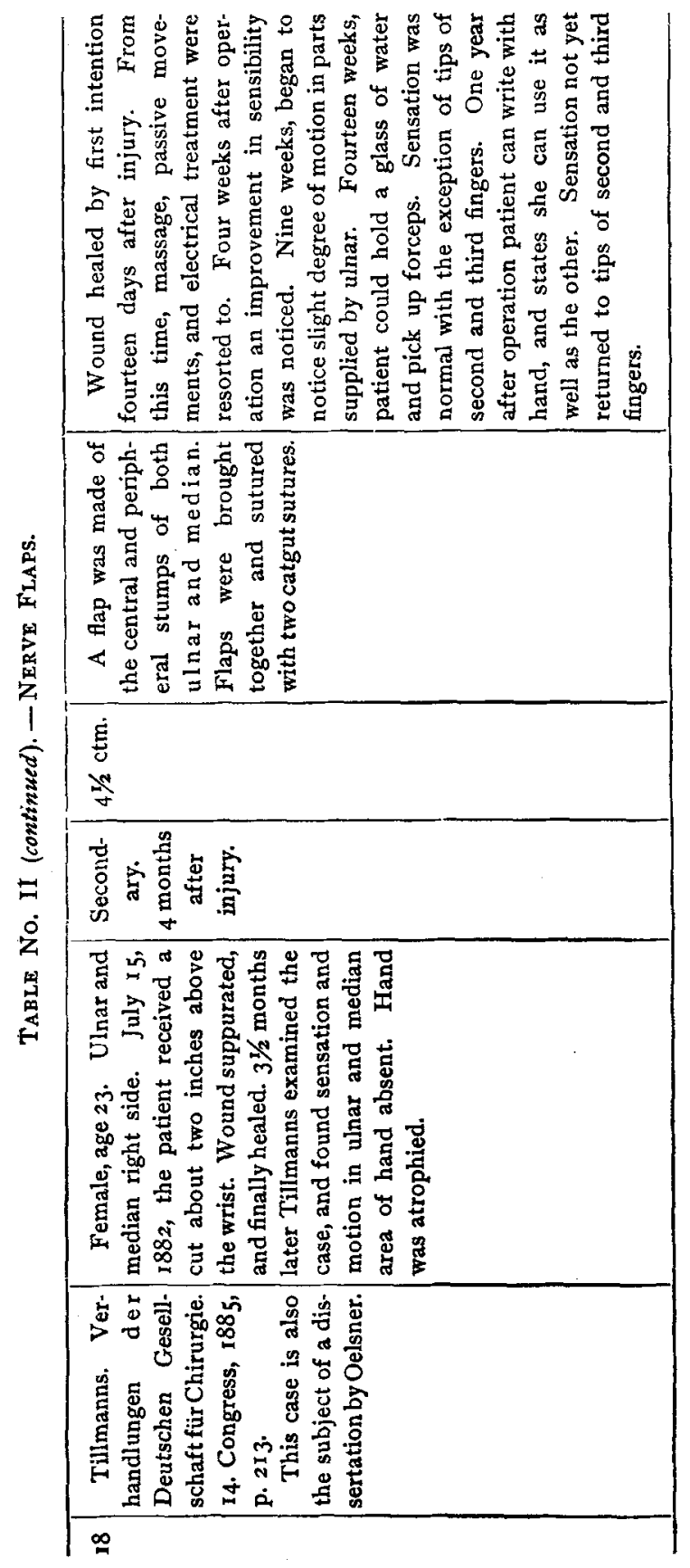




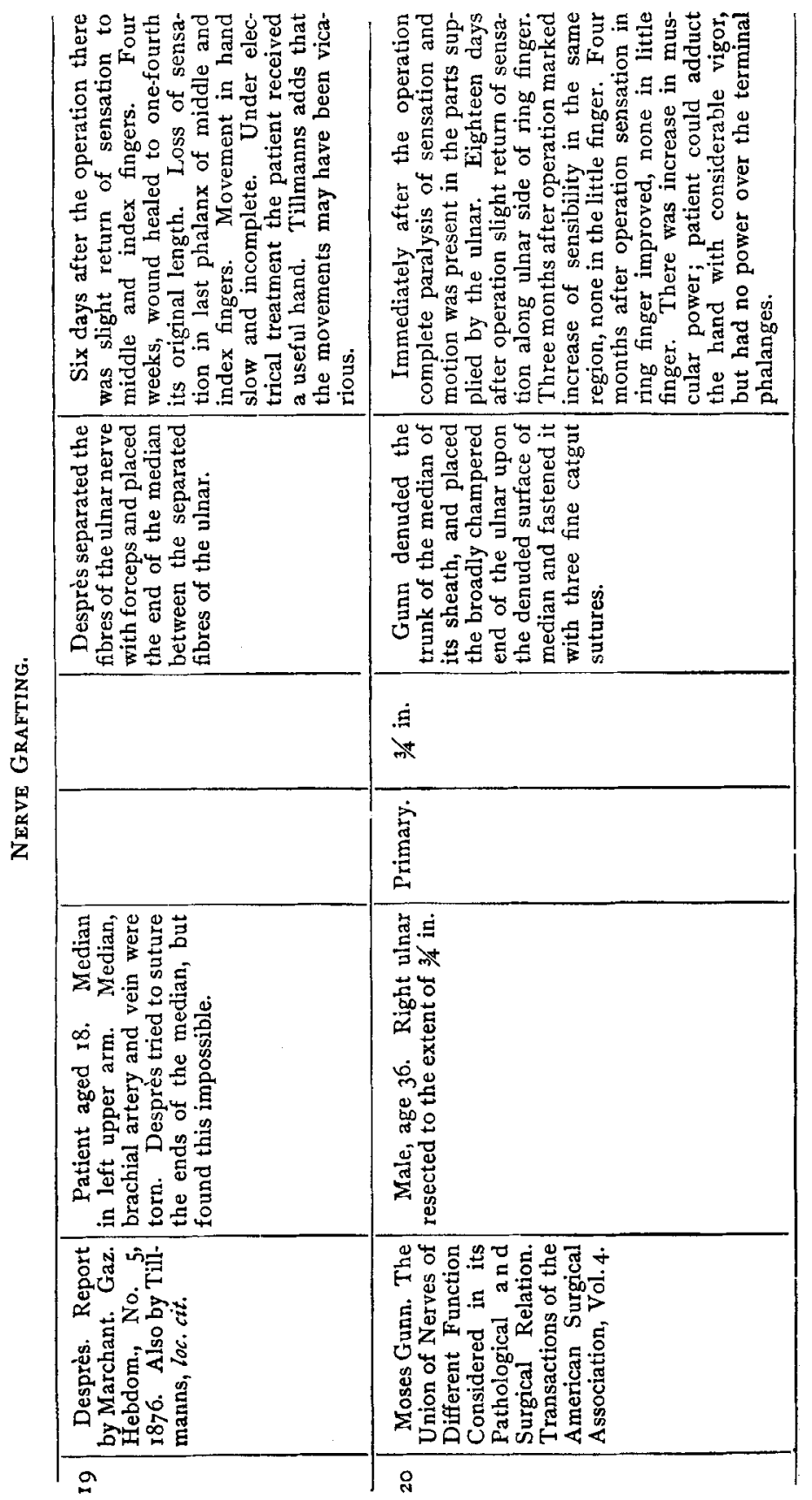


[VoL. XI.

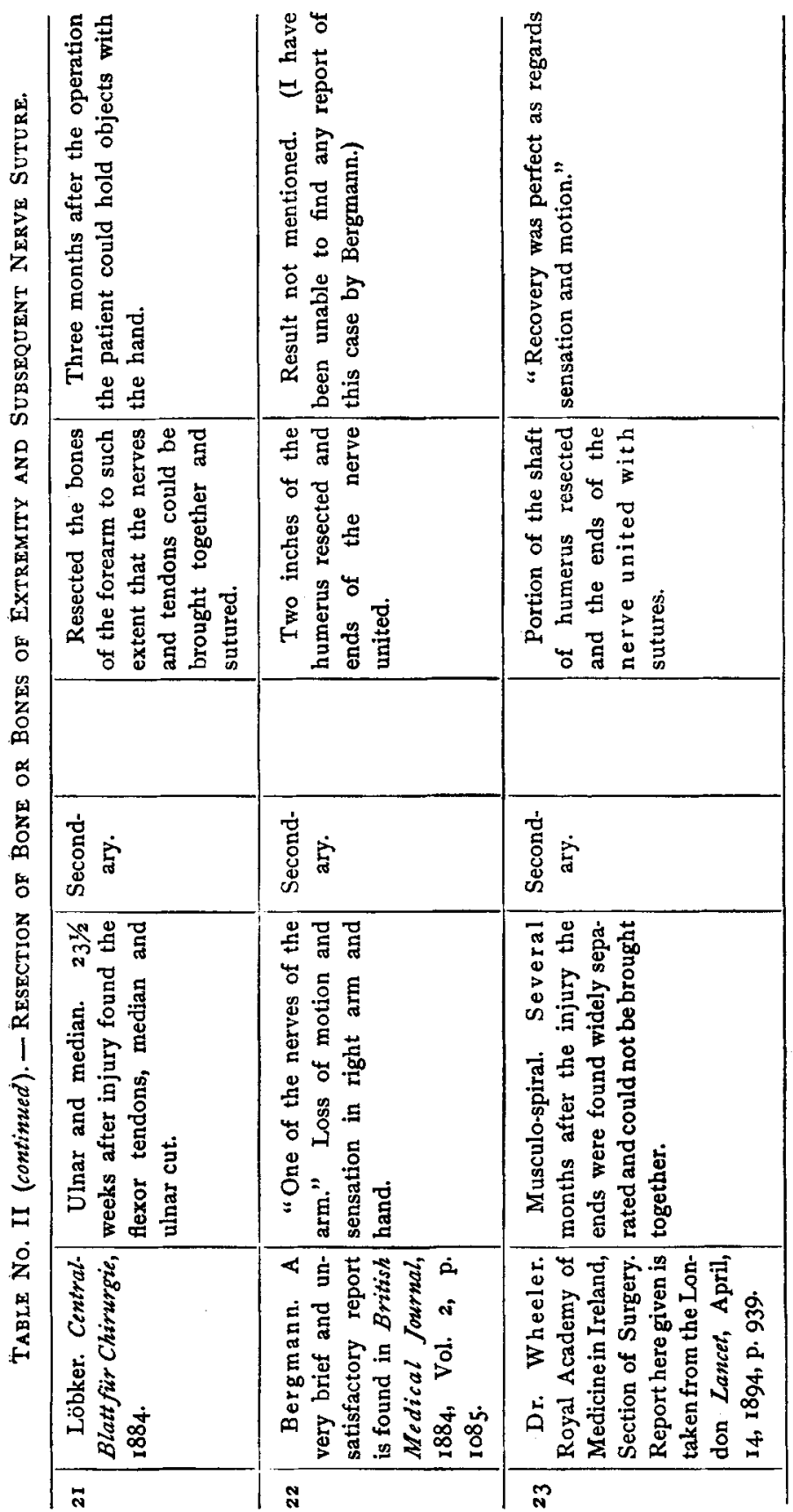




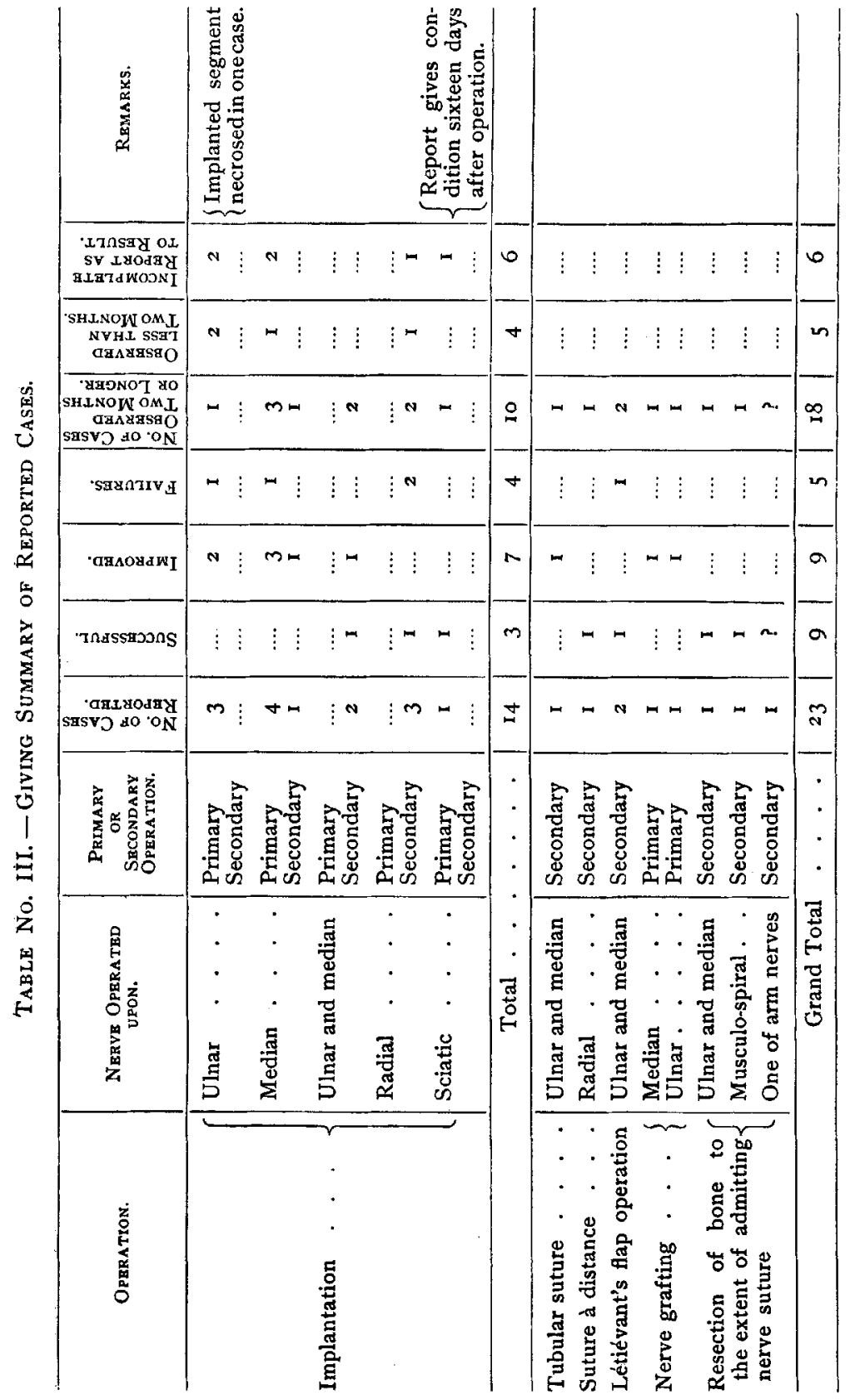


It is an exceedingly difficult matter to give a correct summary in a table of the above character, the reports at hand often admitting of more than one interpretation. An attempt has been made to give the operator's construction of the results obtained by him, even though this might seem to the writer unwarranted. Unfortunately, in the great majority of the reported cases, sensation and motion do not seem to have been carefully tested; and too little account is often taken of the fact that sensation and even motion is present, at least to some extent, after section of a nerve, in the area to which the injured nerve is distributed. This is admirably shown in case I7 (reported by Létiévant), where, several months after section of the ulnar and median, the sensibility of the hand was not impaired. Weir Mitchell has collected a number of cases, which may be used in corroboration of the above statement. We have further the experiments of Arloing and Tripier, who found that, in order to obtain complete loss of sensation in any of the digits of a dog's foot, it was necessary to cut the four nerve branches distributed in the same. Similar results were obtained by Vanlair after division of the nerves of the posterior extremity. This, of course, makes it difficult to say to what extent the sensibility and muscular contractility, found some time after an operation in the area to which the injured nerve is distributed, should or should not be credited to a regeneration of the divided nerve.

The operation for nerve implantation has been performed fourteen times, eight times as a primary and six times as a secondary operation. Of this number, three are reported as successful, seven as improved, and four as failures. In one of the successful cases, namely, that published by Edward Atkinson, the report covers a period of but sixteen days after the operation, at which time the sensibility was said to be so fully established that the child could localize the prick of a pin anywhere on the limb. This rapid return of sensory function can hardly be attributed to a regeneration of the divided nerve at this early date. Howell and Huber estimate that in man sensation does not return to the peripheral part of a divided nerve until about three months after the operation of suturing 
the divided nerve. In Atkinson's case, the impulses were, no doubt, carried along one of the other cutaneous nerves having their distribution in the extremity. The experiments of Vanlair are of interest in this connection. He divided sometimes one, sometimes another, of the nerves in the posterior extremity of dogs, and found that there was very little loss of sensation after section of any one of the nerves.

A closer study of Landerer's case (No. 8) may also be of interest in this connection. In this case more than six months had elapsed since the radial nerve had been injured, and no regeneration had taken place. Three weeks after implanting a rabbit's sciatic, electrical stimulation above and below the injury excited muscular contraction. He assumes that the implanted segment was at least for a time preserved (erhalten), and conveyed impulses; later it (the implanted segment) may have been replaced by fibres of the radial. Landerer seems to forget that clinical and experimental evidence would justify the assumption that, in the above case, the peripheral portion of the radial was in a state of complete degeneration at the time of the implantation, so that impulses conveyed through the implanted segment could not have reached the muscles. Then, again, all experiments bearing on this subject, except those reported by Glück, show that the implanted portion always degenerates, and even more rapidly than does the peripheral end of a divided nerve ; so it could not have carried impulses. Clinical records show that as a rule the return of motion takes place more slowly than the sensory function. Landerer's conclusions would, therefore, hardly stand critical investigation. The muscular contraction observed on electrical stimulation may have been due to a direct stimulation of the muscles, or to stimulation of some of the other nerves in the arm; any other explanation does not suggest itself to me.

In a number of cases reported as improved, sensation alone was reëstablished; the cases either having been dismissed before voluntary muscular movement was observed, or no mention is made concerning its return.

The rapid return of sensation in cases Nos. 7 and 14 would seem to show that the impulses must have been conveyed along 
some other path than the injured nerve (in the first the median and in the second the ulnar). The reported cases, where, after section of one or even two of the arm nerves, sensation was not at all or only partially impaired, would lend credence to such a statement.

Of the four cases classed as failures, two (Nos. I and 2) are reported by Albert. In one of these, the case was dismissed ten days after the operation; in the other the implanted segment came away in a necrosed state. In Kaufmann's case (No. 3) the operation was followed by fever, probably due to suppuration. The case was not observed for a time long enough to admit of regeneration of the peripheral end. In Vogt's case (No. 6) the implantation was made 15 months after the injury to the radial, and, after vivifying the ends, they were $12 \mathrm{ctm}$. apart. The operation was followed by suppuration. The fate of the implanted nerve is not noted; its connection with the radial may have been lost. The report extends only two months after the implantation, which, judging from the results obtained in other operations on injured nerves, is not long enough to admit of regeneration.

Of the reported cases, the percentage of recoveries is nearly as large for secondary as for primary operations. No attempt is here made to give the average time required for the return of sensation and motion after implantation. The small number of cases at my disposal did not seem to me large enough to warrant such an attempt.

Very little need here be added to what has already been given in the table concerning the other nine cases in which operative means other than implantation were resorted to. I would, however, beg indulgence for again referring to the two cases of nerve grafting (Nos. 19 and 20) reported by Desprès and Gunn, as their interpretation of the results obtained seems to me wholly unwarranted. In Desprès' cases the peripheral median was grafted on to the ulnar; the wound does not seem to have healed by first intention. Six days after the operation there was some return of sensation to the middle and index fingers, and, at the end of four weeks, the sensibility in these fingers over the two proximal phalanges would seem to be 
normal, while it was absent in the distal phalanges. It will be remembered that the thumb, index, and middle fingers are supplied conjointly by the median and radial. A return of sensation in these fingers would therefore not give conclusive evidence of median regeneration, as the impulses may have been carried along the radial. Weir Mitchell long ago drew attention to the fact that the index and middle fingers may be flexed and the thumb opposed, to some extent at least, by muscles not supplied by the median.

In lieu of the above facts, Tillmanns would seem to express himself correctly, when he states that in the above case the "Motilität" may have been vicarious.

Gunn's case involved the grafting of a resected ulnar to the accompanying median. In this case there was loss of sensation and motion in the ulnar region of the hand. Eighteen days after the operation, there was a slight return of the sensibility along the ulnar side of ring finger, which gradually increased, so that four months after the operation it was quite normal; there, was, however, no sensation in the little finger. If we recall the distribution of the ulnar in the hand, it will be remembered that the ring finger is supplied by this nerve only on the ulnar side, the radial side receiving its innervation from both the median and the radial, while the little finger has no other nerve supply. The sensory impulses coming from the ulnar side of the ring finger may, therefore, have been carried along the median or radial. The results of Arloing and Tripier, already quoted, show that this would be the case for dogs. It is important to notice that there was no return of sensibility in the little finger, a fact not explainable if the return of sensation to the ulnar side of the ring finger is attributed to ulnar regeneration. The ring and little fingers could not be flexed at any time after the operation, although the flex. carp. ul. seemed to contract. If the explanation given above is correct, the evidence in both of these cases would show that regeneration of the peripheral portion of the divided nerve had not taken place through the engrafted connection.

The conclusions drawn from data obtained from the experimental work reviewed, the clinical cases reported, and from the 
results obtained in my own experiments will be presented at the end of this paper.

\section{Part II. - Record of Experiments and Physiological Examinations.}

As has been previously stated, the aim of this research has been, - to try, experimentally, the various methods suggested for repairing loss of substance in peripheral nerves, when such loss is so great that the ends of the divided nerve cannot be brought together by the ordinary methods of nerve suture; to find out, if possible, which one of the many methods used is likely to give the most favorable result; to obtain some idea of the time required for the return of function to the peripheral end ; and to establish the structural changes which take place during degeneration and regeneration. The experimental work has, therefore, been partly physiological and partly histological. The record of the experiments and the physiological observations made will form one part of this paper, and the results obtained from microscopical examination of the preparations will be recorded in another part.

The animals used for operations were dogs. With but few exceptions the ulnar nerve was selected for experimentation; in some few instances the median or sciatic was used. At the time of operation and examination the animals were narcotized with large doses of morphia sulphate injected hypodermically in the inguinal region, and, if thought necessary, this was followed by ether. Antiseptic precautions were observed with as much detail as can well be indulged in when the operations have to be performed in a general laboratory. The hair over the course of the nerve selected for the operation and the surrounding parts was removed with a razor, and the skin thoroughly washed, first, with soap and water, and then with a five per cent carbolic acid solution. The animal was then covered with towels sterilized by steam. The instruments and sponges were sterilized in the same way, and while operating the instruments were kept in a two and one-half per cent carbolic acid solution, and the sponges in a $\frac{1}{2000}$ bichloride of mercury 
solution. The catgut used for suturing the nerve was sterilized for thirty minutes in boiling alcohol.

In each case the wound was closed by a double set of sutures. The subcutaneous connective tissue, which had been divided in cutting down to the nerve, was brought together over the sutured nerve by means of four to six chromatized catgut sutures. The edges of the wound in the epidermis were then united with braided silk and covered with iodoform. It was hoped that, even though the "skin wound " might open in a few days, the connective tissue which formed a covering for the nerve would, in the meantime, have united, and thus retain in place the implanted substance; this was found to be the case. Now and then several of the silk sutures gave way, but in no instance were the ends of the nerve stumps nor the implanted portion exposed. In those experiments where a segment of a nerve was implanted, this was, in all but two cases, taken from the sciatic of a cat. While the nerve to be sutured in the dog was being exposed and resected, an assistant chloroformed a cat, removed the skin from the posterior surface of one of its hind legs, and then thoroughly washed the denuded surface with a five per cent carbolic acid solution. The sciatic was then exposed, exsected, and transferred to the wound in the dog's arm. No attempt was made to stitch the central end of the segment taken from the cat's sciatic to the central stump of the dog's ulnar. The manner of preparing the bone tube and the bundle of catgut threads, implanted in a number of cases, will be described in detail when such operations are mentioned. The irritability of the nerves was tested at the time of examination with induction shocks from a $\mathrm{Du}$ Bois Reymond coil, the ordinary wire electrodes being used. The strength of stimulus necessary to produce reflexes or excite contractions of muscles supplied by the nerve under examination was estimated by the distance separating the primary and secondary coil. In all examinations the same battery, induction coil, and electrodes were used, so that the results obtained in the various experiments admit of comparison. It is, of course, understood that much reliance cannot be placed on such comparisons, as the strength of the shocks 


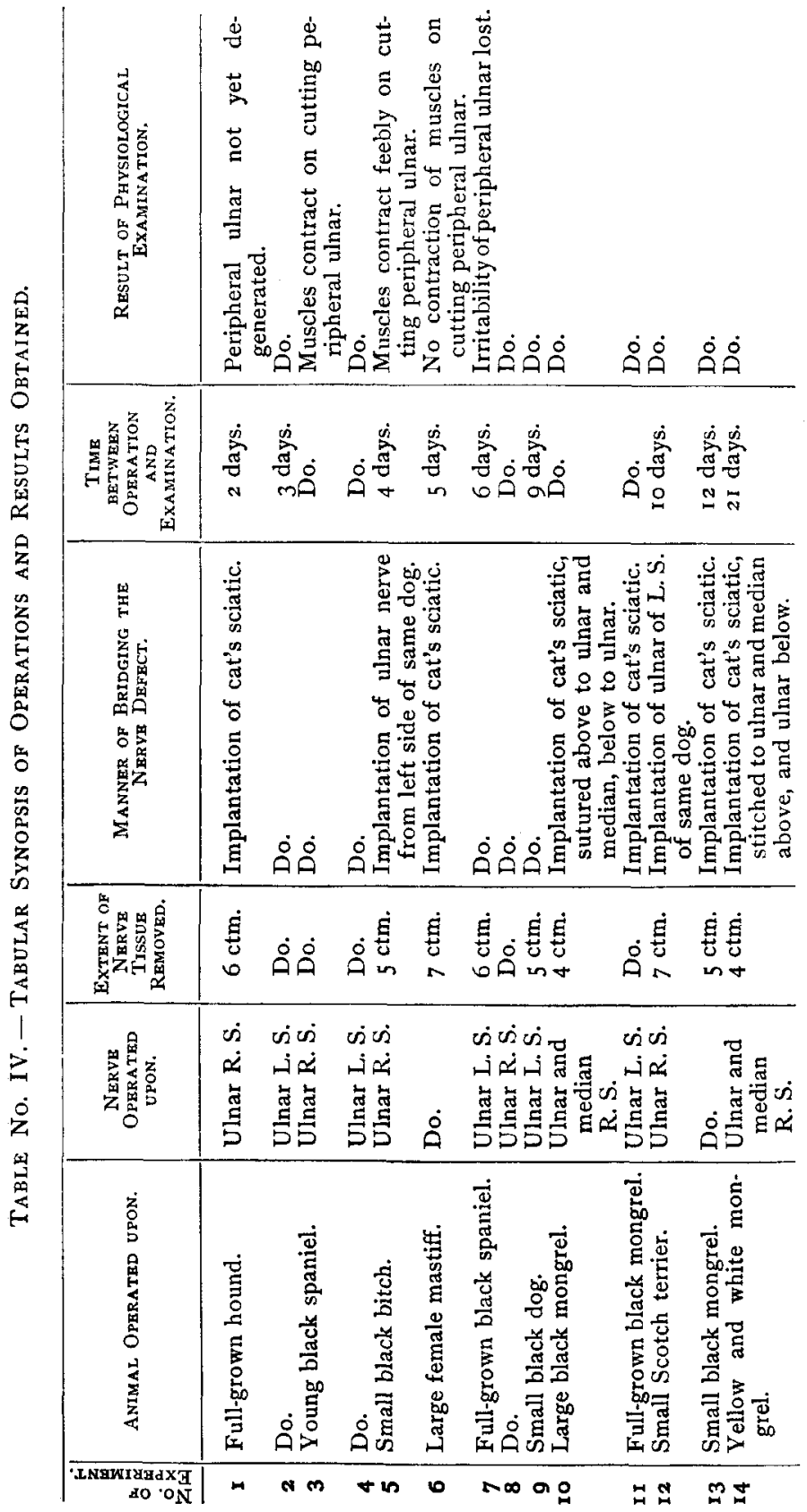



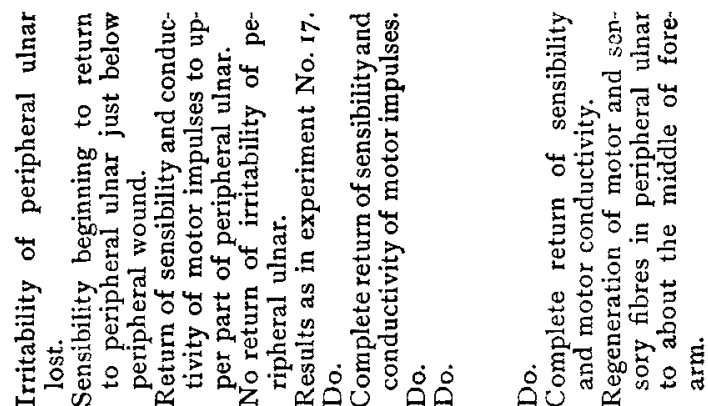

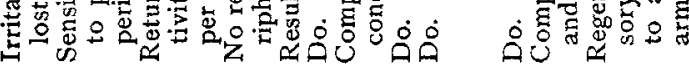

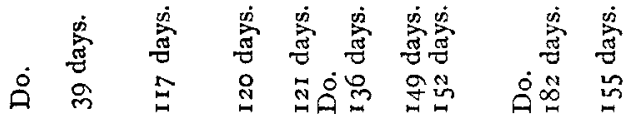

\begin{tabular}{|c|c|c|c|}
\hline 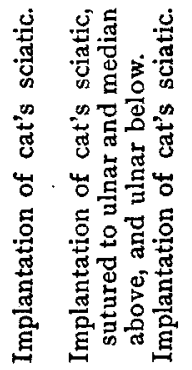 & $\dot{\circ} \therefore \dot{\circ}$ & 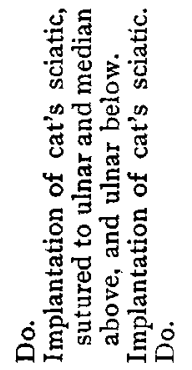 & 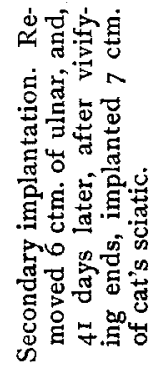 \\
\hline
\end{tabular}

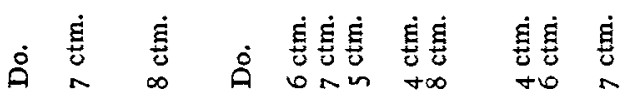

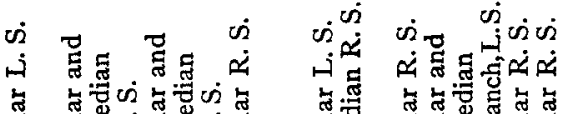

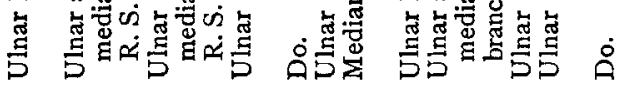

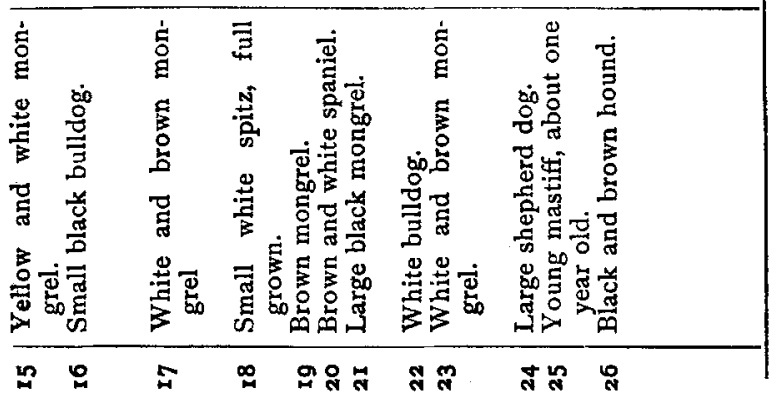




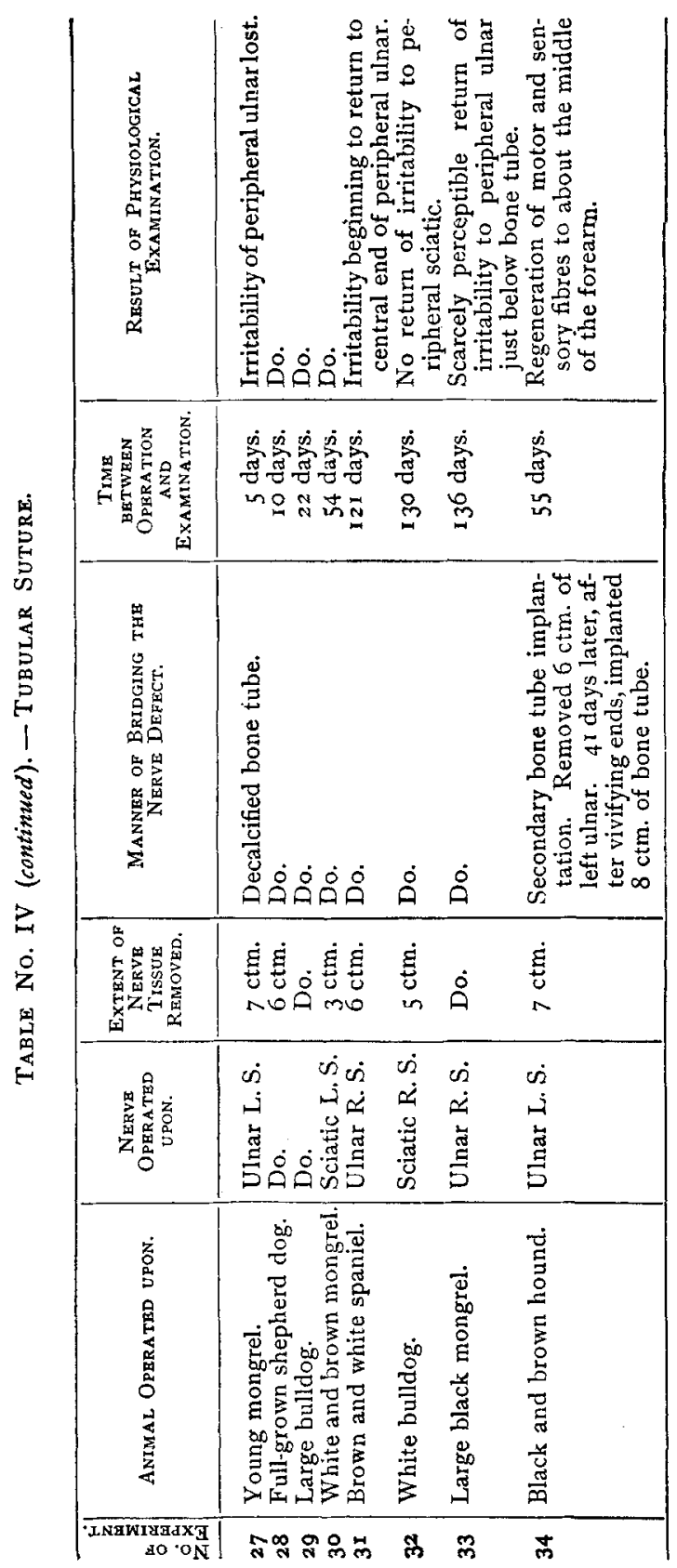



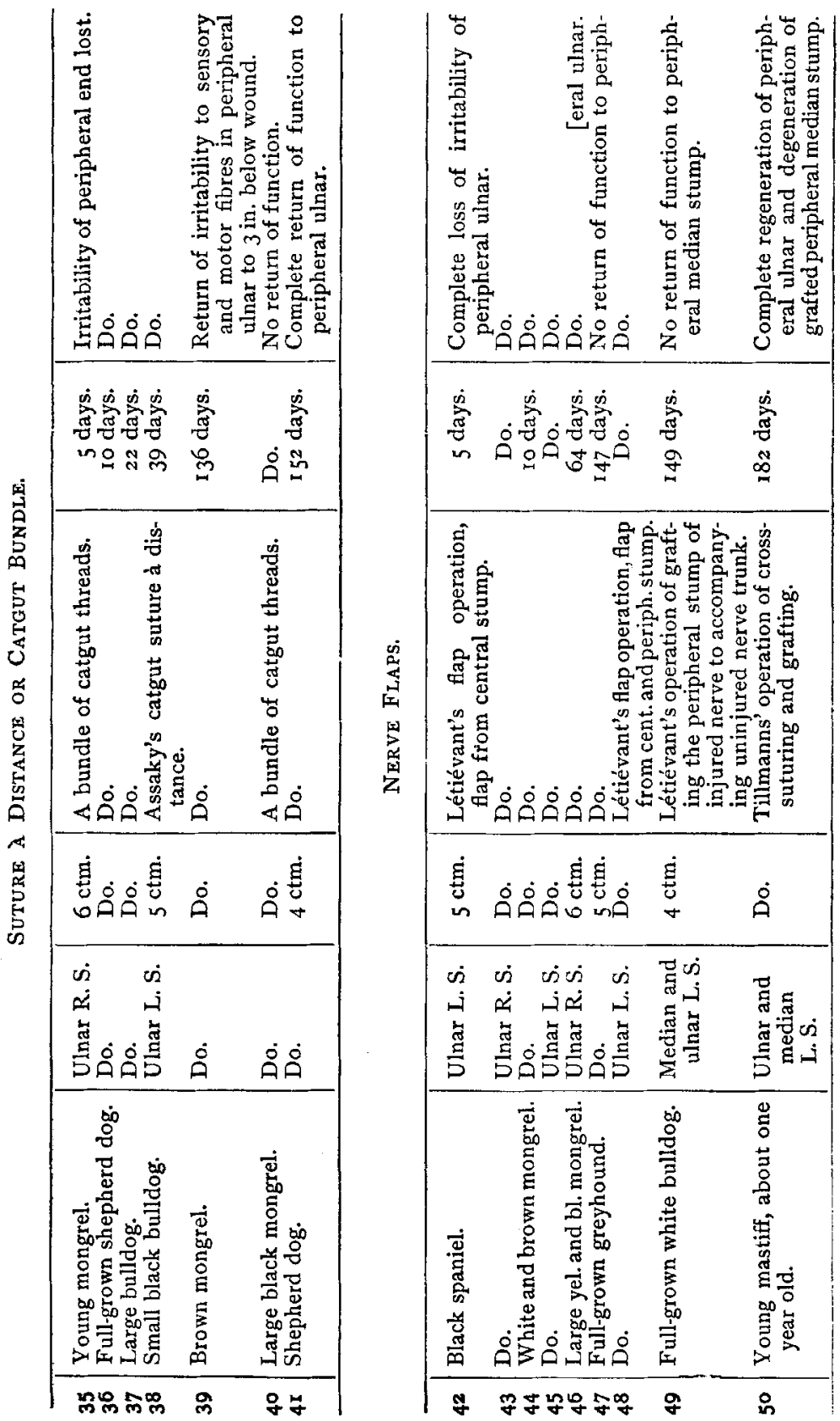
672

HUBER.

[VoL. XI.

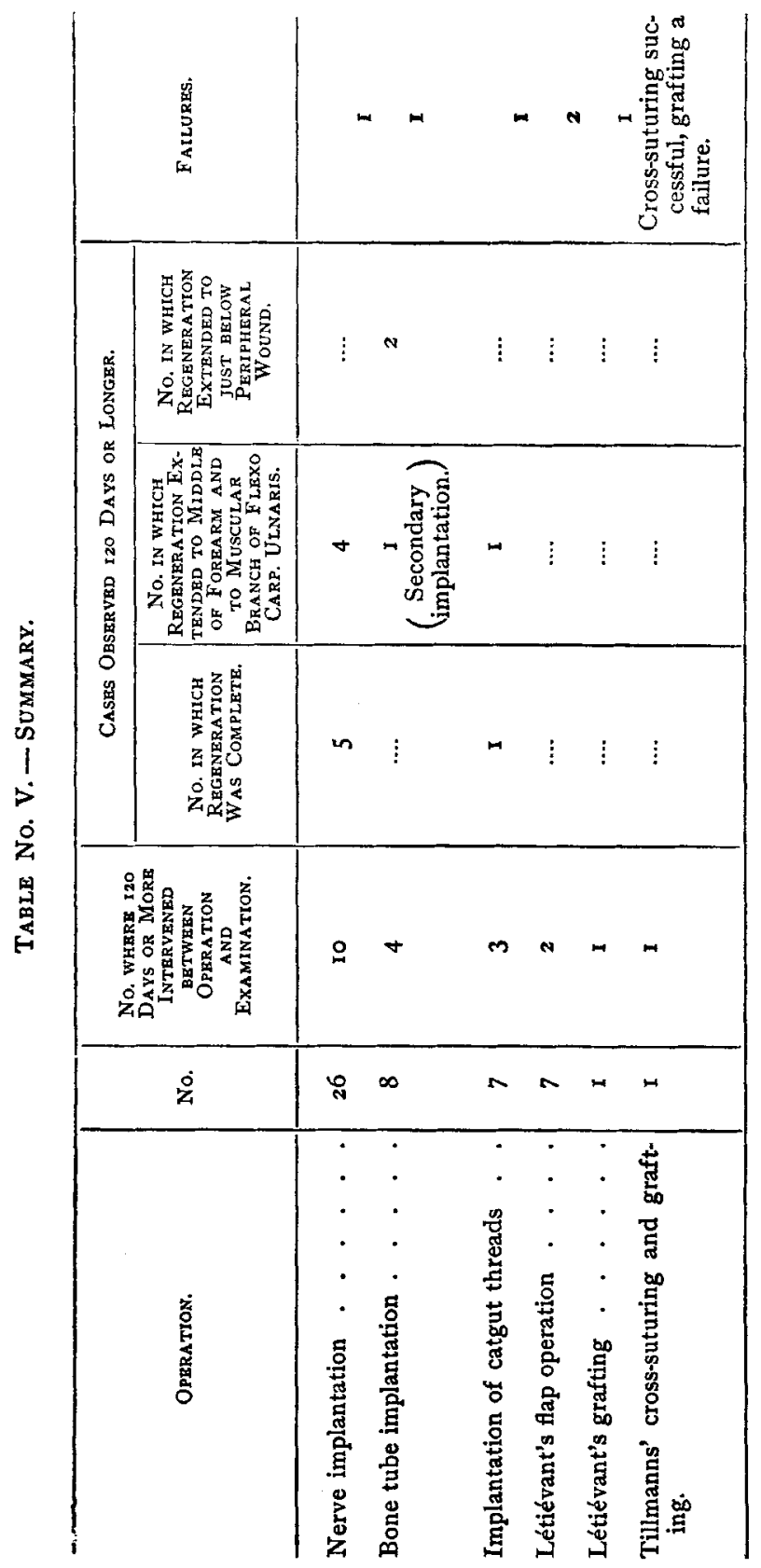


emanating from a Du Bois Reymond instrument, in which the distance between the primary and secondary coils is ten centimeters, would not, of necessity, be the same at different times even though the same apparatus were used. The distance separating the primary and secondary coils is expressed by the symbol $x \mathrm{ctm}$. S. $C$.

In describing the operations here recorded, the following terms have been made use of to designate the different portions of the nerve operated upon, and its relation to the substance implanted : the central portion of the resected nerve has been called the central stump; the peripheral portion, the peripheral stump; the junction of the central end of the implanted portion and the central stump, the central zeound; and the junction of the peripheral end of the implanted substance and the peripheral stump, the peripheral wound.

The order of the operations given in the table on pp. 668-72, some of which are more fully described in the following pages, is not chronological. It seemed to the author more logical to base it upon the time intervening between the operation and the examination. In doing this it was found necessary to rearrange the notation of the experiments. Often two experiments were made on one dog, the right and left sides being used in succession. In all, thirty dogs were operated upon.

\section{Record of Operations and Physiological Examinations.}

This record gives a full account of only a part of the operations made. As a detailed description of all the experiments would involve some repetition, only those of interest physiologically have been selected. For the remaining experiments the reader is referred to the preceding tabular synopsis.

\section{(a) Nerve Implantation.}

Experiment 1. - Dec. 9, 1893 .

Full-grown hound. Hypodermic injection of $\frac{3}{5} \mathrm{grm}$. morph. sulph., followed by ether.

Operation. - The right ulnar nerve was exposed for a distance of about $8 \mathrm{ctm}$., and exsected to the extent of $6 \mathrm{ctm}$. A segment of equal length was removed from the left sciatic of a cat, and placed between the cut stumps of the ulnar. The implanted segment was retained in place by 
means of a catgut suture passed through each end of the transplanted segment of the cat's sciatic, and through central and peripheral stumps of the ulnar, in this way bringing the ends of the implanted segment in close apposition with the ends of the ulnar stumps. The divided connective tissue was then closed over the nerve by means of five buried chromatized catgut sutures. The dermis was brought together by means of a continuous silk suture.

Examination. - Dec. I1, I 893 (two days after operation).

The wound was healing by first intention. The central end of the implanted segment was fixed to the peripheral end of the central ulnar stump by an inflammatory newly formed tissue. The catgut could not be seen. The peripheral end of the implanted segment was fixed to the peripheral ulnar by the suture. The electrical test was not recorded. Cutting the peripheral ulnar with scissors produced contraction of the muscle supplied by the ulnar.

The nerve was hardened in Flemming's solution, and stained in safranin and licht grün.

The results of experiments 2,3 , and 4 were essentially the same as in the first experiment.

Experiment 5. - Aug, I0, 1893.

Small black bitch. Hypodermic injection of $\frac{2}{5} \mathrm{grm}$. morph. sulph., followed by ether.

Operation. - The right uinar was exposed, and resected to the extent of $5 \mathrm{ctm}$. The left ulnar was then removed to the extent of $5 \mathrm{ctm}$., and implanted between the ends of the resected right ulnar, and fixed by means of a single direct catgut suture above and below, and the wound closed.

Examination. - Aug. 14, 1893 (four days after operation).

The epidermal wound was open for a short distance, the implanted nerve was imbedded in granulation tissue.

The muscles contracted very feebly on cutting the peripheral ulnar.

The nerve was hardened in Müller's fluid, and stained in anilin blue and safranin.

Experiment 6. - Aug. 10, 1893 .

Large female mastiff. Hypodermic injection of $\frac{4}{5}$ grm. morph. sulph., followed by ether.

Operation. - The right ulnar was exposed for $8 \mathrm{ctm}$., and resected to the extent of $7 \mathrm{ctm}$. A segment of equal length was transplanted from the left side, and wound closed.

Examination.-- Aug. I 5, I 893 (five days after operation).

The epidermal stitches had given way. The nerve ends and implanted segment were surrounded by granulation tissue.

No contraction of the muscles occurred on cutting the peripheral ulnar.

The nerve was hardened in Müller's fluid, and sections stained in anilin blue and safranin. 
In experiments 6 to $\mathrm{I}_{3}$, inclusive, there was found complete loss of irritability of the peripheral stump of the divided nerve, as shown by mechanical and electrical stimulation.

Experiment 14. - Oct. 23, 1893.

Yellow and white mongrel, narcotized by means of $\frac{3}{5} \mathrm{grm}$. morph. sulph.

operation. - The right ulnar and median were exposed, and resected to the extent of $4 \mathrm{ctm}$., and a segment of equal length removed from a cat's sciatic was implanted, stitched above to ulnar and median by a single direct catgut suture, and below to the peripheral ulnar. The subcutaneous tissue was sutured over the nerve by means of five buried catgut sutures, and the epidermis closed by five silk sutures.

Oct. 27. Several silk sutures had given way, and the wound was granulating.

Nov. 14. Wound almost entirely healed. The hair was falling out on the inner side of forearm, and a small ulcer had formed on radial side of the wrist. The sensation in the foot seemed quite normal, and the dog used the foot in walking.

Examination. - Nov. 14, I893 (twenty-one days after operation).

The implanted nerve and ends of the nerve stump were surrounded by well-formed connective tissue.

Electrical stimulation with induction shocks at $5 \mathrm{ctm}$. S. C., below implanted segment, showed no contraction, and no evidence of pain. Stimulation above the implanted segment at $5 \mathrm{ctm}$. S. C., after severing the nerve $5 \mathrm{ctm}$. above central wound, showed no contraction.

The nerve was hardened in Müller's fluid, and stained in anilin blue and safranin.

Experiment 15. - Oct. 23, 1893 .

This experiment was performed on the ulnar of left side of dog used for experiment 14.

The operation, duration of experiment, and the results obtained were the same as in the preceding experiment.

The nerve was hardened and stained as in experiment 14.

Experiment 16. - April 21, I894.

Small black bulldog about one year old. $\frac{3}{5}$ grm. morph. sulph. was. injected.

Operation. - The ulnar and median were resected to the extent of $7 \mathrm{ctm}$., and $7 \mathrm{ctm}$. of a cat's sciatic implanted and sutured, above to ulnar and median with single direct catgut sutures, below to peripheral ulnar with same sutures. Wound closed.

Wound healed by first intention. At no time did the dog seem to have any loss of sensation or motion in the operated leg or foot.

Examination. - May 28, 1894 (thirty-nine days after operation). 
Wound completely healed. On exposing the nerves the central stump of the ulnar and median was found to terminate in a large bulb, from which a cord, much smaller in cross-section than the central nerve stump, could be traced to the peripheral ulnar. The central bulb, the implanted portion, and the central end of the peripheral stump of ulnar were firmly imbedded in fibrous tissue.

Electrical stimulation of the peripheral ulnar with induction shocks at $5 \mathrm{ctm}$. S. C. (after all the other nerves in the arm above the elbow had been cut) showed no contraction of the muscles in the forearm. The presence of feeble reflexes led to the inference that there was some return of sensibility in the peripheral ulnar just below the peripheral wound. Stimulation of the ulnar above the implanted segment after the ulnar had been severed from the center showed no contraction at $5 \mathrm{ctm}$. S. C.

Cutting the ulnar above and below the implanted segment produced no contraction.

The nerve was hardened and stained as in experiment 14.

Experiment 17. - Oct. 20, 1893.

White and brown mongrel. $\frac{3}{5}$ grm. morph. sulph was injected, followed by ether.

Operation. - The right ulnar and median were resected to the extent of $8 \mathrm{ctm}$., and a segment of equal length removed from a cat's sciatic was implanted, and sutured above by a single direct catgut suture to the ulnar and median, and below to the peripheral ulnar. The wound was closed in the usual way.

Oct. 27. Wound closed ; healing by first intention.

Dec. 17. Wound entirely healed; the dog seemed to use the foot as before the operation.

Jan. I. No ulcers on the foot.

Examination. - Feb. 1 7, I 894 (I 77 days after implantation).

The sensation in the foot as tested by pricking with a needle seemed normal.

On exposing the nerve, a slight enlargement was seen at the lower end of the stump, and a narrow band, showing here and there faint longitudinal striation, could be traced from the central bulb to just above the central end of the peripheral ulnar, where it was lost in connective tissue.

Physiological tests :-

(I) Stimulation with induction shocks at $13 \mathrm{ctm}$. S. C., of the peripheral ulnar just below the peripheral wound, gave movements of flexion in the muscles supplied by the ulnar. This was especially plainly seen in the flexor carpi ulnaris. There was also evidence of pain as shown by reflex movements. Stimulation at the same place, after cutting the central ulnar stump $6 \mathrm{ctm}$. above the central wound and after cutting median and musculo-spiral nerves and resecting them as far as possible, gave similar results except, of course, no signs of pain. 
(2) Stimulating the central ulnar at $18 \mathrm{ctm} . \mathrm{S}$. C. above implanted segment, after severing from the center, gave marked contraction in the muscles supplied by the ulnar.

(3) Direct stimulation of muscular branch to flex. carp. ul. gave good contractions at $15 \mathrm{ctm}$. S. C.

(4) Mechanical stimulation, such as striking the nerve with a small rubber hammer at a point one inch below the peripheral wound, gave flexion of flex. carp. ul.

(5) Contraction was produced in the muscle supplied by ulnar when the nerve was cut with scissors above the implanted segment, and cutting the muscular branch below the peripheral wound caused flex. carp. uI. to contract. Unfortunately the record does not state whether the nerve was stimulated at the wrist or not.

The nerve was hardened in Müller's fluid, and stained in anilin blue and safranin.

Experiment 18. - Aug. I8, 1893.

Small white Spitz. Hypodermic injection of $\frac{2}{5}$ grm. morph. sulph. followed by ether.

Operation. - The ulnar of the right side was resected to the extent of $8 \mathrm{ctm}$., and $8 \mathrm{ctm}$. of a cat's sciatic implanted, and wound closed.

Aug. 30. Wound healed by first intention.

Examination. - Dec. I2, I893 (120 days after operation).

The dog was prepared for an operation on the posterior extremity. $\frac{3}{5}$ grm. morph. sulph. was given; while sterilizing the instruments the dog died from the effects of the morphia. As the apparatus for testing the nerves was not at hand, and the dog was dead some time before the dissection could be made, no reliance can be placed upon the results.

Exposing the nerves showed the peripheral end of the central ulnar to be bulbous, and the peripheral ulnar of normal appearance. Spanning between the two stumps of the ulnar could be seen four or five very fine glistening threads of the appearance of nerve fibres. Stimulation of the peripheral ulnar (thirty-five minutes after the death of the dog) excited no movement and no refiexes.

I was not able to tell whether the apparent failure in the experiment was due to the time intervening between the death of the animal and the physiological tests or not. The experiment is recorded because it shows the only incident where, after a period of more than 120 days after the implantation, regeneration through the implanted segment had not taken place. The histological examination of the nerve involved in this experiment, showed four well-formed nerve bundles in the upper part of the implanted segment, but no trace of these could be seen in the lower portion.

Experiment Ig. - Jan. 23, 1894 .

Brown mongrel. $\frac{2}{5}$ grm. morph. sulph. injected. 
Operation. - The ulnar of the right side was exposed, and $6 \mathrm{ctm}$. removed; a segment of equal length taken from a cat's sciatic was implanted, sutured above and below with a single catgut suture, and wound closed.

Jan. 3I. Two epidermal stitches had given way. The wound healed a few days later.

Examination. - June 23, 1894 (I21 days after operation).

There were no trophic ulcers on the foot. The dog used the foot very well in walking up and down stairs. Exposing the nerves showed the peripheral end of the central ulnar stump to be slightly bulbous. The peripheral ulnar was normal in appearance, and the implanted segment firmly imbedded in fibrous tissue.

Physiological tests :-

(I) Stimulation with induction shocks at $15 \mathrm{ctm}$. S. C. of peripheral ulnar below implanted segment excited contractions of muscles supplied by the ulnar; and evidence of pain was shown by the reflexes, but the latter were not very marked.

(2) After severing the central ulnar stump about $6 \mathrm{ctm}$. above the central wound, and cutting the median and musculo-spiral, stimulation of the central stump produced good contraction of muscles in ulnar area at I $5 \mathrm{ctm}$. S. C.

(3) Direct stimulation of the muscular branch to flex. carp. ul. and flex. profund. dig. at $5 \mathrm{ctm}$. S. C. excited contractions of these muscles, which were very clearly seen after the muscles were exposed.

(4) Stimulation of peripheral ulnar at wrist, at $2 \mathrm{ctm}$. S. C., excited no movement of the digits and no evidence of pain.

(5) Stimulation of ulnar in the middle of forearm produced feeble reflexes at $5 \mathrm{ctm} . \mathrm{S}$. C., showing some regeneration of sensory fibres.

(6) Cutting the nerve with scissors gave distinct contractions, the nerve being cut both above central wound and below peripheral wound. Cutting the muscular branches to flex. carp. ul. and flex. profund. dig. also produced contraction, but no contraction resulted when the nerve was cut at the wrist.

The nerve was hardened in Müller's fluid, and stained in anilin blue and safranin.

Experiment 20. - Jan. 24, 1894 .

Brown and white spaniel. Hypodermic injection of $\frac{2}{5} \mathrm{grm}$. morph. sulph.

Operation. - The left ulnar was exposed, and a segment $7 \mathrm{ctm}$. removed; a piece of equal length taken from a cat's sciatic was implanted, sutured above and below with a single direct catgut suture, and the wound closed.

Jan. 31, 1894. Wound healed by first intention.

Examination. - May 5, I894 (121 days after operation). 
Electrical stimulation with induction shocks after exposing the nerve in the arm gave the following results :-

(I) Stimulation of peripheral ulnar just below implanted segment at I $2 \mathrm{ctm}$. S. C. gave good contraction of the muscles supplied by the ulnar. There was much pain as shown by reflex movements. The median and musculo-spiral were cut and resected before the tests were made.

(2) Stimulation of central ulnar just above implanted segment at I $2 \mathrm{ctm}$. S. C., and after severing the central ulnar about $4 \mathrm{ctm}$. above the central wound, gave marked contraction of the flexor muscles supplied by the ulnar nerve.

(3) Stimulation of muscular branch to flex. carp. ul. at $\mathrm{I} 2 \mathrm{ctm} . \mathrm{S} . \mathrm{C}$. gave contraction of this muscle.

(4) No contraction resulted when the ulnar was stimulated at the wrist at $5 \mathrm{ctm}$. S. C. The nerve was not stimulated at this point before the central ulnar was cut.

(5) Mechanical stimulation by cutting the nerve with scissors above the implanted segment, below the implanted segment, and cutting of muscular branches to flex. carp. ul. and flex. profund. dig., called forth marked contractions in muscles supplied by the ulnar and its branches. There was no movement of the digits when the ulnar was cut at the wrist.

The nerve was hardened in Muiller's fluid, and stained in anilin blue and safranin.

Experiment 21. - Dec. 20, 1893.

Large black mongrel. $\frac{3}{5} \mathrm{grm}$. morph. sulph. injected, followed by ether.

Operation. - The right median nerve was exposed and resected to the extent of $5 \mathrm{ctm}$., and $5 \mathrm{ctm}$. of a cat's sciatic implanted, and sutured above and below with a single direct catgut suture, and the wound closed. The wound healed by first intention.

Examination. - May 5, I 894 (1 36 days after operation).

Stimulation with induction current gave following results :-

(I) Stimulation of median below implanted segment at $15 \mathrm{ctm}$. S. C. gave contraction in muscles of forearm supplied by median, and much pain as shown by well-developed reflexes. Equally marked flexion resulted upon stimulating the peripheral median after severing the central median $4 \mathrm{ctm}$. above central wound.

(2) Stimulating the central median just above the implanted segment at I $5 \mathrm{ctm}$. S. C. produced well-developed movement of flexion.

(3) Direct stimulation at $12 \mathrm{ctm}$. S. C. of several of the small muscular branches given off just below the elbow, gave contraction in muscles supplied by them.

(4) Mechanical stimulation by cutting the nerve with scissors produced very marked contractions.

The nerve was hardened in Müller's fluid, and stained in anilin blue and safranin. 
Experiment 22. - Nov. 25, 1893 .

White bulldog. $\frac{3}{5} \mathrm{grm}$. morph. sulph. injected.

Operation. - The right ulnar was exposed and resected to the extent of $4 \mathrm{ctm}$, and an equal segment of cat's sciatic implanted, sutured above and below with a single direct catgut suture, and wound closed in the usual way.

Dec. I3, I893. The epidermal wound was still open and lined by granulations. The connective tissue seemed to have healed over the implanted nerve and ends of ulnar stump.

Examination. - April 23, I 894 (I 49 days after operation).

The dog could use the foot apparently as well as before the operation, and the sensation in the foot seemed normal.

Tests with induced current as follows :-

(I) Stimulation of peripheral ulnar a short distance below implanted segment (after cutting and resecting median) at $\mathrm{i} 8 \mathrm{ctm}$. S. C., gave good contractions of muscles supplied by ulnar, and slight reflexes; marked reflexes when stimulated at $9 \mathrm{ctm}$. S. C. Stimulation of peripheral ulnar at $18 \mathrm{ctm}$. S. C., after severing the central ulnar about $5 \mathrm{ctm}$. above the central wound, excited marked movements of flexion.

(2) Stimulation of central ulnar (after separation from center), at i 8 $\mathrm{ctm}$. S. C., gave good contractions in muscles supplied by the nerve, feeble contractions when stimulated at $24 \mathrm{ctm}$. S. C.

(3) Direct stimulation of muscular branch to flex. carp. ul. at $18 \mathrm{ctm}$. S. C. gave movements of flexion.

(4) Stimulation of ulnar at wrist at $9 \mathrm{ctm}$. S. C. called forth movements of flexion in digits.

(5) Cutting the ulnar above implanted segment, below implanted segment, and cutting the branches to flex. carp. ul. and flex. profund. dig., was followed by marked contraction of the muscles supplied. Cutting the ulnar at the wrist was followed by feeble contraction of digits.

The nerve was hardened in Müller's fluid, and stained in anilin blue and safranin.

In experiments 23 and 24 the results were almost identical with those recorded for experiment 22.

Experiment 25.- Nov. 29, 1893 .

Young mastiff about one year old. $\frac{4}{5} \mathrm{grm}$. morph. sulph. injected, followed by ether.

Operation. - The ulnar of right arm was exposed, and a segment $6 \mathrm{ctm}$. long removed. An equal segment taken from a cat's sciatic was implanted, and sutured above and below with a single direct catgut suture.

Dec. 4. Greater portion of the wound healed by first intention; the lower end of the wound was open and lined by granulations.

Examination. - May 30, 1894 (1 82 days after operation).

Wound healed. Sensation in foot normal, as far as could be determined by pricking the parts. On exposing the ulnar only a very slight enlargement was noticed on the end of the central stump. 
Electrical examination with induced shocks gave the following results :-

(I) Stimulation of peripheral ulnar at $10 \mathrm{ctm}$. S. C., just below peripheral wound, caused much pain, as shown by well-developed reflexes, and called forth muscular contractions in the muscles supplied by the ulnar. Similar contractions resulted when stimulated after the central ulnar was cut, and after the median and musculo-spiral were resected.

(2) Stinulation of peripheral ulnar at wrist at $10 \mathrm{ctm}$. S. C. (a distance 7 inches below peripheral wound) caused movements of toes and quite well developed reflexes, showing regeneration of at least some of the sensory and motor fibres as far down as the foot.

(3) Stimulation of central ulnar at $15 \mathrm{ctm}$. S. C. produced movements of flexion.

(4) Direct stimulation of the muscular branches to flex. carp. ul. and flex. profund. dig. at Io ctm. S. C. produced contraction in these muscles.

(5) Mechanical stimulation resulting from cutting the nerve with scissors excited strong muscular contractions, the nerve being cut above and below implanted segment, at the muscular branches, and at the wrist.

The nerve was hardened in Müller's fluid, and stained in anilin blue and safranin.

Experiment 36. - March 9, 1894 (secondary implantation).

Young black and brown hound. $\frac{3}{5}$ grm. morph. sulph., then ether.

Operation. - Six ctm. of the right ulnar was removed, and wound closed.

March I4. Wound healed.

April I 9 (forty-one days after this operation). The ulnar was again exposed. The end of the central stump terminated in a large bulb which was imbedded in fibrous tissue. No nerve fibres were seen to extend below the bulb. The central end of the peripheral ulnar was not enlarged.

Electrical examination :-

The central bulb was very sensitive, as shown by the marked reflexes when only very weak stimuli were used. The peripheral ulnar was completely degenerated. The end of the central stump was resected to a line just above the bulb, and the peripheral ulnar vivified. The space between the two ulnar stumps amounted to about $7 \mathrm{ctm}$. A piece of equal length was taken from a cat's sciatic and implanted, and was sutured above and below to the ulnar stump with a single direct catgut suture. The connective tissue was united over the nerve with five buried sutures, and the skin with a continuous silk suture. Wound healed by first intention.

Sept. 21, 1894 (155 days after implantation) the dog was examined. Sensation in the foot was not impaired. On exposing the ulnar, a small bulb was seen at the end of central ulnar; this was not sensitive.

Electrical examination :-

(I) Stimulating the peripheral ulnar below the implanted segment at $8 \mathrm{ctm}$. S. C. gave good contractions of muscles supplied by this nerve, and 
marked evidence of pain as shown by reflexes; this after the median had been cut and resected.

(2) Stimulation of the ulnar above the implanted segment, after severing the ulnar from the center, gave marked contractions at $12 \mathrm{ctm} . \mathrm{S}$. C.

(3) Stimulating the ulnar in the middle of the forearm gave feeble reflexes at $8 \mathrm{ctm} . \mathrm{S}$. C.

(4) Stimulating at wrist caused no movements and no reflexes.

Regeneration seems to have taken place through the implanted segment to a little below the middle of the forearm.

The nerve was hardened in Müller's fluid, and stained in anilin blue and safranin.

(b) Tubular Suture Bone Tube Implantation.

The experiments of others, notably those of Vanlair, had caused me to look with favor on the use of the bone tube in operations for remedying

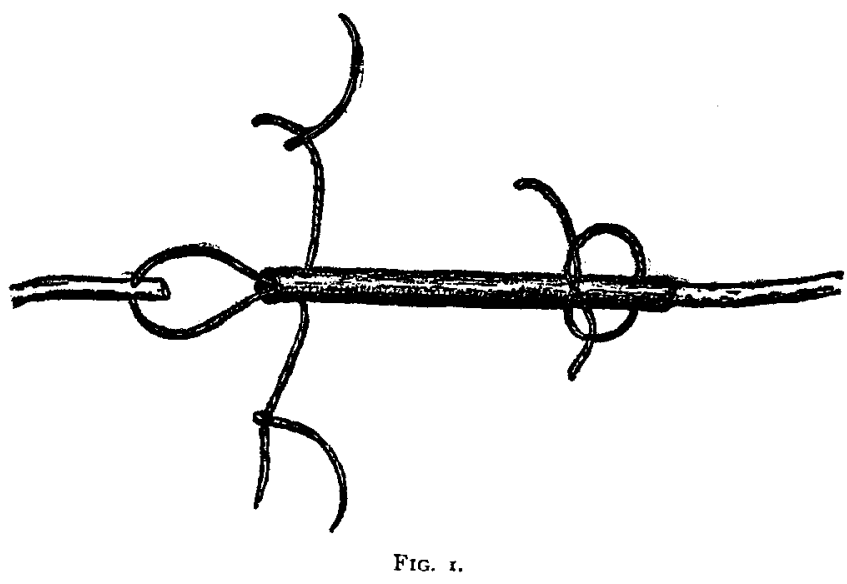

nerve defects, but the results here recorded do not fulfill this anticipation. The bone tubes used were prepared in the following manner: The ulnars of chickens and turkeys were decalcified, after cutting off the ends, in one per cent hydrochloric acid, then thoroughly washed in flowing water, placed into ether for a few hours, and finally transferred to a five per cent solution of carbolic acid, where they remained until needed. Just before using, the bone tubes were boiled for fifteen minutes in alcohol, and then placed in sterilized distilled water, from which they were implanted. After resecting the nerve to the desired extent, the central and peripheral ends of the resected nerve were inserted into the ends of the bone tube for a distance of about I ctm., and held in place by a single suture above and below, passed through the sides of the tube, and at the same time through the ends of the nerve inserted within its lumen. The mode of procedure is 
shown in Fig. I. The connective tissue was then united over the bone tube by means of four to six buried chromatized catgut sutures, and the edges of the epidermis brought together by silk sutures. By closing the wound in this way it was found that, while the silk sutures might break through, the deep sutures would aid the connective tissue in uniting over the bone tube and keeping it in place.

Experiment 27.-- May 30, 1894.

Young mongrel. $\frac{2}{5} \mathrm{grm}$. morph. sulph, injected.

Operation. - The ulnar of the left side was exposed for a distance of $8 \mathrm{ctm}$., and resected to the extent of $7 \mathrm{ctm}$. The ends of the resected nerve were inserted into the ends of a bone tube about $8 \mathrm{ctm}$. long, and held in place by a catgut suture passed through the nerve and bone tube, and the wound closed.

Examination. - June 4, I 894 (five days after operation).

Epidermal wound open, connective tissue healed over bone tube, and covered with healthy granulations. On removing the granulation tissue a transparent flat band attached above and below to the resected ulnar could be recognized, presumably the implanted bone tube. Electrical stimulation of peripheral ulnar stump showed it to be degenerated.

The nerve was hardened in Flemming's solution, and stained in safranin and licht grün.

Experiment 28. - May 30, I 894.

Full-grown shepherd dog. Hypodermic injection of $\frac{3}{5} \mathrm{grm}$. morph. sulph.

Operation. - The left ulnar was resected $6 \mathrm{ctm}$., and the resected ends inserted into a bone tube, and retained in place by catgut sutures. Wound closed.

Examination. - June 9, 1894 (ten days after operation).

The greater portion of the wound healed by first intention. On exposing the ulnar the implanted bone tube was not recognized. The end of the central stump was slightly enlarged. The peripheral ulnar was degenerated, as shown by electrical and mechanical stimulation.

The nerve was hardened in Flemming's solution, and stained in safranin and licht grün.

The same physiological result was obtained in experiment 29. The nerve was removed, hardened in Müller's fluid, and stained in anilin blue and safranin.

Experiment 30. - Dec. 15, 1893 .

White and brown mongrel. $\frac{2}{5}$ grm. morph. sulph. injected, followed by ether.

Operation. - The left sciatic was exposed, and resected to the extent of $3 \mathrm{ctm}$. The central and peripheral ends of the nerve were drawn into the ends of the bone tube, and sutured in this position. Wound closed. 
Jan. I, I 894. Wound nearly healed.

Feb. I, I894. Dog used the foot in walking, sometimes touching the floor with the plantar surface of the foot, at other times with the dorsum of the foot. He used the foot in walking up stairs, but often did not reach far enough, and missed the step.

Examination. - Feb. 7, 1894 (fifty-four days after operation).

Electrical stimulation of central sciatic above bone tube, even with strong stimulus, produced no movement in the muscles supplied by the sciatic. The same results were obtained when the peripheral sciatic was stimulated below the bone tube, and when the internal and external popliteal branches were stimulated.

No contraction resulted from cutting the central sciatic.

The nerve was hardened in Müller's fluid, and stained in anilin blue and safranin.

Experiment 31. - Jan. 24, 1894.

White and brown spaniel. Hypodermic injection of $\frac{3}{5} \mathrm{grm}$. morph. sulph.

Operation. - A segment $6 \mathrm{ctm}$. long was removed from the right ulnar, the cut ends inserted within the ends of a bone tube, and sutured. Wound closed.

Examination. - May 5, I 894 (I2I days after operation).

The end of the central stump was slightly enlarged.

Electrical stimulation :-

(I) Stimulation of ulnar below bone tube at $5 \mathrm{ctm}$. S. C. produced slight evidence of pain, as shown by feeble reflexes, but no movement in muscles supplied by ulnar.

(2) Stimulation above the bone tube caused no movements. There was no contraction of the muscles supplied by the ulnar when the nerve was cut with scissors central to the bone tube. It would seem that a few sensory fibres had reached the peripheral ulnar.

The nerve was hardened in Müller's fluid, and stained in anilin blue and safranin.

Experiment 32. - Dec. 13, 1893.

White bulldog. $\frac{3}{5} \mathrm{grm}$. morph. sulph. injected.

Operation. - The right sciatic was exposed, and $5 \mathrm{ctm}$. exsected. The cut ends of the nerve were placed into the ends of a bone tube, retained in place by catgut sutures, and wound closed.

Dec. 18. Greater portion of the wound healed by first intention.

Jan. 1 894. Extensive ulcer on the dorsal surface of the right hind foot, and the toes red and swollen. In walking the dog dragged this foot, and when used for support touched the floor with the dorsal surface.

Feb. 15. No improvement in utility and appearance of the foot. 
April 23. Foot not so red and swollen, ulcerating surfaces granulating, and the dog seemed to have better control of the foot than he had for the first three months after the operation.

Examination. - April 23 (I 2 I days after operation).

The peripheral end of the central stump ends in a large bulb, which is very sensitive.

Physiological examination resulted as follows:-

(I) Stimulating sciatic below the bone tube with strong induction shocks caused no movement and no reflexes.

(2) Stimulating the sciatic above the bone tube with induction shocks at $5 \mathrm{ctm}$. S. C. produced no contraction of the muscles supplied by the sciatic. Cutting the nerve above the bone tube caused no movement of the muscles.

(3) Stimulating the external and internal popliteal with strong induction shocks gave no contraction of the foot.

The nerve was hardened in Müller's fluid, and stained in anilin blue and safranin.

Experiment 33. - Dec. 20, 1893.

Large black mongrel. $\frac{3}{5}$ grm. morph. sulph. injected.

Operation. - The right ulnar was resected to the extent of $5 \mathrm{ctm}$, the ends united with the bone tube, and wound closed.

Examination. - May 5, 1894 (130 days after operation).

Healing ulcer on the outer surface of the foot.

Stimulation of the peripheral ulnar just below the bone tube with induction shocks at $9 \mathrm{ctm}$. S. C. produced scarcely perceptible reflexes, and no flexion. Reflexes not increased with strong stimulus. Stimulation of the central ulnar above the bone tube at $5 \mathrm{ctm}$. S. C. excited no contraction in muscles supplied by ulnar. Mechanical stimulation, by cutting the nerve above and below the bone tube, excited no movement.

The nerve was hardened in Müller's fluid, and stained in anilin blue and safranin.

Experiment 34. - March 9, 1894.

Black and brown hound. Hypodermic injection of $\frac{3}{5}$ grm. morph. sulph., followed by ether.

Operation. - The left ulnar was resected to the extent of $6 \mathrm{ctm}$., and the wound closed without suturing the nerve.

April ig (forty-one days after resecting the nerve). The ulnar was again exposed. The peripheral end of the stump presented a large and very sensitive bulb. No nerve fibres could be traced beyond this enlargement. The central end of the peripheral ulnar was not enlarged, and proved to be completely degenerated, as shown by its not responding to induction shocks. The ends of the central and peripheral stump were vivified, leaving a space of about $7 \mathrm{ctm}$. between the resected ends. These were inserted into the ends of a bone tube and sutured. The wound was then closed in the usual manner. 
Examination. - Sept. 21, I894 (155 days after second operation).

(I) Stimulation of the peripheral ulnar just below the bone tube with induction shocks at $8 \mathrm{ctm}$. S. C. gave flexion of the muscles supplied by the nerve, together with signs of pain, as shown by the reflex movements; this after the median had been resected.

(2) Stimulating central ulnar above bone tube at $12 \mathrm{ctm}$. S. C. excited contraction of the muscles supplied by ulnar.

(3) Stimulation of muscular branch to flex. carp. ul. at $8 \mathrm{ctm}$. S. C. excited contraction of this muscle.

(4) Stimulation of the ulnar at wrist gave no contraction and no reflexes.

(5) Cutting the nerve with scissors above the bone tube, below the bone tube, and cutting muscular branch to flex. carp. ul. excited contraction of muscles supplied by the nerve.

\section{(c) Implantation of Catgut Bundle.}

In the following series of seven experiments, threads of catgut, as suggested by Glück and Assaky, were employed to unite the ends of the resected nerve.

Experiment 35. - May 30, 1894 .

Young mongrel. $\frac{3}{5}$ grm. morph. sulph.

Operation. - The ulnar of the right side was exposed, and $6 \mathrm{ctm}$. removed. In place of the suture à distance, as suggested by Assaky, the author, in this and five other experiments, employed a bundle of catgut

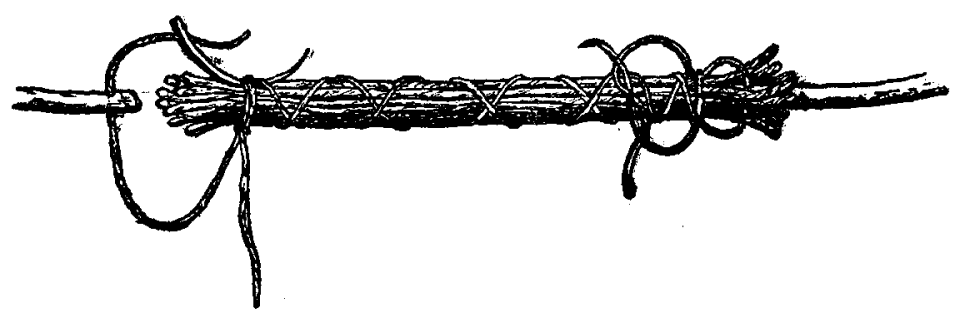

Fig. 2.

threads about I ctm. longer than the exsected nerve segment, and composed of eight No. 3 chromatized threads about which were wound two very fine catgut threads. The ends of the threads encircling the bundle were allowed to remain long, so that they might be employed as sutures for uniting the implanted bundle to the cut ends of the nerve. A bundle of catgut threads thus prepared and made antiseptic by boiling for fifteen minutes in alcohol and then washing in sterilized distilled water, was implanted and sutured above and below to the central and peripheral ends of the resected nerve, care being taken to have the ends of the several catgut threads composing 
the implanted bundle, come up over and form a sheath or a cuff around the ends of the nerve stump. The form of the catgut bundle, and the manner in which it was united to the resected nerve ends is shown in Fig. 2. The wound was closed by stitching the subcutaneous connective tissue over the implanted catgut, and closing the dermal incision with interrupted silk sutures.

Examination. - June 4, I 894 (five days after operation).

Wound nearly healed by first intention. On opening the wound the catgut bundle was found imbedded in a mass of granulation tissue, and when isolated, was found to be quite firmly united to the central and peripheral portion of the resected nerve by means of granulation tissue.

Stimulation of the peripheral ulnar with strong induction shocks excited no movements in the muscles supplied by ulnar. No contraction was observed when the nerve was cut with scissors.

The nerve was hardened in Flemming's solution, and stained in safranin and licht grün.

The same results were obtained in experiments 36 and 37 .

Experiment 38. - April 20, 1894 .

Small black bulldog. $\frac{3}{5}$ grm. morph. sulph.

Operation. - The ulnar of the left side was exposed, and $5 \mathrm{ctm}$. removed. In this case the central and peripheral ends of the nerve were united by a long catgut suture, carried forward and backward three times, and at each turn the catgut thread was passed through the nerve stump, Assaky's suture à distance. The wound was then closed.

Examination. - May 30, 1894 (39 days after operation).

Wound healed. Physiological tests as follows :-

(I) Stimulation of the peripheral ulnar below the catgut threads with strong induced current gave no contraction of the muscles and no reflexes.

(2) Stimulation of the central ulnar above the implanted catgut bundle excited no contractions.

(3) Cutting the nerve with scissors excited no contraction of muscles supplied by ulnar.

The nerve was hardened in Müller's fluid, and stained in anilin blue and safranin.

Experiment 39. - Jan, 25, 1894 .

Brown mongrel. $\frac{3}{5}$ grm. morph. sulph., followed by ether.

Operation. - A segment $5 \mathrm{ctm}$. in length was removed from the left ulnar, the resected ends united by suture à distance, and wound closed.

Jan. 31 . Wound healing by first intention.

Examination. - June 8, 1894 (I36 days, four and a half months, after operation).

Peripheral end of central stump terminated in a large bulb.

(I) Stimulation of peripheral ulnar just below catgut suture with induced current at $\mathrm{I} 2 \mathrm{ctm}$. S. C. excited strong contraction of muscles supplied by 
ulnar; reflexes feeble. Contraction not so marked after the central ulnar was cut.

(2) Stimulation of central ulnar just above catgut suture, after it had been divided at a point about $6 \mathrm{ctm}$. above suture, excited muscular movement at $12 \mathrm{ctm}$. S. C.

(3) Direct stimulation, at $9 \mathrm{ctm} . \mathrm{S}$. C., of muscular branch to flex, carp. ul. excited feeble contraction of this muscle.

(4) Stimulating the peripheral ulnar in forearm caused no contraction.

(5) Stimulation at $12 \mathrm{ctm}$. S. C. of a narrow band, presumably a newformed nerve trunk extending from central to peripheral ulnar, caused strong contraction of flex. carp. ul.

(6) Cutting the central ulnar, peripheral ulnar, and muscular branch to flex. carp. ul., with scissors, excited strong contractions.

The physiological examination leads to the conclusion that the new nerve fibres had reached the upper portion of peripheral ulnar and the muscular branch to flex. carp ul., but as yet had not grown any distance down the peripheral stump.

The nerve was hardened in Müller's fluid, and stained in anilin blue and safranin.

Experiment 40. - Dec. 20, 1893.

Large black mongrel. Hypodermic injection of $\frac{3}{5}$ grm. morph. sulph., followed by ether.

Operation. - The ulnar of the left side was resected $5 \mathrm{ctm}$, and a bundle composed of eight No. 3 catgut threads implanted, sutured to the resected ends of the ulnar, and wound closed.

Examination. - May 5, 1894 ( 136 days after operation).

(r) Stimulating with strong induction current of peripheral ulnar below the catgut bundle excited no reflexes and no contraction of muscles supplied by ulnar.

(2) Stimulating central ulnar after severing the nerve $5 \mathrm{ctm}$. above the implanted catgut bundle caused no contraction.

(3) Cutting the central ulnar, peripheral ulnar, and muscular branch to flex. carp. ul., excited no contractions.

Conclusion. - No return of function to sensory or motor fibres in the peripheral ulnar.

The nerve was hardened in Müller's fluid, and stained in anilin blue and safranin.

Experiment 4r. - Dec. 2, 1893.

Shepherd dog. Hypodermic injection of $\frac{3}{5} \mathrm{grm}$. morph. sulph., followed by ether.

Operation. - The left ulnar was resected to the extent of $4 \mathrm{ctm}$., and a catgut bundle implanted and sutured above and below to the resected ulnar. Wound closed.

Examination. - May 30, 1894 (152 days after implantation). 
(1) Electrical stimulation with induced current at $12 \mathrm{ctm}$. S. C. of peripheral ulnar just below peripheral wound excited muscular movements and reflexes.

(2) Stimulating the central ulnar, after cutting the nerve about $5 \mathrm{ctm}$. above the central wound and after resecting the median, excited strong contractions of muscles in ulnar region, at $24 \mathrm{ctm}$. S. C.

(3) Direct stimulation of muscular branch to flex. carp. ul. at $12 \mathrm{ctm}$. S. C., excited contraction of the muscle.

(4) Very feeble movements of the digits were observed when the peripheral ulnar was stimulated at the wrist with strong induction shocks.

(5) Cutting the central ulnar, peripheral ulnar, and muscular branch to flex. carp. ul. with scissors, excited strong contraction of the muscles supplied.

Conclusion. - Nearly complete regeneration of peripheral portion of resected nerve.

The nerve was hardened in Müller's fluid, and stained in anilin blue and safranin.

\section{(d) LÉTIÉVANT'S FlaP OPERATION.}

In the following seven operations, the value of a nerve flap, as suggested many years ago by Létiévant, was tried as a method for uniting the widely separated ends of a divided nerve.

Experiments 42 and 43. - June 2, 1894.

Black spaniel. $\frac{3}{5}$ grm. morph. sulph.

Operation. - (Exp. 42, left ulnar; 43, right ulnar.) The ulnar nerves of the left and right sides were exposed, and in each case resected to the extent of $5 \mathrm{ctm}$. The distance separating the central and peripheral stumps of the ulnar was bridged by a nerve flap made from the central stump. To make this flap the following steps were taken: a thin sharp knife was passed through the substance of the central stump about $1 / 2 \mathrm{ctm}$. from its end, the cutting edge pointing central-ward. Without removing the knife, the incision was continued up the nerve trunk for a distance equaling in length the space separating the ends of the resected nerve, care being taken to bisect the nerve, as nearly as possible, into equal parts. Before removing the knife, the upper end of one of the halves was severed from the undivided central ulnar; the flap so formed was then turned down, and its free end stitched by means of a catgut suture to the central end of the peripheral ulnar. The wound was then closed in the usual manner.

Examination. - June 7, 1894 (five days after operation).

Electrical stimulation of the central ulnar, of flap, and of peripheral ulnar excited no contraction of muscles supplied by nerves operated upon.

The nerves were hardened in Flemming's solution, and stained in safranin and licht grün. 
Experiments 44 and 45 .- June 2, 1894.

White and brown mongrel. $\frac{3}{5}$ grm. morph. sulph.

Operation. - No. 44, right ulnar ; 45 , left ulnar.

After ten days there was degeneration of peripheral ulnar.

Experiment 46. - April 20, 1894.

Large yellow and black mongrel. $\frac{3}{5}$ grm. morph. sulph., followed by ether.

Operation. - The right ulnar was exposed, and $6 \mathrm{ctm}$. cut out. A flap was made from the central stump and sutured to the peripheral ulnar, and wound closed.

Examination. - June 23, I 894 (64 days later).

Wound completely healed, and the dog did not seem to suffer any inconvenience in the use of the extremity. On exposing the ulnar the peripheral end of the central stump was slightly enlarged.

(I) Electrical stimulation of peripheral ulnar at $5 \mathrm{ctm}$. S. C., just below its junction with the flap, excited no contraction and no reflexes.

(2) Stimulating in the region of the flap, after freeing it by dissection, caused pain, as shown by reflex movements, but no contraction.

(3) Stimulating the central ulnar with a strong current gave no contractions.

Conclusion. - There was a down-growth of sensory fibres for a short distance below the end of the central stump, but not into the peripheral ulnar.

The nerve was hardened in Müller's fluid, and stained in anilin blue and safranin.

Experiment 47. - March 6, 1894 .

Full-grown greyhound. $\frac{3}{5}$ grm. morph. sulph. injected, followed by ether.

Operation. - A segment $5 \mathrm{ctm}$. long was removed from the right ulnar, and a nerve flap made from the central stump was turned down and stitched to the peripheral ulnar. Wound closed.

Examination. - July 31, I894 (I 47 days after).

Electrical stimulation of the exposed ulnar, below the peripheral flap, with a strong induced current excited no contraction of muscles in ulnar area, and gave no evidence of pain as would be shown by reflexes.

Cutting the ulnar at various points gave the same negative results. The physiological examination showed no regeneration.

The nerve was hardened in Müller's fluid, and stained in anilin blue and safranin.

Experiment 48. - March 6, I894.

Full-grown greyhound. $\frac{3}{5}$ grm. morph. sulph. injected, followed by ether.

Operation. - Removed $5 \mathrm{ctm}$. of the left ulnar. The free ends of two nerve flaps, one made from the central stump about $3 \mathrm{ctm}$. long, the other 
from the peripheral stump and of equal length, were brought together, sutured by means of a direct catgut suture, and wound closed.

Examination. - July 31, 1894 (I47 days after).

Electrical stimulation of the ulnar below flaps excited no contraction and no reflexes. The same negative results were obtained when stimulating above the flaps, and when stimulating the muscular branch to flex. carp. ul.

The nerve was hardened in Müller's fluid, and stained in anilin blue and safranin.

\section{(e) Nerve Grafting.}

Experiment 49. - Nov. 25, 1893 .

Full-grown white bulldog. Hypodermic injection of $\frac{3}{5} \mathrm{grm}$. morph. sulph.

Operation. - The ulnar and median nerves of the left arm were exposed, $4 \mathrm{ctm}$. removed from the median, and the central end of peripheral median stump was stitched by means of three catgut sutures to the accompanying ulnar. Before stitching, a small area of the trunk of the ulnar was denuded of its connective tissue sheath. The central median stump was allowed to end free in the wound. The wound was closed with catgut and silk sutures.

Examination. - April 23, 1894 (149 days after).

After removing the skin and subcutaneous connective tissue, the peripheral median stump was found to be firmly united to the accompanying ulnar. The central median stump terminated in a large bulb.

Electrical stimulation of the peripheral median showed it to be degenerated ; no contraction of muscles supplied, and no reflexes were observed.

\section{( $f$ ) Létífvant's and Tillmanns' Operation, that is, Cross- Suturing the Long Ends and Grafting the Short Ends of Two Parallel Nerves Cut at a Different Level.}

Experiment 5o. - Nov. 29, 1893.

Young mastiff about one year old. $\frac{4}{5}$ grm. morph. sulph., followed by ether.

Operation. - The ulnar and median were exposed. From the two nerves were exsected segments $4 \mathrm{ctm}$. long. The portions removed were taken from different levels of the two nerves. As will be seen from Fig. 3, the ulnar was divided much higher up than the median, and as the segments removed from the two nerves were of about the same length, the peripheral stump of the ulnar was longer than that of the median. In cases where, as in the present experiment, an incision passes obliquely over two nerves having a parallel course, and where so much nerve substance is lost that the respective ends cannot be brought together, Tillmanns recommends a "cross-suturing" of the longer ends, and a grafting of the shorter stumps 
to the accompanying nerve trunk. Tillmanns' suggestion was made use of in this operation. The longer central stump of the median was sutured to the longer peripheral stump of the ulnar. The short central stump of the ulnar was grafted (stitched) to the central median, and the short peripheral

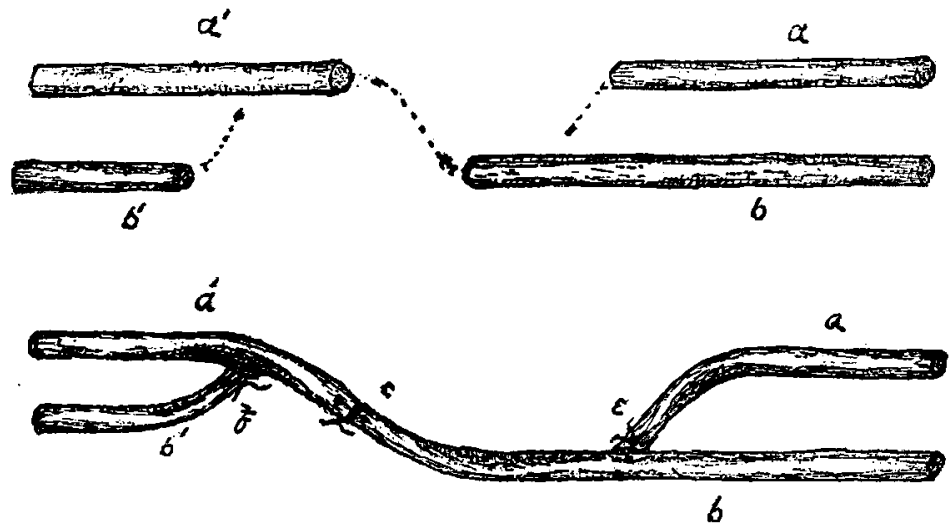

Fig. 3. $-a$, central ulnar stump; $a^{\prime}$, peripheral ulnar stump ; $b$, central median stump; $b^{\prime}$, peripheral median stump; $c$, cross-suture of central median and peripheral ulnar segment $i e$, grafting of peripheral end of central uinar segment to median; $f$, grafting of central end of peripheral median stump to ulnar.

stump of the median to the peripheral ulnar as shown in Fig. 3. The connective tissue was carefully stitched over the nerves by means of numerous buried catgut sutures, and the skin wound closed with silk sutures.

Dec. I4, 1893. Nearly the entire wound healed by first intention. Examination. - May 30, 1894 (I 82 days after operation).

On laying bare the nerves in the arm, the following conditions were met with :- -

The central median stump was found united to the peripheral segment of the ulnar. The central ulnar stump was fixed to the median by means of connective tissue, and on careful dissection was found to end in a bulb. The peripheral median was attached to the peripheral ulnar.

Physiological examination gave the following results :-

(1) Electrical stimulation by induction shocks at $15 \mathrm{ctm}$. S. C. of peripheral ulnar below its junction with median, excited strong contraction in muscles supplied by ulnar, and much pain, as shown by the well-developed reflexes.

(2) Stimulating the central median above junction with the ulnar, with induction shocks at $15 \mathrm{ctm}$. S. C., gave strong contraction of flex. carp. ul. and flex. prof. dig., as could easily be seen on observing these muscles after their exposure.

(3) Direct stimulation of the muscular branches to the above muscles excited contraction. 
(4) Stimulating the peripheral ulnar at wrist excited movements of the digits and reflex movements, showing a return of motor and sensory function of ulnar branches in the foot.

(5) The central ulnar stump, which was, as will be remembered, grafted to the median, was cut $8 \mathrm{ctm}$. above the point of grafting, and then stimulated by induction shocks at $5 \mathrm{ctm}$. S. C., but no movement could be observed in the muscles supplied by the median or ulnar.

(6) The peripheral stump of the median, which had been grafted to the ulnar, was found to be degenerated.

(7) Mechanical stimulation by cutting the median above its junction with ulnar, by cutting the peripheral ulnar, and by cutting the muscular branches, excited contraction of flex. carp. ul. and flex. prof. dig.

(8) No contraction resulted after cutting the central ulnar and peripheral median stump.

Conclusion. - Complete regeneration of peripheral ulnar through fibres of the central median stump. The engrafted stump of median was degenerated.

The nerves were hardened in Müller's fluid, and stained in anilin blue and safranin.

\section{Part III. - Histological.}

Methods. - Of the great number of methods employed by the various writers who have made a study of degeneration and regeneration of divided peripheral nerves, very few bring out with clearness the changes undergone by the axis cylinder. The fate of the myelin can be quite easily traced if the degenerating nerve is hardened in a fluid having osmic acid as one of its constituents. The structural changes undergone by the nerve nuclei can be readily followed in preparations hardened in Flemming's or Hermann's solution, and stained in safranin. After much experimenting with the various methods used for staining the axis cylinder in peripheral nerves, the author came to the conclusion that, as far as his experience goes, the best results were to be obtained with Stroebe's anilin blue and safranin stain. This method, slightly modified, was used in preparing the great majority of the histological preparations. In each experiment the entire peripheral stump of the operated nerve, the implanted piece, and about one inch of the central stump, were removed and hardened from three to four weeks in Müller's fluid, at a temperature of forty degrees $\mathrm{C}$.; then washed in 
flowing water for about thirty minutes, and placed into ninetyfive per cent alcohol for three or four days.

(To keep the nerve fibres straight during the process of hardening the following device was made use of : One end of each of two small glass rods, the one about eight, the other about three inches long, was pushed through a cork of a size to fit a six-inch test tube ; the other ends of the two rods were bent in the form of a hook. After removing a nerve segment from a dog its central end was tied to the short hook, its distal end to the long one, and the long rod was moved up or down in the cork until the nerve attained the proper degree of extension. The hardening was then carried on in a test tube.)

After remaining in ninety-five per cent alcohol the required time, each nerve was divided into pieces varying in length from one-half to one inch. Two consecutive segments, one of which was used for longitudinal, the other for transverse sections, were placed in properly labeled test tubes, in which they were carried through absolute alcohol, toluol, soft and hard paraffin, and were then imbedded in a mixture composed of four parts of hard paraffin and one of spermaceti.

Sections varying in thickness from five to ten mikrons were cut and fixed to a cover glass by a method described by the author in a former paper. The method consists in floating the paraffin sections on distilled water, then carefully warming the water until they flatten out, which they usually do very readily. A thin layer of "albumin fixative" is now spread on a cover glass ; this is then inserted under the sections floating on the water, one or more of which are drawn up on the cover glass, a small sable-hair brush being used for this purpose. When this has been done, the cover slip with the sections on it is drawn out of the water and set aside, best in a warm oven at forty degrees $\mathrm{C}$. for several hours. Nearly all the albumin fixative is washed away, so it does not interfere with the staining, yet enough seems to remain on the cover to cause the section to adhere more firmly than when water is used, as recommended by Gaskell, or when fifty to seventy per cent alcohol is employed, as recommended by Gaule.

Cutting in paraffin admits of thinner sections than when 
celloidin is used, as Stroebe recommends, and the technic of staining is simpler. The cover glass can be handled much more easily than thin celloidin sections. Then, too, one can often fix ten to fifteen sections to one cover, so there is a great saving of time. The paraffin is removed in the usual way, and then the cover with the sections on it is carried through "the alcohols" into distilled water.

The technic of Stroebe's anilin blue-safranin method is as follows :-

(I) Sections are stained from one to five hours in a saturated aqueous solution of anilin blue (Grübler's wasserlösliches Anilinblau).

(2) They are then rinsed in distilled water.

(3) Decolorized in an "alkali alcohol wash," which is prepared by dissolving I grm. of caustic potash in IOO c.c. of absolute alcohol, and filtering. Just before using thirty to forty drops of this solution are mixed with 30 c.c. of absolute alcohol. On placing the sections into this wash they lose their blue color, and assume a reddish-brown tinge; at the same time reddish-brown waves are given off from the preparation. The bleaching is continued until the reddish-brown waves cease to form, which usually takes about one to two minutes. If many sections are to be bleached it will be found necessary to renew the alkali wash.

(4) The sections are now transferred to distilled water, in which the blue color again returns, of a much lighter hue, however. The sections remain in the water about ten minutes.

(5) Counter-stain in a saturated aqueous solution of safranin for about one-half hour.

(6) Rinse in distilled water.

(7) Wash and dehydrate quickly in ninety-five per cent, then in absolute alcohol.

(8) Clear in oil of bergamot, and place the sections into xylol, from which they are mounted in Canada balsam. The xylol leaves a clean surface on the cover after evaporating, and is for this reason to be used after oil of bergamot.

The axis cylinder will be stained deeply blue, the myelin reddish-yellow, or of an orange tinge, and the nerve nuclei, and all 
other nuclei, of a safranin color, the protoplasm a faint red. In case the safranin stain is extracted too much the blue stain will predominate in the section. Yellow elastic tissue will sometimes stain very much like an axis cylinder, but the definite outline of the elastic fibres, and their relation to other structures, will make it possible to obviate any misinterpretation. In a number of experiments, especially those in which the earlier degenerative changes of myelin and the behavior of the nerve nuclei were made the subject of study, the nerves were hardened in Flemming's solution (extension being maintained in the manner described for Müller's fluid-hardened nerves), imbedded in paraffin, sectioned and fixed to the cover glass, and doubly stained with safranin and licht grün, after Benda's method.

In making teased preparations it was found quite helpful to cut sections twenty to thirty mikrons thick, remove the paraffin, stain in anilin blue and safranin, or safranin and licht grün, and then tease these stained sections in oil of bergamot, and mount in balsam. Sections, especially such as contain much fibrous tissue, can thus be easily teased, and the nerve fibres are, as a rule, not so liable to be broken up as when teased in the usual way.

\section{(a) Degeneration and Regeneration after Implantation of a} Nerve Segment.

The degenerative changes which befall the implanted segment do not differ materially from this process as observed in peripheral nerves after severance from its center, except that the changes take place more rapidly.

By the end of the second day the myelin and axis cylinders of the nerves of the implanted segment are found to be broken up into larger and smaller fragments, and there is already an increase of the protoplasm within the sheath of Schwann. At this stage the segments of myelin vary largely in size and shape : some are long, and entirely fill the sheath of Schwann in that portion of the degenerating fibres in which they are found; others are in the form of small, round, or oval balls, 
surrounded by the proliferated protoplasm; between these extremes one finds every gradation. The segments are usually surrounded by a layer of myelin varying in thickness, and showing a decided difference in the extent to which it is stained with osmic acid. The protoplasm has a homogeneous appearance, staining faintly red in safranin. I am unable to state, as a result of the preparations examined, what is the cause of the fragmentation of the myelin and axis cylinder. In the sections at my disposal the degenerative changes were too far advanced to make any observation on this point. It does not, however, seem probable that the fragments of myelin bear any relation to the so-called segments of Lantermann or Schmidt. Their irregular shape and size would exclude such a possibility. The nerve nuclei are found in larger number than in normal fibres, where, as is well known, a single internodal nucleus is present. As a rule they occupy a position in the middle of the fibre between two segments of myelin. It is somewhat difficult to estimate their number, as the nodes of Ranvier cannot be clearly made out at this stage. To some extent, at least, the proliferation of the nuclei would seem to result from karyokinetic division of preëxisting internodal nuclei ; now and then one is found in the early stages of cell division. I was not fortunate enough, even after looking through a large number of sections, to find a nucleus in the monaster or diaster stage. The nucleus shown in the middle one of the five fibres reproduced in Pl. XXXIV, Fig. I, which represents a portion of a longitudinal section of the implanted segment two days after the operation, presents a structure differing from that of the majority of the nuclei seen. The chromatic filaments (chromosoma) are clearly discerned, and the nucleoli are wanting, although the nuclear membrane is still present; while the resting nuclei present a very delicate nuclear network, and usually two, three, or four prominent nucleoli. Now and then one finds a nucleus of hour-glass or dumb-bell shape, which leads one to think that some of the nuclei fragment (amitotic division), and in this way contribute to the proliferation of the nuclei seen. A great number of polynuclear white-blood cells are found in the lymph spaces between the connective 
[VoL. XI.

tissue bundles of the epineurium, also between the junction of the central ulnar stump and the central end of the implanted segment, and between the peripheral ulnar and the peripheral end of the implanted nerve. From the central and peripheral wound they may be traced for a short distance between the nerve fibres of the implanted segment, in less number between the nerve fibres of the peripheral and central ulnar in the neighborhood of the wounds. I was not able to find any polynuclear leucocytes within the sheath of Schwann of the nerve fibres in the transplanted segment, nor within the ends of the nerve fibres of the central and peripheral stump of the ulnar. The nerve fibres of the peripheral and central portion of the ulnar are apparently of normal structure, the axis cylinder is not interrupted, and the myelin presents a normal appearance. That the fibres of the peripheral end possessed conductivity is shown by the fact that the muscles supplied by the ulnar contracted when the nerve was cut about $3 \mathrm{ctm}$. below the peripheral wound. The "traumatic degeneration," as described by Bünger, Stroebe, and others, extends only a short distance along the fibres of the central and peripheral ulnar, and is a process differing essentially from the " secondary degeneration," which involves the entire peripheral portion of the severed nerve. In the immediate neighborhood of the trauma the myelin is broken up into fragments, and in some of the fibres the sheath of Schwann is filled with a granular débris, staining a gray-black in osmic acid. The axis cylinder is, as a rule. unbroken, and can be seen imbedded in the myelin.

During the third day segmentation of the myelin in the implanted fibres continues, and the fibres begin to show a very irregular shape, many of them showing nodular enlargements, in which are found one or several large fragments of myelin; these alternate with segments of the nerve of much smaller diameter, composed largely of proliferated protoplasm in which may be imbedded smaller drops or granules of myelin. A chemical change has taken place in many of the fragments of myelin, evinced by the way in which they stain with osmic acid and safranin. In a normal nerve, hardened in osmic acid (Flemming's solution) and stained with safranin, the myelin 
assumes a black color, and is not touched by the safranin. The same fact is observed during the early stages of degeneration (myelin black and the protoplasm of a reddish tinge); as degeneration proceeds, one sees that the myelin begins to be stained also by the safranin, and now assumes a color which is a mixture of the black and red stain. This change takes place more rapidly near the nuclei. There is no marked increase of the nuclei of the sheath of Schwann over that observed at the end of the second day, although one finds now and then one in mitosis, as is seen in Pl. XXXIV, Fig. $2 b$. The nuclei are less numerous in a degenerating fibre of the implanted segment than would be observed in degenerating fibres of the peripheral end at a corresponding stage. Polynuclear leucocytes are found in large numbers in the endoneural connective tissue between the nerve fibres at this stage (see Pl. XXXIV, Fig. 2), especially so in the outer portion of the implanted nerve trunk. The fact that they are first observed in the epineurium, at a little later stage in the lymph space between this sheath and the nerve fibres, finally between the nerve fibres near the epineurium, leads to the conviction that they wander in through the connective tissue sheaths surrounding the implanted nerves. At this stage the endoneural connective tissue cells are proliferating by means of mitotic division, as is shown in Pl. XXXIV, Fig. $2 d$. The peripheral portion of the ulnar is up to this time of normal histological structure, and stimulation with induction shocks excites contraction of the muscles supplied.

During the fourth and fifth days the fragmentation and absorption of the myelin in the implanted fibres goes on quite actively, yet not with the same rapidity in the different fibres nor in different portions of the same fibre. The myelin would seem to be absorbed more rapidly than the axis cylinders. In longitudinal sections and teased preparations made from an implanted nerve taken from a dog five days after the operation, and stained in anilin blue, irregular segments of the axis cylinder, stained deep blue with the dye, are seen in nearly every fibre. Some of these fragments are long, now and then slightly twisted (see Pl. XXXIV, Fig. $3 a$ ), often ending in 
bulbous enlargements. These larger segments are often found free in the proliferated protoplasm filling the sheath. About some of them are found layers of fine granules concentrically arranged, stained like the fragments of the axis cylinder ; they may show the manner in which the axis cylinder segments are resolved. The shorter "axes segments" are as a rule surrounded by a thin layer of myelin of a yellowish color. In the above preparation polynuclear leucocytes are found in large numbers between the nerve fibres, and between the ends of the implanted segments and the stump of the ulnar. The spindle-shaped cells ("specific nerve granulation cells"), described by Glück as developing between the cut ends of a nerve, and as uniting the central and peripheral axis cylinders, were in no case observed. During the fourth and fifth days degeneration begins in the peripheral end of the divided nerve. The myelin and axis cylinders begin to be broken into fragments, and some of the nuclei of the sheath of Schwann are in process of karyokinetic cell division. An inevitable result of the fragmentation of the axis cylinders is the loss of the conductivity of the fibres in the peripheral nerve, as shown by the fact that they do not carry impulses when stimulated with induction shocks or mechanically. The permeation of the polynuclear leucocytes, as observed in the implanted segment, was not observed in the degenerating peripheral ulnar.

During the sixth, seventh, and eighth days, fragmentation and absorption of the myelin and axis cylinders of the fibres in the implanted segment goes on so rapidly that by the end of the ninth day it becomes very difficult to recognize the implanted nerve. At this time the nearly collapsed sheaths of Schwann take a green stain (tissue hardened in Flemming's solution and stained in safranin and licht grün), and contain a protoplasm in which are found a few granules faintly tinged with the safranin (see Pl. XXXIV, Fig. 4). At rare intervals the observer meets larger or smaller balls of myelin stained black with the osmic acid. One such fibre is shown in the figure; at either side of the myelin fragments the tubular sheath becomes rapidly smaller, and resembles in structure the other fibres reproduced. The nuclei of the sheath of Schwann 
are not numerous ; they, as a rule, occupy a central position in the collapsed sheath, and are surrounded by the protoplasm. Between the degenerated fibres are found spindle-shaped connective tissue cells and polynuclear leucocytes in larger number than the figure would lead one to infer; and not unfrequently capillaries or small arterioles filled with red and white blood cells are met with. Pl. XXXIV, Fig. 5, represents a portion of a typical nerve fibre taken from the peripheral ulnar nine days after the operation for implantation. A comparison of this with PI. XXXIV, Fig. 4 (portion of implanted segment of the same dog), shows that in the degenerating fibres of the peripheral ulnar segment, the absorption of the myelin has not advanced nearly so far, while the proliferation of the nuclei is more marked than in the fibres of the implanted segment. That this proliferation of the nuclei takes place after the manner of a typical mitosis has been shown by Torre, Bünger, Stroebe, and myself in a former article, and I am, at this time, able to corroborate the observation already recorded. The peripheral end of the central ulnar stump degenerates to the extent of about $3 / 4 \mathrm{ctm}$. The degeneration is essentially the same as observed in the peripheral ulnar. Between the central end of the implanted segment and the peripheral end of the central ulnar stump is seen a layer of embryonic connective tissue, composed largely of branched and spindle-shaped connective tissue cells and polynuclear leucocytes enclosed in the meshes of a very loose fibrous reticulum. A narrow layer, of similar structure, unites the peripheral end of the implanted segment and the peripheral ulnar.

From the ninth to the twenty-first day very little structural change worthy of mention is observed in the fibres of the implanted segment. In long. sect. of this tissue, removed twentyone days after the operation, hardened in Muiller's fluid, and stained in anilin blue and safranin, the collapsed sheaths are not well made out. In teased preparations (see Pl. XXXIV, Fig. 7) they appear as narrow tubes, often compressed and containing a small amount of protoplasm and here and there a nucleus. Between the fibres are found connective tissue elements and leucocytes. In the peripheral ulnar of the above 
experiment, the myelin and axis cylinders had been entirely absorbed in the great majority of the fibres. The old sheaths are filled with a continuous band of protoplasm, imbedded in which are found the nuclei, with their long diameter parallel to the longitudinal direction of the fibre (see Pl. XXXIV, Fig. $8 a)$. Even at this stage, however, remnants of the medullary sheath are found in some of the fibres; and, in these, it is sometimes possible to find small fragments of the old axis cylinder (see Pl. XXXIV, Fig. 8d), which take a deep blue color when stained in anilin blue. The longitudinal striation of the protoplasm as described by Bünger, in which he recognizes the anlage for the new axis cylinders, was at no time observed. The protoplasm has a homogeneous appearance and stains faintly blue in sections colored in anilin blue and safranin, in case the safranin is again thoroughly washed out of the specimen ; or may have a faint reddish color in preparations overstained in the safranin. By far the most interesting observations to be made on the operated nerve, examined twenty-one days after implantation, are to be found in the longitudinal sections or teased preparations through the junction of the central ulnar and the implanted piece. In this region the process of regeneration is already established. As the regeneration of the peripheral portion of a divided nerve, and especially the regeneration of the axis cylinders, has been a subject on which observations have been largely at variance, I may be allowed to state some of the opinions expressed. We have, in the first place, the views upheld by Schiff, Laveran, and Remak; that during the degeneration of the peripheral nerve, the axis cylinder is not affected, but retains its structure and forms the axes of the new fibres. That this is not the case has been clearly shown a great number of times. All axis cylinder stains show, that, during degeneration of the nerve fibres, its continuity is broken, and the resulting fragments are always absorbed. Neumann and Eichhorst contend that during degeneration of the peripheral end, the medullary sheath and axis cylinder undergo a chemical change of such a nature that, structurally and chemically, it is not possible to differentiate between the two; "the process of regeneration 
consists in a differentiation of this common substance into a new axis cylinder and a new myelin" (see Howell and Huber, from whom this quotation is taken). Neumann believes that the new axis cylinder is developed in short pieces, one for each internodal segment. This segmental anlage is, according to Neumann, seen in the peripheral end of the central portion of the injured nerve, in the wound (in his experiment, the continuity of the axis cylinders and myelin was interrupted by means of a ligature tied very firmly around the nerve and then removed), and in the central end of the peripheral stump, extending from here to the periphery. Bünger states that the new axis cylinders are developed from the proliferated protoplasm and nuclei of the degenerating fibre. By the end of the second week after the injury, the protoplasm becomes longitudinally striated, and is differentiated into a band-like structure, the new axis cylinder. The development takes place in short segments, which later unite to form the band, Stroebe and Notthaft, in two very careful researches, have critically reviewed Bünger's results, and find no evidence in support of his statements. Among those who believe that the new axis cylinder is developed from some one of the cellular elements in the peripheral portion of the injured nerve, may be mentioned Hjelt and Wolberg, who trace its origin from the cells of the connective tissue surrounding the nerve fibres ; and Einsiedel, Korybutt-Daskiewics, Beneke, and Leegard, who maintain that the proliferated nuclei of the sheath of Schwann are the anlage for the new axis cylinders. The present conception of the structure and development of the axis cylinder, according to which it is regarded as a long process extending uninterruptedly from the nerve cells to its place of distribution, either in a motor or sensory ending, makes it difficult to accept any one of the above views. In support of this assertion, we may finally give the observation of a goodly number of investigators, who maintain that the new axis cylinder is formed during regeneration after the manner of its development in the embryo, that is, in the form of a bud or a sprout, which grows from the ganglion cell (or its severed process, the axis cylinder), toward the periphery. 
This conception of the regeneration of the new axes was first defended by Ranvier, and has since been held by Vanlair, Assaky, Howell and Huber, Stroebe, Notthaft, and Willard. After this brief summary, of the views held concerning the formation of the axis cylinder during the process of regeneration, I will now turn to the results obtained in my experiments. In longitudinal sections and teased preparations through the junction of the central end of the ulnar and the implanted seg. ment, made from two nerves removed twenty-one days after the implantation (Exps. I4 and 15), the following observations are to be made:-

At this time it is quite easy to determine the extent to which the central end has degenerated, as, in the area marking the upper limit of the degenerated part of the fibres, the myelin is found in larger or smaller fragments, and does not present the normal appearance seen in the same fibre a short distance nearer the center. In these fragments of myelin one now and then finds remnants of the old axis cylinder taking the characteristic stain. In many of these fibres nothing is seen of the new axis cylinder in that part containing the fragments of myelin, or just below, while it is clearly made out in the normal portion of the fibres just above. In others, the new axis cylinder can be traced for a short distance into the portion of the fibre containing the fragments of myelin; here it often has a somewhat tortuous course, and ends free in the proliferated protoplasm. The fragments of myelin are not disposed around the axis cylinder in the form of a sheath, but are usually to the side of it. In still other fibres, the axis cylinder can be traced through the segment of the nerve, showing the broken up myelin, into the more distal portion of the degenerated central fibre, which presents structurally the appearance of a completely degenerated nerve, that is, a collapsed sheath of Schwann containing a homogeneous nucleated protoplasm. One such fibre is represented in Pl. XXXIV, Fig. 6. The central end of the fibre points toward the top of the page. In this part the axis cylinder is surrounded by the medullary sheath; just below are seen a number of fragments of myelin; between them the somewhat wavy axis cylinder is winding its 
way towards the periphery into the completely degenerated part of the fibre, ending free in the protoplasm ; ten nuclei of the sheath are seen in this short segment. In the layer of connective tissue found between the central ulnar and implanted segment are to be seen a few very fine threads stained deeply blue, surrounded by a thin layer of a pale blue color. They are found between the connective tissue fibrillae and cellular elements constituting the layer just mentioned. I was often able to trace them through several fields of the microscope when studied with a $\frac{1}{12}$ inch oil immersion, but found no example where I could observe their connection with one of the fibres of the central end. In order to see these fine new axis cylinders clearly, for that is what they undoubtedly are, it is necessary to cut very thin sections, 5 to 7 mikrons in thickness ; and, as their course is always somewhat irregular, one can easily see that a section, embracing a portion of the central nerve fibre and a young axis cylinder in connection with it, as it winds its way through the developing connective tissue for a distance of about $1 / 2 \mathrm{ctm}$, would be exceedingly rare. Stroebe was able to see such a connection. We find on p. 208 of his article the following statement: "Nicht selten treten jedoch auch Beziehungen der schmalen Axencylinder in der Druckstelle zu jenen mit kolbiger Endanschwellung versehenen Axencylindern des centralen Stumpfes auf, welche bei den früheren Stadien beschrieben wurden (see Pl. VII, Fig. I, 2, and 3. bei K. A. of his article). Man sieht die junge Faser sich vom alten Axencylinder centralwärts von dessen terminaler Verdickung dort, wo der Axencylinder, abgesehen von geringer Ausschwellung, wieder normal ist, abzweigen, dann in der alten Scheide weiter peripherwärts ziehen und so zwischen die Zellzüge der Compressionsstelle eintreten." Stroebe used rabbits in his experiments, compressing the "large ear-nerve" with an instrument constructed by him. The observations above recorded were made on nerves removed from the rabbit seven days after compression, hardened in Müller's fluid, and stained in anilin blue safranin. Even after the most careful search in longitudinal and cross-sections, and teased preparations made from the implanted portion (Exps. 
I 4 and I5) just below the central wound, no axis cylinders were seen; one meets only the degenerated fibres shown in Pl. XXXIV, Fig. 7. This, together with the fact that there are no elements in the connective tissue (if our conception of the structure of the axis cylinder is correct) from which the few axis cylinders there found might have been developed, would, I think, justify the assumption that they are buds from the central axis cylinders ; although, in my preparations, I am not able to make out a connection between the axis cylinder of the central fibre and the axes found in the connective tissue just below.

At thirty-nine days after the implantation new axis cylinders are found in the implanted segment, in the peripheral wound, and in the central end of the peripheral ulnar. When sections of the central wound are compared with the ones made from the same region of a nerve removed twenty-one days after implantation, a very much larger number of axis cylinders is evident in the connective tissue uniting the central ulnar and the implanted segment. Here some are found arranged in small bundles, others are disposed singly. The bundles and single fibres are often seen deviating from a course parallel to the axis of the nerve. They can be traced above into the central stump, and below into the implanted segment. The deeply stained axis cylinders are surrounded by a narrow border tinged faintly blue. Long, rod-shaped nuclei with rounded or beveled ends are observed in the pale blue layer, closely applied to the new axis cylinders. In cross-sections of the implanted segment, about I ctm. below the central wound, a small portion of one of which is reproduced in Pl. XXXIV, Fig. 9, the degenerated fibres of the implanted nerve are seen as small, oval, or round tubes, the wall of which is formed by the old sheath of Schwann, containing a homogeneous protoplasm which scarcely stains. In a few of the collapsed fibres a nucleus is observed. This section presents an appearance differing from a crosssection of a degenerated nerve trunk at a similar stage, in the large amount of connective tissue found between the fibres. This connective tissue, which, as far as my observation goes, always develops around and between the elements of the 
implanted segment, separates the degenerated nerve fibres into smaller and larger bundles, around which it is often arranged in the form of a sheath. In such a cross-section the relation of the newly formed axis cylinder to old sheaths is well seen. The deeply stained dots, representing cut ends of the axes, are now and then found within an old sheath, as shown in Pl. XXXIV, Fig. 9 c. Often a very delicate sheath, found within the old one, surrounds them. Others are seen by the sides of the degenerated sheaths, as shown in $b$ of this figure. In longitudinal sections and teased preparations of the peripheral portion of the implanted segment, relatively few axis cylinders are found; in PI. XXXV, Fig. Io b, two are represented, among a larger number of degenerated implanted fibres $(a)$. In the connective tissue uniting the peripheral end of the implanted segment to the peripheral ulnar still fewer axis cylinders are observed. In longitudinal sections of this part of the nerve, several fields are often passed before one is met with. Their course is much more irregular than that presented by the axes seen in the connective tissue of the central wound. Preparations made from the peripheral ulnar about I $\mathrm{ctm}$. below the peripheral wound, show the great majority of the fibres in complete degeneration. Only at very rare intervals is a characteristically stained axis cylinder found. The appearance presented in one of my teased preparations from this locality is given in Fig. II. The entire peripheral ulnar from a point about $\mathrm{I} \mathrm{ctm}$. below the peripheral wound to the wrist, as also the muscular branches to flex. carp. ulnaris and flex. prof. dig., were divided into small pieces, which were used, some for cross, others for longitudinal sections ; but in none of these did I meet with an appearance which might have been interpreted as representing an axis cylinder. It is very interesting to recall that in this experiment (No. 16) stimulation of the peripheral ulnar just below the peripheral wound, with strong induction shocks, excited no contractions of the muscles supplied by this nerve; however, impulses would seem to have been carried along the few regenerated nerve fibres (some of which, no doubt, were sensory) found in the upper end of the peripheral ulnar and the peripheral 
wound, as the record of the experiment shows that feeble reflexes were observed. I may briefly summarize the above results, and the interpretation given them in the following statement : many of the down-growing axis cylinders from the central nerve fibres have reached the connective tissue layer between the central stump and the implanted segment; of this number a very small per cent have reached the upper end of the peripheral ulnar, some others the peripheral wound and peripheral portion of the implanted segment, and a larger number the middle and central end of the implanted nerve.

The regeneration of the peripheral ulnar is far advanced by the end of the fourth month. A review of the results obtained at the physiological examination in Exps. 17, 19, and 20, show a return of function to the motor fibres going to flex. carp. ul., and also that the sensory fibres have the power of conducting impulses, at least down to the middle of the forearm (Exp. 19). Microscopical examination corroborates these conclusions. It is at this time very easy in longitudinal sections to trace the axis cylinders of the fibres in the central end through the connective tissue into the upper end of the implanted segment. Usually the old axis cylinder ends in a slight enlargement, from which, or from the axis cylinder just above it, a smaller thread, stained deeply in anilin blue, the new axis cylinder, surrounded by a narrow sheath of myelin, can be traced. Now and then an appearance shown in Pl. $\mathrm{XXXV}$, Fig. 12, is seen. In such cases the central axis cylinders would seem to have divided into several branches, these growing for a longer or shorter distance toward the periphery within the old sheath of Schwann. In the fibre reproduced in the figure, only one of the new axis cylinders becomes the axis of a nerve fibre; the others are seen to end in small bulbous enlargements. Similar observations have been made by Ranvier, and by Howell and Huber (Fig. 60, and not so well represented in Fig. 62), and very clearly shown in Figs. 8, 9, and ro of PI. VIII, illustrating Stroebe's article. The course of the nerve fibres through the central wound (the connective tissue between the central stump and implanted segment) I have tried to represent in Pl. XXXV, 
Fig. I3, in which is reproduced a part of a longitudinal section through this region from a nerve removed II 7 days after implantation. Some of the small bundles, it will be seen, have a definite direction, parallel to the long axis of the nerve; others have a wavy or twisted course $(c-c)$, and one small bundle, $d$, is seen in cross-section. A study of many sections from this region gives me the conviction that the new nerve fibres are winding their way through the spaces in the connective tissue.

In the implanted portion the fibres are arranged in bundles, separated by fibrous connective tissue, which varies in amount in different parts of the implanted nerve. As seen in crosssection, the bundles show a closer proximity in the axial part than they do toward the borders. Here one meets with small bundles, separated entirely from the other nerve fibres, and some distance from them. Each small bundle is surrounded by a distinct layer of connective tissue forming a perineural sheath. The distance separating the bundles is much greater in the peripheral part of the implanted nerve than nearer the central wound, and the bundles are not so numerous. (See Pl. XXXV, Figs. I 7 and I8.) The former shows a portion of a cross-section of the central, the latter of the peripheral end of an implanted segment 157 days after operation. In longitudinal sections of the implanted piece a large number of the nerve fibres have a direction parallel to the axis of the nerve, but are often slightly wavy; some of the small bundles, especially such as occupy a position near the borders of the implanted nerve, pass out of it, and are lost in the surrounding connective tissue.

Very interesting observations are to be made on longitudinal sections of the peripheral wound in the nerves of the experiments above referred to (about I 20 days after implantation). Pl. XXXV, Fig. I4, presents an appearance commonly met with. The course of the axis cylinders is here very much more irregular than in any other part of the regenerated nerve. The new axes are often seen deflected to one side or the other, and it is not unusual to see them turned back, and growing toward the center for a short distance. In sections, owing to 
their tortuous course, only short segments of axis cylinders are met with. Many are lost in the connective tissue surrounding the nerve trunk, and do not reach the peripheral ulnar. With one of the nerves a small portion of the striped muscle tissue, a part of one of the forearm flexors, on which the ulnar rests just above the elbow, was removed. In sections through this, several small bundles composed of six to eight nerve fibres, having a very tortuous course, were seen in the endomysium between the muscle fibres. I attribute the conditions here met with to the fact that before the down-growing axis cylinders of the central end reach the peripheral wound, the developing connective tissue between the lower end of the implanted portion and the peripheral ulnar has already become quite firmly organized, and offers much greater resistance to the downgrowing axes than does the connective tissue of the centralwound which, at the time when the new fibres are first seen, is more embryonic in its character. For it will be remembered that in the experiments, where twenty-one days intervened between the implantation and the removal of the nerve, a few newly formed axis cylinders were found in the connective tissue layer between the central stump and implanted nerve. Beyond this no new fibres were observed, and by the end of the thirty-ninth day after the operation the greater number of the new axis cylinders had passed the central wound, and could be traced a shorter or longer distance into the implanted nerve, while only very few are seen in the lower wound and central end of the peripheral ulnar.

Still another interesting fact is shown in teased preparations and longitudinal sections of the peripheral ulnar, and of the muscular branches to the flex. carp. ul. in the above experiments. The preparations show that the regenerated fibres are found in larger numbers in the central end of the peripheral stump and the muscular branches, the proportion becoming much smaller in sections made from the peripheral part of the nerves. In two of the experiments (Nos. 19 and 20) no axis cylinders are seen $2 \mathrm{ctm}$. below the middle of the forearm; while in Exp. I7 very few were present in the ulnar at the wrist. Teased preparations show that some of the regenerated 
fibres are to be seen within the old sheaths, while others are found between them. Now and then the axis cylinder will be seen to end abruptly in the protoplasm of one of the degenerated old fibres. In Pl. XXXV, Fig. I $5 A$ (in which portions of three fibres from the muscular branch to the flex. carp. ul, are represented), the axis cylinders end in a bulbous enlargement at $c$, beyond which the old sheath $(s)$ could be traced through several fields of the microscope. Above the bulbous enlargement the axis cylinder is enclosed within a narrow layer of myelin $(n \mathrm{~m})$, and surrounding this is seen a new sheath of Schwann. $B$ of the same diagram presents essentially the same condition, except that the end of the axis cylinder is not enlarged, but has for a short distance a wavy course. (I would crave indulgence for the awkward way in which the fibres in Pl. XXXV, Fig. 15 , are placed. It will be noticed that the peripheral end of one $[A]$ points toward the right, while that of the other $[B]$ points toward the left. The sketch was made from teased preparations, and the error was not noticed until the diagram was completed.) This same appearance was met with in other parts of the peripheral ulnar, as is shown in $\mathrm{Pl}$. XXXV, Fig. I $6 E$ (from a teased preparation of the peripheral ulnar at the wrist 117 days after operation. Exp. I7). In this fibre the new axis cylinder is not surrounded by a medullary sheath. In the nerves from this experiment nearly all the fibres of the peripheral ulnar at the wrist present the appearance of a completely degenerated nerve (see Pl. XXXV, Fig. 16 $A$ ). In a few of the degenerated fibres unabsorbed fragments of myelin are still present (Pl. XXXV, Fig. I6 $B$ ). One such fibre containing a new axis cylinder is shown in $D$ of the same figure.

The appearance presented in specimens made from nerves removed 149 to 182 days after implantation (Exps. 21 to 25) differ from the ones above described only in the extent of regeneration. I may briefly state that the longer the interval between the implantation of the nerve and the time of its removal, the more complete is the return of function, and the more regenerated fibres are to be seen in the peripheral end of the injured nerve. In all of the last-named experiments elec- 
trical stimulation of the ulnar at the wrist excited distinct movements of the digits; and microscopical examination of the nerve in this region revealed the presence of regenerated fibres. Pl. XXXV, Fig. I9, shows the extent of regeneration at the wrist 182 days after implantation. It will be seen that many of the fibres possess axis cylinders, and some of the fibres $(a)$ present the structural appearance of a normal nerve.

Only one experiment of secondary implantation of a nerve was made. The right ulnar of a dog was resected $6 \mathrm{ctm}$., and without suturing the ends of the nerve the wound was closed. After a period of forty-one days the nerve was again exposed. At this time the end of the central ulnar segment was much enlarged, and seemed very sensitive. The ulnar was redivided just above the bulb, and after vivifying the central end of the peripheral ulnar a segment of cat's sciatic was implanted. Sections of the portion removed from the peripheral stump of ulnar showed that the nerve fibres had undergone complete degeneration.

Sections of the bulb (Stumpfneurome, amputations or Durchschneidungsneurome) removed from the central ulnar stump present the appearance so often described for such structures. Kölliker states that the bulbs must be looked upon as expressing the regenerative energy of the nerve, an hypothesis which, no doubt, expresses correctly the existing conditions. Structurally this bulb consisted largely of small groups of new nerve fibres very complexly interwoven between bundles of fibrous tissue. Such neuromes would seem to develop from the degenerated part of the central stump and the connective tissue surrounding its end. Above the bulb the fibres of the ulnar presented a normal appearance.

The dog was killed I 55 days after the second operation. The results of the physiological and histological examination of the nerve involved in this experiment are so similar to the ones obtained in experiments of primary implantation of about 120 days' duration, which have already been recorded, that a detailed description of them at this stage would only be a repetition of observations already given.

I have purposely avoided making any mention of the develop- 
ment of the medullary sheaths about the newly formed axis cylinders, as the anilin-blue safranin method (used for staining sections made from all nerves where the process of regeneration was made the subject of study, from 21 to 182 days after implantation) is not a suitable stain for making out the origin of this sheath. In the author's sections prepared after this method the medullary sheath is not differentiated until a time when it has obtained some degree of prominence. Stroebe recognizes in the delicate pale blue sheath, which surrounds the more deeply stained axis cylinders, a structure already referred to several times, the beginning of the layer of myelin. $\mathrm{He}$ states that in sections stained after Weigert's haematoxylin method "the young fibres are stained deeply black ; they possess, therefore, at their first appearance a medullary sheath, the pale blue layer in anilin-blue preparations; accordingly, the medullary sheath is an attribute of the young fibres from the time of their first appearance." The diagrams illustrating Willard's articles show that the medullary layer must be developed at a very early stage; as in his preparations, stained with Weigert's haematoxylin, the nerve fibres were stained deeply black at a time when he was first able to recognize them. Bünger states that " the myelin is formed as a narrow continuous sheath, which stains black in osmic acid, and secondarily as a thicker layer which develops in segments, and at a later stage fuses with the former (an die erste anschliesst und mit derselben verschmilzt)."

If the narrow continuous sheath, which assumes a pale blue color in the anilin-blue safranin stain, is to be regarded as the anlage for the medullary layer, $I$ think that we must admit that in its first development, it must have a slightly different chemical structure than it does at a later stage; for when it is more fully developed, in preparations stained by the above method, it has a yellowish or an orange color, even after much of the safranin has been washed out of the sections, as may be seen from Stroebe's and my own diagrams. The virtue of the anilin-blue safranin method, is to be found in its clear axis cylinder differentiation, and was for this reason used. The time at my disposal did not admit of my making duplicate 
preparations fixed in osmic acid, or for the imbedding of portions of nerves in celloidin, so that Weigert's method might be used.

In each experiment alternate longitudinal and cross-sections of the portion of the nerve involved were made, so that I might, if possible, come to some definite conclusions concerning the mode of development of the axis cylinders. On some of the sections of nerves hardened in Müller's fluid and imbedded in paraffin, the Weigert method was tried, but with no results. I was, therefore, compelled to forego a closer study of the development of the medullary sheath, and confine my attention to regeneration of the axis cylinder, a structure of far greater importance.

In closing this part of the discussion, I may, however, be permitted to quote the following from Howell and Huber's article:-

"It is quite easy to find in the peripheral trunk newly regenerated fibres, showing a delicate continuous layer of myelin; but to demonstrate how this myelin is deposited is more difficult ; to ascertain this one must obtain his specimens from just that portion of the nerve in which the process is actively going on. Figs. $36,37,39,40$, and 41 give an idea of how the myelin first appears. As shown in these figures, it appears first as irregular deposits in the protoplasm of the embryonic fibres, and usually first in the neighborhood of the nuclei. Delicate prolongations of the myelin are often seen running from one small mass of myelin to another, and eventually these latter become connected together forming a varicose tube, shown in various stages in Figs. 36-5I. There would seem to be no doubt that it is first formed as disconnected drops. These may afterwards become united into slender processes to form a bead-like string, which sooner or later elongates to an even tube, or the drops may first elongate to form cylindrical segments, which eventually unite to form continuous delicate tubes of myelin." I possess at the present time no facts which would prevent my accepting the above statements.

The following brief conclusions, based on a review of the 
experiments dealing with resection and subsequent implantation of a nerve segment, and a study of the microscopical appearances presented, may, for the sake of clearness, be summarized as follows :-

I. After primary implantation of a segment of a nerve trunk between the resected ends of a peripheral nerve, the implanted portion, the entire peripheral stump, and about $3 / 4 \mathrm{ctm}$. of the central stump degenerate.

II. The myelin and axis cylinders of the implanted nerves are absorbed within the first ten days after the operation. The absorption takes place more slowly in the peripheral degenerating portion of the nerve, and in the degenerated part of the central stump.

III. The degenerated fibres of the implanted segment and injured nerve present essentially the same structural appearance, collapsed sheaths containing a nucleated band of protoplasm. The nuclei are, however, less numerous in the degenerated fibres of the implanted part than in the degenerated fibres of the peripheral and central stump of the injured nerve.

IV. Regeneration begins in the central stump, and proceeds centrifugally. It consists in a down-growth of the axis cylinders of the nerve fibres of the central end, through the central wound, the implanted segment, the peripheral wound, and the peripheral portion of the injured nerve.

$V$. By the end of the twenty-first day, some of the downgrowing axes have reached the central wound.

VI. By the end of the thirty-seventh day, the greater proportion of the down-growing axes have passed the central wound; some few have passed through the implanted segment and the peripheral wound, and have reached the upper end of the peripheral part of the nerve. There is some return of irritability to this part of the nerve as shown by the presence of reflex movement on stimulation with strong induction shocks.

VII. By the end of the 120 th day, regeneration extends to a short distance below the middle of the forearm, and to the muscular branches of the flex. carp. ul. and flex. prof. dig. (in experiments involving the ulnar). Many of the new axis cylinders 
in the peripheral ulnar are surrounded by a medullary sheath, and present the structural appearance of a normal nerve.

VIII. After the 136 th day in primary implantation between the resected ends of a median, and the i 49 th day after the same operation in the ulnar, the down-growing axis cylinders have reached the peripheral part of the injured nerve, as shown by physiological and histological examination.

IX. The down-growing axis cylinders are found in the old sheaths of Schwann in that portion of the fibres of the central stump which underwent degeneration, within and between the old sheaths in the implanted segment, and bear a similar relation to the old sheaths in the degenerated peripheral part of the nerve.

(b) Microscopical Appearances in Experiments of Tubular Suture.

A study of longitudinal and cross-sections through the region of the implanted bone tube in Exps. 27, 28, 29, with periods of five, ten, and twenty days after uniting the ends of a resected nerve with a bone drain, show that absorption of the bone must take place very rapidly, as scarcely any portion of it is found by the end of the tenth day, and no trace of it at the end of the twentieth day. Even in the experiment of five days' duration, the wall of the bone tube was so altered structurally, that it bore very slight resemblance to decalcified bone. In its place is seen a network of coarse trabeculae, very irregular in shape and size, stained very deeply red, and presenting a homogerteous appearance in preparations hardened in Flemming's solution, and stained in safranin and licht grün. The meshes of this network are filled with polynuclear white blood cells and connective tissue cells. (The bone drain used in the above experiment was made from the ulnar of a chicken, the shaft of which has only a thin layer of compact bone.) In the lumen of the implanted bone tube, in the experiment of five days' duration, is found a very loose connective tissue, rich in spindle-shaped and branched connective tissue cells, and only a few connective tissue fibrillae, irregularly interwoven, are 
seen. In the other two experiments, the connective tissue between the ends of the resected nerve presents a dense structure, not so dense, however, as the connective tissue surrounding the implanted bone tube. However, my experiments were not numerous enough to admit of any full description as to the nature of the absorption of the implanted bone.

In the above three experiments, the entire peripheral portion of the nerve operated upon was found in process of degeneration, the extent of which was proportional to the time intervening between the resection of the nerve and death of the animal. The peripheral end of the central segment was degenerated to the extent of I ctm., while central-ward it presents a normal appearance. In the experiment of twenty days' duration, regeneration had begun in the peripheral end of the central stump. Longitudinal sections through the central wound in this experiment, stained in anilin blue and safranin, simulate very closely the appearances presented by a section through the central wound twenty-one days after the implantation of a nerve segment, which has been previously described and diagrammed in $\mathrm{Pl}$. XXXIV, Fig. 6 . In the undegenerated part of the fibres of the central end, the axis cylinder presents a normal appearance; it often ends distally in a small bulbous enlargement, from which or from the axis cylinders just above, can be traced, for a shorter or longer distance, fine threads stained deeply with the anilin blue (the new axis cylinders) into the degenerated portion of the central fibre. Some few of the axis cylinders of the central end show the branching diagrammed in P1. XXXV, Fig. I2. In the connective tissue below the central stump no axis cylinders were met with.

In the experiment of fifty-four days' duration (No. 30) the connective tissue between the outer and inner ham-string muscles, which surrounded and united the central and peripheral ends of the resected sciatic, was removed, and to the eye no trace of the bone tube was visible. In longitudinal section of the peripheral end of the central stump of the sciatic and the connective tissue just below, the following observations are to be made: The sciatic is seen to end in a large bulb nearly a ctm. in diameter, and is surrounded by a dense con- 
nective tissue layer. From one side of this bulb there extends into the connective tissue below the bulb, a small bundle of nerve fibres about I $\mathrm{mm}$. in thickness, composed largely of new axis cylinders, some of which are surrounded by a thin layer of myelin. For a distance of about $\mathrm{t} / 2 \mathrm{ctm}$. the fibres constituting the above bundle have nearly a straight course, and are parallel to a line uniting the central and peripheral parts of the resected nerve. Just below this point the nerve bundle would seem to split up, brush-like, into larger and smaller groups of fibres ; these, for the greater part, now have a very irregular course. In cross and longitudinal sections of the cicatricial tissue I to $2 \mathrm{ctm}$. below the central bulb only scattered nerve fibres and small bundles of fibres are met with.

In the connective tissue just above the central end of the peripheral portion of the resected nerve, I was not able to find any axis cylinders. Sections made from different parts of the external and internal popliteal show these to be completely degenerated; only the collapsed sheath of Schwann containing a nucleated band of protoplasm, with here and there a fragment of unabsorbed myelin, were seen.

In Exp. 32, of I30 days' duration, where the sciatic was resected $5 \mathrm{ctm}$. and a tubular suture made, there was no return of functional activity to the peripheral end, as tested with electrical and mechanical stimulation. Histological examination, however, revealed the presence of new axis cylinders in the connective tissue between the central and peripheral parts of the sciatic, to a point just above the peripheral wound. From the lower end of the bulb, in which the central stump terminated, bundles of small nerve fibres, some naked, others possessing thin medullary sheaths, could be traced into the connective tissue below the bulb. At first these bundles have a regular, straight, or slightly wavy course. This regular arrangement is lost about I ctm. from the end of the central sciatic, and below this point the connective tissue contains small bundles of nerve fibres running in every direction, the nerve fibres becoming less numerous as the peripheral wound is reached, where they are entirely wanting. The popliteal branches were completely degenerated. 
In Exps. 31 and 33 (resection and tubular suture of the ulnar), of I2 I and I 36 days' duration, there was a slight return of functional activity to the peripheral end, as stimulation of the ulnar just below the peripheral wound excited reflexes, but no muscular contractions. Histological examination of these nerves shows new nerve fibres in the upper end of the peripheral stump, a larger number in the connective tissue between the resected ends of the nerve, where their number is inversely proportional to the distance below the lower end of the central nerve trunk. The peripheral ulnar, from a point $3 \mathrm{ctm}$. below the lower wound to the wrist, was divided into short pieces. Alternating segments were used for longitudinal and cross-sections. In none of the sections made were any axis cylinders found.

To determine whether the bone tube might be employed as a secondary operation, in cases where there was loss of nerve substance, a right ulnar of a dog was resected to the extent of $6 \mathrm{ctm}$., and the wound closed (Exp. 34). Forty-one days later the nerve was again exposed, and, after vivifying the ends, a tubular bone-drain suture made. Longitudinal sections of the segment removed from the central part of the peripheral stump, only showed degenerated fibres in the form of collapsed sheaths containing a small amount of nucleated protoplasm. Presumably the entire peripheral part of the nerve presented the same structure at the time of the second operation. The central end of the nerve was seen to end in a large bulb. The microscopical appearances presented by this nerve 155 days after the second operation may be thus briefly stated: A second bulb had formed on the end of the central stump, beyond which a large number of small bundles of nerve fibres were found in the connective tissue just below the bulb. Cross-section of the cicatricial tissue just above the central end of the peripheral part of the resected nerve shows that a relatively small proportion of the nerve fibres found higher up had reached this region, as only a small per cent of these is met with in such sections. Regeneration extends to about the middle of the forearm, and to the muscular branch of the flex. carp. ul., although only a very small number of axis cylinders 
are found in this part of the nerve. In the ulnar, below the middle of the forearm, no regenerated nerve fibres were found.

The experiments of tubular suture, although not as successful in the results obtained as are the ones reported by others, notably Vanlair, seem to me to demonstrate some interesting facts. In the first place, they offer a more striking proof of the down-growth of the axes of the central end during the process of regeneration, than do experiments of ordinary nerve suture or even implantation of a nerve segment. Attention has already been drawn to this fact while reviewing the results obtained by Vanlair in Part I of this paper. In Exps. 30 and 32 new nerve fibres were found in the connective tissue between the central and peripheral part of the resected nerve, in larger number and more regularly arranged the nearer the central stump the observations were made. The peripheral part of the resected nerve of the above experiments was completely degenerated, and could therefore in no way contribute to the regeneration. And if the axis cylinder is a process of a cell of epiblastic origin, a theory which I think is now generally accepted, an independent formation of axis cylinders in the connective tissue is excluded. The experiments further show that a return of functional activity in any part of the peripheral segment of a divided nerve is concomitant with a histologically demonstrable presence of axis cylinders at that level in the peripheral nerve, and that irritability is first present near the wound and slowly extends centrifugally.

The bone tube would play only a secondary rôle in regeneration after the tubular suture. In its place there is found at the end of ten to fifteen days a loose connective tissue, which offers less resistance to the down-growing axis cylinders than does the fibrous tissue surrounding the implanted bone drain. The growing axes follow this path of lesser resistance, and some few reach the peripheral end of the nerve. An explanation as to why the new nerve fibres have a more regular arrangement in the fibrous tissue near the central wound than they show in the fibrous tissue nearer the peripheral part of the resected nerve, may be found in the fact that, at a time when the axes are beginning to grow toward the periphery, 
the less developed connective tissue just below the central stump offers less resistance to them than does the same tissue at a later stage, it having attained a denser and more highly organized structure.

\section{(c) Suture d̀ Distance and Implantation of a Catgut Bundle.}

Nearly all experimenters and operators who have studied the regeneration of a peripheral nerve after resection or after loss of substance to the extent that an ordinary suture cannot be made, recognize the necessity of establishing between the divided ends of the nerve a path along which the regenerated fibres may grow. As has been previously stated, Glück implanted strands of Danish leather, strips of muscle and tendon, bone tubes, catgut bundles, etc., thinking that the implanted substance might guide the new nerve fibres, and cause them to grow in the direction hoped for. Glück met with failure in all of the above experiments. That regeneration may be attained after the use of a tubular suture, is shown by the recorded experiments of Vanlair, Bünger, and myself. The same may be said of the results obtained by Assaky after suture à distance with chromatized catgut. In the six experiments reported by him, in which this method was employed, regeneration of the peripheral end occurred in each case. In the seven experiments of suture à distance made by myself, the physiological examination (for details see Part II) showed a regeneration of the peripheral part of the divided nerve, in two out of three experiments observed for a period of more than I 20 days after the operation. That the catgut threads play only a secondary part in the regeneration is shown by a microscopical examination of the nerves involved in Exps. 35, 36 , and 37 , of five, ten, and twenty days' duration. In sections made through the region of the catgut bundle, it will be seen that the implanted threads begin to be absorbed before the end of the fifth day, and are almost entirely absorbed by the end of the tenth day. The connective tissue about the implanted threads is seen in active proliferation in the immediate neighborhood of the bundle, and between its component threads 
are seen large numbers of polynuclear leucocytes, branched and spindle-shaped connective tissue cells found in a loose fibrous tissue framework. By the twentieth day no trace of the implanted catgut is to be seen. I must, however, describe a curious appearance met with in a section of the connective tissue uniting the central and peripheral part of the resected nerve of this experiment. When such sections are examined with a low power, it will be seen that in certain parts the fibrous tissue is loosely interwoven, is rich in connective tissue and polynuclear white blood cells, and contains here and there small groups of fat cells. The portions of the section having this structure are band-like in shape. Such areas are from I to $2 \mathrm{~mm}$. broad, and in section cut in line with the implanted catgut bundles, they now and then extend from one end to the other, in a section $I \frac{1}{2} \mathrm{ctm}$. long. Others may have only one half or one quarter that length. Such areas have quite straight borders ; two, three, or four may be found in a longitudinal section. They are separated one from the other by a narrow band of much firmer fibrous tissue. In sections made at right angles to the implanted segment, six to eight round or oval patches of the same loose fibrous tissue, surrounded by layers of a denser connective tissue, are met with. I am inclined to think that the looser connective tissue supplants the implanted and absorbed catgut threads, while the denser tissue was developed between the threads, its formation beginning before the catgut was absorbed.

In the above three experiments, the fibres of the peripheral part of the resected nerve are found in process of degeneration. In the experiments of five and ten days' duration, the peripheral portion of the nerve fibres of the central end are found degenerated for a distance of about $1 / 2 \mathrm{ctm}$.; and in the experiment of twenty days' duration, signs of regeneration are present. In longitudinal sections of this part of the nerve, new axis cylinders are found in the degenerated part of the central fibres, and some few in the connective tissue surrounding the resected end of the central stump. The appearance presented is like that already described for sections made from this region in nerves removed about twenty days after opera- 
tion in the implantation of a nerve segment, or the performance of a bone-drain suture. The down-growing axis cylinders of the central end would seem to make much slower progress in cases where the suture à distance is made, than in those where the resected ends are bridged with a segment of a nerve trunk. In Exp. 16, where a nerve segment $7 \mathrm{ctm}$. long was implanted, newly formed nerve fibres were found in the central end of the peripheral portion of the resected ulnar, and through the whole length of the implanted segment thirtynine days after the implantation. In Exp. 38, of like duration, a segment $5 \mathrm{ctm}$. in length was removed from an ulnar and the resected ends united by a suture à distance; in this case regeneration of the peripheral part of the ulnar was not accomplished. Small bundles of axis cylinders were found in the connective tissue about $4 \mathrm{ctm}$. below the central wound, but in cicatricial tissue surrounding the central end of the peripheral stump none were found. In longitudinal sections through the peripheral end of the central stump and the connective tissue just below, bundles of small nerve fibres, the majority of which consist only of an axis cylinder surrounded by the pale blue sheath seen in anilin blue and safranin stained preparations, are seen to extend from the undegenerated part of the central stump into the connective tissue. Here they at first have quite a regular course which, however, must soon be lost, as in sections made of the tissue 1 to $2 \mathrm{ctm}$. nearer the periphery, only short, twisted, and bent segments of the small nerve bundles, surrounded by fibrous tissue, are met with. Below this point the bundles become less numerous, and, if anything, more twisted, until, as already stated, they cannot be found. The nerve fibres found in the cicatricial tissue uniting the central and peripheral stumps in this experiment, have a much more irregular course than do the newly formed fibres seen in longitudinal sections of the implanted segment in Exp. I6, which would, I think, seem to indicate that in the former experiment the budding axis cylinders met with much greater resistance in their down-growth toward the peripheral portion of the resected nerve, than do developing axes which grow through a degenerated implanted nerve segment. 
Cicatricial tissue between the resected ends of the ulnar (Exp. 38) cannot be differentiated into columns of a loosely interwoven tissue, surrounded by layers of a denser fibrous tissue, as was described for preparations made from Exp. 37 , twenty days after implanting the catgut threads. It presents a structure of about the same density throughout. I am unable to state, whether the new axis cylinders which begin to grow out from the central end about twenty days after suture à distance (at a time when tracts of a looser structure are to be found in the fibrous tissue uniting the resected ends), follow these paths or not.

In the peripheral portion of the ulnar in Exp. 38, only degenerated nerve fibres, with collapsed sheaths containing a nucleated band of protoplasm, were found.

In Exp. 39 (of 135 days' duration), regeneration of the ulnar extends to about the middle of the forearm and to the muscular branch of the flex. carp. ul., as in this portion of the nerve newly formed nerve fibres are to be seen in and between the old sheaths of the degenerated fibres. Structurally, many of the nerve fibres consist only of an axis cylinder; in others a thin layer of myelin is recognized. In the peripheral ulnar from a point a little below the middle of the forearm, only degenerated fibres are found. In Exp. 4I (of I 52 days' duration), sections made from any part of the peripheral ulnar show regenerated fibres. In both of these experiments, in the cicatricial tissue uniting the resected ends, bundles of nerve fibres, which have their origin in the central stump, and which can be traced from the connective tissue into the peripheral stump, are found. In the connective tissue the bundles of nerve fibres have a very tortuous course, as may be seen from Pl. XXXV, Figs. 20 and $2 \mathrm{I}$, made from sections of the tissue supplanting and surrounding the catgut threads in Exp. 4I. Pl. XXXV, Fig. 20, represents a part of a longitudinal section cut from tissue taken from about $\mathrm{I} \mathrm{ctm}$. below the central wound. It will be seen that while some of the nerve bundles $(a)$ have a direction which is nearly parallel to a line uniting the central and peripheral ends of the resected nerve, others $(d)$ have, at least for a short distance, a course which is 
at right angles to it. Many of the bundles $(c)$ are cut transversely or very obliquely, and some are wavy or of a corkscrew shape. This is even more apparent in cross-sections of this tissue. Pl. XXXV, Fig. 2I, represents a portion of such a section. In this some of the bundles of nerve fibres $(e)$ are seen in longitudinal section. A comparison of this figure with Pl. XXXV, Figs. I7 and 18 , which show portion of a crosssection of an implanted nerve segment, and the bundles of new nerve fibres which have grown through it, ${ }^{5} 52$ days after its implantation, is of interest. In Pl. XXXV, Figs. I 7 and 18 , the bundles of nerve fibres are separated by a relatively small amount of fibrous tissue, and all the bundles are seen in crosssection, which could only be the case, if they had a course which was nearly straight, while in PI. XXXV, Fig. 21, the fibrous tissue predominates, and the very tortuous course of the small bundles is evident from the fact that they are met not only in cross but also in oblique and longitudinal sections.

In Exp. 40 no return of functional activity was obtained. The central ulnar stump terminated in a large bulb, from which bundles of young nerve fibres are given off. They can be traced only for a short distance into the cicatricial tissue below the bulb. In the connective tissue, just above the central end of the peripheral stump, a remnant of the implanted catgut bundle, about $\mathrm{I}^{\mathrm{I}} / 2 \mathrm{ctm}$. long, was found. In cross-section, the eight threads implanted, are very clearly visible. They appear somewhat broken up, and have been permeated by polynuclear leucocytes and connective tissue celis. Why only a portion of the implanted catgut bundle was absorbed, and not all of it, I am not able to explain. It may be that the unabsorbed threads proved an obstacle to the downgrowing axis cylinders which could not be overcome, and this may have prevented their reaching the peripheral ulnar, a supposition, which, if correct, would go to show that the downgrowing axes reach the peripheral portion of the resected nerve through the looser fibrous tissue supplanting the absorbed catgut threads. 


\section{(d) Létiévant's Flap Operation.}

Létiévant's flap operation was performed seven times (Exps. 42-48). Physiological examination of the nerves involved showed the peripheral segment of the resected nerve to be degenerated in every case. Microscopical examination results as follows: In the experiments of five (Nos. 42 and 43) and ten days' (Nos. 44 and 45) duration, the nerve fibres of the flap made from the central stump, as also the fibres of the peripheral part of the resected ulnar, are found to be in process of degeneration. In longitudinal and cross-sections of these portions of the nerves involved in the above experiments, only fibres presenting a fragmented myelin, and containing an hypertrophied protoplasm in which are to be found an increased number of the nuclei of the sheath of Schwann, are met with. The rapidity of the breaking up and absorption of the myelin is about the same in the nerve fibres found in the flap as for the fibres found in the peripheral part of the resected nerve, differing in this respect from an implanted segment, the fibres of which undergo degeneration much more speedily than do the fibres of the peripheral part of the nerve to which the implanted segment is sutured. Why this should be so is somewhat difficult to explain. The only explanation which I should care to suggest is to be found in the organic union between the flap and the peripheral end of the part of the nerve from which it was made, through which the passage of lymph and blood currents may be maintained. The more favorable nutrition thus afforded may to some extent retard the degeneration. Between the degenerated fibres of the flap are found a large number of polynuclear leucocytes. Between the peripheral end of the flap and the distal ulnar segment the presence of wandering cells and embryonic connective tissue cells, of branched or spindle shape, is to be noted.

It will be remembered that in making the flap a thin knife was pushed through the nerve trunk about $1 / 2 \mathrm{ctm}$. from its end, and without withdrawing the blade the nerve trunk was divided into two parts to the extent desired. In that part of the central stump from which the flap was cut many fibres 
having a beaded appearance are to be seen. The extent of myelin fragmentation varies, however, in the different fibres. Now and then the medullary sheath is broken up, while the continuity of the axis cylinder would not seem to be interrupted. On this point, however, I can only speak tentatively, as in safranin and licht grü stained sections the axis cylinder is not very clearly differentiated. The larger number of the degenerated fibres in the central stump is found in the immediate neighborhood of the path traversed by the knife in forming the flap. The degeneration would, therefore, seem to be the result of the traumatism incurred while bisecting the nerve trunk.

In the experiment of sixty-four days' duration (No. 46) the central stump is slightly enlarged at that point in the central segment where, after bisecting the nerve preparatory to making the flap, the upper half of the end to be turned down as the flap was severed from the central end. In longitudinal sections through this region of the central segment a large nerve bunble, the fibres of which are very irregularly arranged, is observed. This bundle is given off from the peripheral end of the enlargement above referred to. It no doubt represents the half of that part of the bisected central stump which was not cut while making the flap. Many of the nerve fibres making up this bundle do not differ structurally from fibres seen in section of any peripheral nerve, while others have only a very narrow medullary layer, and still others are devoid of this sheath. I assume that the fibres presenting the appearance of fully developed medullary nerves did not undergo degeneration, while such as show only a narrow layer of myelin and the naked axis cylinders, represent regenerated fibres. The bundle above mentioned can be traced for a distance of about $4 \mathrm{ctm}$. below the enlargement. They then split up, and the nerve fibres are soon lost in the connective tissue surrounding them. Near the peripheral wound, and in the peripheral part of the resected ulnar, no axis cylinders were seen. In sections through the region of the down-turned flap the collapsed sheaths, containing a small amount of nucleated protoplasm, were found. In these no evidence of regeneration was seen. In this experiment the budding axis cylinders of the central 
ulnar segment did not follow the course of the reflected flap, but were lost in the connective tissue surrounding the peripheral end of the central stump.

In the experiments of 147 days' duration (Nos. 47 and 48 ) the appearances presented on microscopical examination were essentially the same as those described for Exp. 46. The central segment presents a slight enlargement, beyond which extends a bundle of nerve fibres, some of which are medullated, while others are not. At a point about $4 \mathrm{ctm}$. below the enlargement this bundle breaks up, and the nerve fibres assume a very irregular course, running in all directions, and are finally lost in the connective tissue. In Exp. 47 a few small bundles of nerve fibres were observed in the neighborhood of the peripheral wound, but could not be traced through the wound into the peripheral ulnar segment. In the above experiments sections were made from the different parts of the ulnar below the place of resection, but no regenerated fibres were found. The conclusions reached may be summarized in the following statements :-

I. The nerve flap, whether it be made from the central or peripheral stump of a resected nerve, degenerates throughout its whole extent. The entire peripheral segment likewise degenerates.

II. In that part of the central stump from which the nerve flap was made many degenerated fibres are found, a result of the traumatism incurred while forming the flap.

III. The junction of the flap with the peripheral end of the central stump is not of such a nature as would offer favorable mechanical conditions, such as would best guide the downgrowing axis cylinders of the central stump to the peripheral part of the resected nerve. The experiments show that the budding axis cylinders are lost in the connective tissue surrounding the peripheral end of the central segment.

\section{(e-f) Nerve Grafting and Cross-Suturing and Grafting.}

The microscopical examination of the nerves involved in Exps. 49 and 50 corroborate in every way the results obtained at the physiological examination of the nerves involved 
in the above experiments, the details of which are given in the second part of this paper. The peripheral median stump, which was stitched (grafted) to the accompanying ulnar (Exp. 49), was found to be completely degenerated, and no new axis cylinders or nerve fibres were to be found in the connective tissue uniting the central end of the peripheral part of the median to the ulnar. The central median stump terminated in a large bulb presenting the microscopical appearance usual for such structures. The ulnar, to which the median was grafted, was in no way altered structurally.

In Exp. 50, in which, it will be remembered, the ce ${ }_{\Perp}$ tral part of a resected median was sutured to the peripheral portion of a resected ulnar (the segments exsected having been taken from different levels in the two nerves), the microscopical examination shows the peripheral part of the ulnar to contain newly formed nerve fibres throughout its whole extent. In longitudinal section through the junction of these two nerves, the young nerve fibres found in the peripheral end of the central median stump can be traced through a narrow layer of connective tissue into the peripheral part of the ulnar. We are, I think, justified in seeking the origin of regenerated fibres found in the ulnar in the down-growing axis cylinders of the central stump of the median, which had been sutured to the peripheral part of the accompanying ulnar.

So far this experiment is a confirmation of the results obtained by other observers, and again proves that union with return of functional activity after cross-suturing two spinal nerves is possible. The short segment of the peripheral median, which was grafted to the peripheral ulnar stump, was completely degenerated; in none of the sections made from it were any new nerve fibres found. The central ulnar segment, stitched to the central median stump, terminated in a large bulb surrounded by connective tissue, by means of which it was united to the median. This tissue was free from naked axis cylinders or new-formed nerve fibres.

Tillmanns' modification of Létiévant's operation of crosssuturing the long ends of two divided nerves having a parallel course, when there is loss of nerve substance to the extent that 
[VOL. XI.

an ordinary suture cannot be made, and when the injury occurs at a different level in the two nerves, which modification consists in grafting the short segments of the two divided nerves to the long one, after they have been cross-sutured, would not seem to be of any value, as, I think, this experiment clearly shows.

\section{General Conclusions.}

A review of all the experimental work reported by other writers and myself, dealing with the operative treatment of a divided peripheral nerve after loss of substance to the extent that an ordinary nerve suture cannot be made, and of such clinical cases as I have been able to collect, will, I think, warrant the following conclusions :-

I. That it is possible to restore the functional activity to the peripheral part of a divided nerve with loss of nerve substance, if the resected ends are united with a segment taken from some other nerve trunk, with catgut threads, or with a bone-drain or tubular suture.

II. Of all the methods tried (implantation of a nerve segment, tubular suture, suture à distance, nerve flap, grafting the central end of the peripheral stump of a divided nerve to an accompanying uninjured nerve, and cross-suturing long ends and grafting short stumps where two nerve trunks are cut at a different level) the most favorable results are to be obtained after the implantation of a nerve segment, the two ends of which have been sutured with one or several direct catgut sutures to the resected ends of the injured nerve. The favorable results obtained by Assaky in his experiments of suture a distance, and Vanlair after bone-drain suture, are not, I think, exceptions to this statement; as in their experiments much shorter segments were removed from the nerve operated upon than was the case in my experiments of resecting a nerve and implanting a segment from another nerve trunk, to which fact the somewhat earlier return of function recorded by them can be attributed.

III. The regeneration of the peripheral end (which always degenerates so that only the old sheaths of Schwann, containing 
a band of nucleated protoplasm developed from the hypertrophied protoplasm and proliferated internodal nuclei of its fibres, are met with) is the result of an outgrowth of new axis cylinders from the undegenerated axes of the central stump, the budding axis cylinders following the paths of least resistance, through the tissue implanted or supplanting the implanted substance, thus reaching the peripheral part of the resected nerve wherein their growth continues.

IV. Since the fibres in an implanted nerve segment degenerate so that only the collapsed sheaths containing a small amount of nucleated protoplasm remain; and the catgut threads used in a suture à distance, and the bone tube employed in a tubular suture, are almost entirely absorbed before regeneration from the central end has reached any degree of prominence, we must conclude that the implanted substances can serve only as a guide to the down-growing axis cylinders. Any further function cannot be ascribed to them.

$V$. That the degenerated fibres of an implanted nerve segment offer much more favorable mechanical conditions to the down-growing axis cylinders of the central stump than does the loose connective tissue supplanting the catgut threads or the bone drain in experiments of suture à distance or tubular suture, is shown by the fact that the new nerve fibres have a much straighter course and more regular arrangement in the tissue uniting the resected ends of the injured nerve in such experiments than in the case where the latter procedures are made use of.

VI. The above methods may be used in a primary operation immediately after injury to the nerve, or as a secondary operation in cases when the operation is performed after a complete or partial healing of the wound. The results are quite as favorable in a secondary operation, although the return of function takes place somewhat more slowly.

VII. Making a nerve flap from the central or peripheral stump is, for the following reasons, not to be recommended : (a) The flap from the central end degenerates, and its connection with the central end does not prevent this; (b) The junction of the flap with the central end is a union not so 
favorable as when an implanted nerve segment is carefully sutured to the central stump; in the latter case the fibres of the implanted piece are brought end to end with the fibres of the central end, in the former not; $(c)$ The down-growing axis cylinders of the central end bud into the fibrous tissue and not into the reflected flap.

VIII. Regeneration through an engrafted connection between the peripheral part of a divided nerve and an accompanying uninjured nerve trunk is not possible.

IX. In the Létiévant-Tillmanns operation (cross-suturing the long ends of two divided nerves and engrafting the short ends to the accompanying long stump) regeneration of but one of the peripheral segments of the two injured nerves can be hoped for; the other peripheral segment remains degenerated; as there is no reason why a regeneration of both the peripheral stumps may not be attained after the implantation of a nerve segment between the respective ends of the two injured nerves, preference should be given to the latter method. 


\section{REFERENCES TO LITERATURE.}

See table of surgical operations for references to such cases.

Albert. Einige Operationen an Nerven. Wiener Med. Presse. Nos. 39 and 4I, I 885, Jahrg. 26. The first case of implantation reported in Verhandl. des Naturw.-Med. Vereines in Innsbruck. Jahrg. 9, I 878 , p. 97 .

Arloing et Tripier. Arch. de phys. norm. et path. I869-1876.

AsSaKy. De la suture des nerfs à distance. Arch. gén. de Méd. p. 529, I 886.

Benda. Verhandl. der Physiol. Gesellsch. zu Berlin. Jahrg. 1891-1892, Nos. 4 and 5, Dec. 18, 189 I.

BENEKE. Ueber die histologischen Vorgảnge in durchschnittenen Nerven. Virchow's Archiv. $\quad$ I872.

Bidder. Arch. f. Anat. u. Physiol. I842, p. 102.

Bruch. Ueber die Regeneration durchschnittener Nerven. Zeitschr. f. wissensch. Zool. Vol. vi, I855, p. $32 \mathrm{I}$.

BüNGER. Ueber die Degenerations- und Regenerationsvorgänge an Nerven nach Verletzungen. Beiträge z. pathol. Anat. u. z. Allgem. Pathol. Vol. $x, 1891$, p. 321 .

BüNGER. Bemerkung $z u$ der Arbeit von G. C. Huber, "Ueber das Verhalten der Kerne der Schwann'schen Scheide bei Nervendegenerationen." Arch.f. Mikr. Anat. Vol. xli, I893, p. 146.

EINSIEDEL. Ueber die Nervenregeneration nach Ausscheidung eines Nervenstückes. I 864 .

Flourens. Annales des Sciences Naturelles. T. xiii, I828, p. I 3.

GLÜCK. Ueber Transplantation, Regeneration und entzündliche Neubildung. Berl. Klin. Wochenschr. Sept. 12 and 19, I881.

GLÜCK. Ueber Neuroplastic auf dem Wege der Transplantation. IX. Congress der Deutschen Gesellsch. f. Chir. zu Berlin. Apr. 8, I880. Langenbeck's Arch. f. Klin. Chir. Vol, xxv, 1880.

GLüCK. Experimentelles zur Frage der Nervennaht und der Nervenregeneration. Virchow's Archiv. 1878.

GLück. Ueber Regeneration und entzündliche Neubildung. Verhandl. $d$. Berl. Med. Gesellsch. I $88 \mathrm{I}$.

GLïck. Transplantation im Allgemeinen und Chirurgische Plastic im Besonderen. Gesellsch. f. Heilkunde. May II, 1886.

Gluge et Thiernesse. Journ. de la Physiol. I859, p. 686

GunN. Union of nerves of different function considered in its pathological and surgical relation. Transactions of the American Surgical Association. Vol. iv.

HACKER, voN. Ein Beitrag zur secundären Nervennaht. Wiener Klin. Wochenschr. Oct. 18, 1894 . 
Howell and Huber. A Physiological, Histological, and Clinical Study of the Degeneration and Regeneration in Peripheral Nerve Fibres after Severance of their Connection with the Nerve Centers. Journ. of Physiol. Vol. xiii, 1892, and Vol. xiv, I893.

Huber. Ueber das Verhalten der Kerne der Schwann'schen Scheide bei Nerven-Degeneration. Arch. f. Mikr. Anat. Bd. xl, p. 409.

His. Zur Geschichte des menschlichen Rückenmarkes und der Nervenwurzeln. Abhandl. d. Math.-Phys. Klasse der kgl. Sächs. Gesellsch. d. Wissensch. Bd. xiii, $\mathrm{r} 886$.

HJElt. Ueber die Regeneration der Nerven. Virchow's Archiv. I86I. Johnson. Nord. Med. Arkiv. Bd. xiv, No. 27. (I have not been able to corroborate the above reference, which was taken from Tillmanns' article.)

KOLLIKER. Gewebelehre.

KöLLIKER, DR. TH. Die Verletzungen und chirurgischen Erkrankungen der peripherischen Nerven. Deutsche Chirurgie. Lief. $24 b, 1890$.

KoRybutt-Daskiewicz. Ueber Degeneration und Regeneration der markhaltigen Nerven. Inaugural-Dissertation. 1877.

Langenbeck und Hueter. Verhandl. d. Deutschen Gesellsch. $f$. Chir. V. Congress, S. Io6.

Leegard. Ueber die Entartungsreaction. Deutsch. Arch. f. Klin. Med. I 880 .

LÉtiévant. Traité des sections nerveuses. Paris, 1873 .

Mitchell, WeIr. Cases of Lesion of Peripheral Nerve-trunks with Commentaries. Am. Journ. of Med. Sc. July, 1883 .

Mitcheld, Weir. Injuries of Nerves. 1872.

Minot. Human Embryology.

Notтa. Sur un cas de régénération des nerfs du bras à la suite de leur destruction dans une étendue de cinq centimètres. Arch. gén. de Méd. $\quad$ I872.

Notтhaft, V. Neue Untersuchungen über den Verlauf der Degenerations- und Regenerationsprocesse an verletzten peripheren Nerven. Zeitschr.f. wissensch. Zool. Vol. 1, p. 134, 1893.

Philippeaux et Vulpian. Note sur des essais de greffe d'un tronçon du nerf lingual entre les deux bouts du nerf hypoglosse, après excision d'un segment de ce dernier nerf. Arch. de phys. norm. et path. 1870 .

RANVIER. Leçons sur l'histologie du système nerveux. 1878 .

Ranvier. De la régénération des nerfs sectionnés. Comptes Rendus. I873.

RANVIER and CornIl. Manual of Pathological Histology. 1882.

Rawa. Centralbl. f. Med. Wissensch. No. 34, I883.

SCH ÜLLER. Die Verwendung der Nervendehnung zur operativen Behandlung von Substanzverlusten an Nerven. Wiener Med. Presse. No. 5 , Jan. 29, I888, Jahrg. 29. 
StroebE. Experimentelle Untersuchungen über Degeneration und Regeneration peripherer Nerven nach Verletzung. Ziegler's Beiträge $z$. path. Anat. u. z. Allgem. Path. Bd. xiii, p. I6o.

Stroebe. Zur Technik der Achsencylinderfärbung im centralen und peripheren Nervensystem. Centralbl. f. Allgem. Path. u. Patholog. Anatomie. Bd. iv, 1893 .

Stroebe. Experimentelle Untersuchungen über die Degeneration und Reparatorischen Vorgänge bei der Heilung von Verletzungen des Rückenmarkes nebst Bemerkungen zur Histogenese der secundären Degeneration im Rückenmark. Ziegler's Beiträge z. path. Anat. u. z. Allgem. Path. Vol. xv, 3. Heft, I894.

Tiedemann. Zeitschr.f. Phys. Bd. iv, Heft 3, p. 386, 183 I.

Tillmanns. Ueber die Operativ-Behandlung von Substanzverlusten an peripheren Nerven. Verhandl. d. Deutschen Gesellsch. f. Chir. XIV. Congress, p. 21 3,1885 .

Torre. See Bizzozero über die Regeneration der Elemente der Gewebe unter pathologischen Bedingungen. Centralbl. f.d. Med. Wissensch. No. 5,1886 .

Torre. Also, Berichte in Sachen der Kerntheilung in den Nervenfasern nach Durchschneidung. Arch.f. Mik. Anat. Vol. xli, 1893 , p. 338.

TSCHIRSCHwirz. Ueber Nervennaht und Nervenplastik. InauguralDissertation. Berlin, I892.

Vanlair. De la régénération des nerfs périphériques par le procédé de la suture tubulaire. Comptes Rendus. T. xcv, p. 99.

VANLAIr. De la dérivation des nerfs. Arch. de Phys. 1885.

VANLAIR. De la névrotisation du cartilage osseux dans la suture tubulaire des nerfs. Arch. de Phys. 1882.

VanLair. Nouvelles recherches expérimentales, sur la régénération des nerfs. Arch. de Biologie. 1885.

VANLAIR. Sur le trajet et la distribution périphérique des nerfs régénérés. Arch. de Phys. 1886.

VANLaIR. La suture des nerfs. Bruxelles, I889.

VIgnal. Arch. de Phys. 1883.

WILlARD. Nerve-suturing (Neurorrhaphy); Degeneration and Regeneration following section; Microscopical Appearances. Internat. Med. Magazine. April, 1894.

WILlard. Nerve-suturing, Neurorrhaphy, Nerve-grafting. Med. News. Oct. 6, 1894 .

WoLbERG. Kritische und experimentelle Untersuchungen über die Nervennaht und Nervenregeneration. Deutsche Zeit. f. Chir. Vol. xviii, p. 502, 1882, and Vol. xix, p. 82, I884. 


\section{EXPLANATION OF PLATE XXXIV.}

All diagrams were made with the aid of the camera lucida.

FIG. I. Shows longitudinal section of the implanted segment two days after operation, fixed in Flemming's solution, and stained in safranin and licht grün. Leitz $\frac{1}{12}$ in., oil immersion, ocular No. 3. The medullary sheath is broken into irregular fragments ; $a$, nerve corpuscles; one of which seems to be in the early stages of karyokinetic cell division; $b$, polynuclear white blood cell.

FIG. 2. Cross-section of middle of implanted segment three days after operation. Fixed in Flemming's solution. Stained in safranin and licht grün. Leitz ${ }_{1}^{\frac{7}{2}}$, oil immersion, ocular No. 3. The cut ends of the nerve fibres are of irregular shape, varying in size and degree of degeneration. The myelin is stained black, and the protoplasm of the fibres of a reddish color; $a$, a nerve corpuscle; $b$, a nerve corpuscle in karyokinetic division. Large number of polynuclear white blood cells in the spaces between the nerve fibres; $c$, endoneural connective tissue cells; $d$, cell in diaster stage.

Frg. 3. Longitudinal section of impianted segment five days after operation. Hardened in Muiller's fluid, and stained in anilin blue. Leit $z \frac{1}{12}$ in., oil immersion, ocular No. 3. $a$, fragments of breaking-down axis cylinder stained deeply blue; $b$, nerve corpuscles; $c$, polynuclear white blood cell ; $a$, remains of medullary sheath.

FIG. 4. Longitudinal section of implanted segment nine days after implantation. Fixed in Flemming's solution, and stained in safranin and licht grün. Leitz $\frac{x}{13}$ in., oil immersion, ocular No. 3. Sheaths of implanted fibres filled with a faintly granular protoplasm; relatively few nerve corpuscles. The uppermost fibre contains one large and several small fragments of myelin.

FIG. 5. Degenerating fibre taken from peripheral ulnar one inch below peripheral wound, nine days after cutting the nerve, showing extent of degeneration and proliferation of nerve nuclei. Flemming's hardening. Stained in safranin and licht grün. Leitz ${ }_{I}^{2}$ in., oil immersion, ocular No. 3.

FIG. 6. Teased preparation from central wound twenty-one days after implantation. Hardened in Mujller's fluid, and stained in anilin blue and safranin. Leitz $\frac{1}{12}$ in., oil immersion, ocular No. 3. The figure shows the distal end of a fibre from central ulnar stump. $a$, enlarged distal end of axis cylinder ending free in embryonic fibre $(c) ; b$, fragments of myelin ; $d$, nerve corpuscles.

FIG. 7. Teased preparation from middle of implanted segment twenty-one days after implantation. Hardened in Müller's fluid, and stained in anilin blue and safranin after Stroebe. Leitz $\frac{1}{12}$ in., oil immersion, ocular No. 3. Shows the collapsed sheaths of nerve fibres of implanted segment. Polynuclear white blood cells and connective tissue cells between the fibres.

FIG. 8. Teased preparation from peripheral ulnar twenty-one days after section. Hardened in Müller's fluid, and stained in anilin blue and safranin. Leitz $\frac{1}{12}$ in., oil immersion, ocular No. 3 . $a$, fibre completely degenerated; $b$, shows remains of medullary sheath $(c) ; d$, ball of myelin containing fragment of old axis cylinder.

FrG. 9. Cross-section of middle of implanted segment thirty-nine days after implantation. Müller's fluid hardening. Stroebe's stain. Leitz $\frac{1}{12}$ in., oil immersion, ocular No. 3. Shows a large amount of connective tissue between old sheaths and new fbres. $a$, completely degenerated nerve fibres; $b$, developing fibres showing axis cylinder surrounded by delicate sheath; $c$, new fibre in old sheath. 


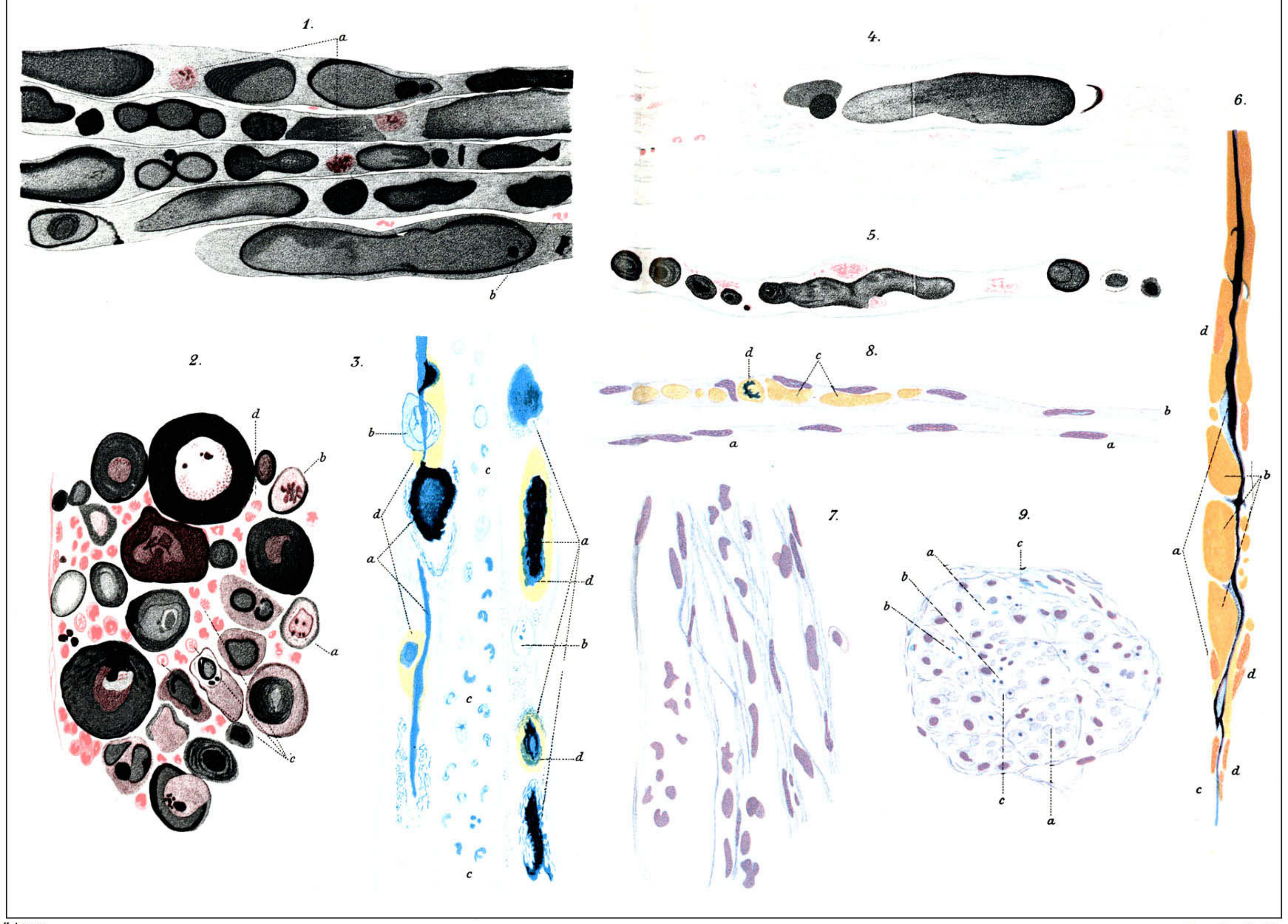




\section{EXPLANATION OF PLATE XXXV.}

Fig. 10. Teased preparation from implanted segment thirty-nine days after implantation, taken just below cross-section as shown in Fig. 9. Müller's fluid hardening. , Stroebe's stain. Leitz $\frac{1}{12}$ in., oil immersion, ocular No. 3. a, old sheaths; $b$, new fibres with delicate axis cylinder stained deeply blue, surrounded by small amount of protoplasm.

FIG. 1 I. Teased preparation from peripheral ulnar just below peripheral wound thirty-nine days after cutting nerve. Müller's fluid hardening. Stroebe's stain. Leitz $\frac{1}{12}$ in., oil immersion, ocular No. 3. a, nerve fibres with axis cylinder; $b$, old sheaths ; $c$, old sheath containing a number of balls of myelin.

Fig. 12. From teased preparation of peripheral end of central ulnar, one hundred and seventeen days after implantation. Müller's fluid hardening. Stroebe's stain. Leitz $\frac{1}{12}$ in., oil immersion, ocular No. 3. $(C)$ central end; $(P)$ peripheral end of fibre as shown in figure. $a$, old axis cylinder from which bud three young axis cylinders; $b$, one of which becomes the axis cylinder of a regenerated fibre at $c ; d$, node of Ranvier.

FIG. I3. Longitudinal section through central wound (connective tissue between stump of central ulnar and central end of implanted segment) one hundred and seventeen days after implantation. Müller's fluid hardening. Stroebe's stain. Leitz $\frac{1}{12}$ in., oil immersion, ocular No. 3. Coursing through the interlacing fibrous connective tissue $(a)$ are seen a number of small nerve bundles, some of which have quite a regular course $(b)$, others a serpentine course, winding their way through the connective tissue $(c) ; d$, a small bundle in cross-section. Some of the nerve fibres are medullated; $e$, small blood vessels.

FIG. 14. Longitudinal section of peripheral wound (connective tissue between stump of ulnar and peripheral end of implanted segment) of dog one hundred and seventeen days after implantation. Müller's fluid hardening. Stroebe's stain. Leit $z \frac{1}{12}$ in., oil immersion, ocular No. 3. $C$, central-ward; $P$, peripheral-ward. $b$, nerve fibres passing quite regularly through connective tissue; $c$, a bundle of nerve fibres evidently deflected in their course by the firmly organized mass of fibrous connective tissue at $a$.

FIG. I 5. Three fibres from teased preparation made from small muscular branch passing to flex. carp. ul. Müller's fluid hardening. Stroebe's stain. Leitz $\frac{1}{12}$ in., oil immersion, ocular No. 3. $A$, nerve fbre showing down-growing axis cylinder $(b)$ ending in bulbous enlargement $(c)$; young fibre contained in old sheath $(s) ; n, s$, new sheath; $n, m$, newly developed myelin. $B$, showing a similar condition except that peripheral end of down-growing axis cylinder has a wavy course; $b$, axis cylinder; $s$, old sheath $n, m$, newly developed medullary sheath. $C$, new nerve fibre with axis cylinder passing down between the old sheaths.

FIG. 16. Teased preparation from peripheral ulnar at wrist one hundred and seventeen days after cutting the nerve. The figure shows a number of typical fibres in different stages of degeneration and regeneration. Müller's fluid hardening. Stroebe's stain. Leitz $\frac{1}{12}$ in., oil immersion, ocular No. 3. $A$, completely degenerated fibre, no regeneration; $B$, degenerated fibre containing balls of broken-down myelin; $C$, new fibre with axis cylinder and a number of nerve corpuscles; $D$, axis cylinder in old degenerated fibre; $a$, two small fragments of myelin ; $E$, fibre showing down-growing axis cylinder ending in slight enlargement at $a ; b$, continuation of old sheath free from axis cylinders containing a small amount of protoplasm and two nerve corpuscles. 


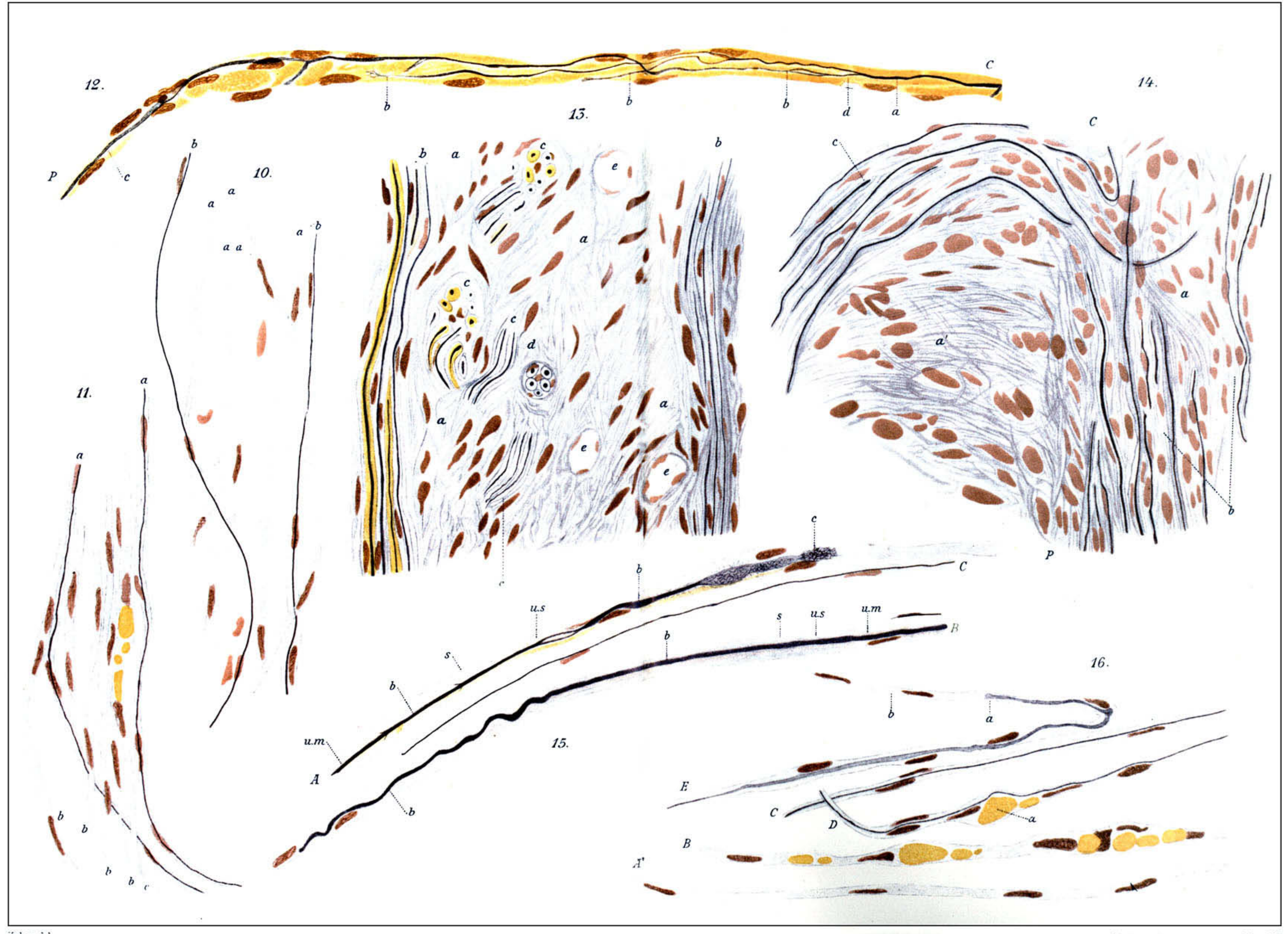




\section{EXPLANATION OF PLATE XXXVI.}

Fig. 17. Cross-section of upper end of implanted segment one hundred and fifty-two days after implantation. Müller's fluid hardening. Stroebe's stain. Leitz objective 7, ocular No. 3. Shows cross-section of small nerve bundles varying in size in groups of $3-5$, separated by a small amount of fibrous connective tissue.

FIG. 18. Cross-section of lower end of implanted segment one hundred and fifty-two days after implantation. Müller's fluid hardening. Stroebe's stain. Leitz objective 7 , ocular No. 3 . In this figure the nerve bundles $(a)$ are much more scattered than in Fig. 17, separated by a larger amount of fibrous connective tissue.

Fig. 19. Cross-section of peripheral ulnar at wrist one hundred and eighty-two days after implantation. Müller's fluid hardening. Stroebe's stain. Leitz $\frac{1}{y^{2} 2}$ in., oil immersion, ocular No. 3. $a$, completely regenerated fibres with welldeveloped axis cylinder and medullary sheath; $b$, regenerating fibres, axis cylinder deveioped but not the medullary sheath ; $c$, empty sheaths, probably of old fibres.

FIG. 20. Longitudinal section through tissue supplanting implanted bundle of catgut, one hundred and fifty-two days after implantation. The sketch was made of section taken about I ctm. below central wound. Müller's fluid hardening. Stroebe's stain. Bausch and Lomb $\frac{1}{4}$ in. obj., and Leitz ocular No. 3. C, centralward; $P$, peripheral-ward. A number of small nerve bundles are seen passing down between bundles of fibrous tissue. $a$, bundles having a course in line with axis of ulnar nerve in this portion of arm; $b$, a bundle having a wavy course $c c$ and $d$, passing in a direction nearly at right angles with the other nerve bundles ; $f$, blood vessels. It will be noticed that a relatively large amount of fibrous connective tissue intervenes between the nerve bundles.

FIG. 21. Cross-section through tissue supplanting implanted catgut bundle one hundred and fifty-two days after operation. The section was made about $2 \mathrm{ctm}$. below central wound. Müller's fluid hardening. Stroebe's stain. Bausch and Lomb $\frac{1}{4}$ in. obj., Leitz ocular No. 3. Many of the connective tissue bundles are seen in cross section $(a)$; some in longitudinal or oblique section $(b) ; c$, blood vessels; $d$, small nerve bundles in cross-section; $e$, bundles cut longitudinally in section, must, therefore, have had a course at right angles to longitudinal axis of ulnar nerve in this part of fore-leg. 


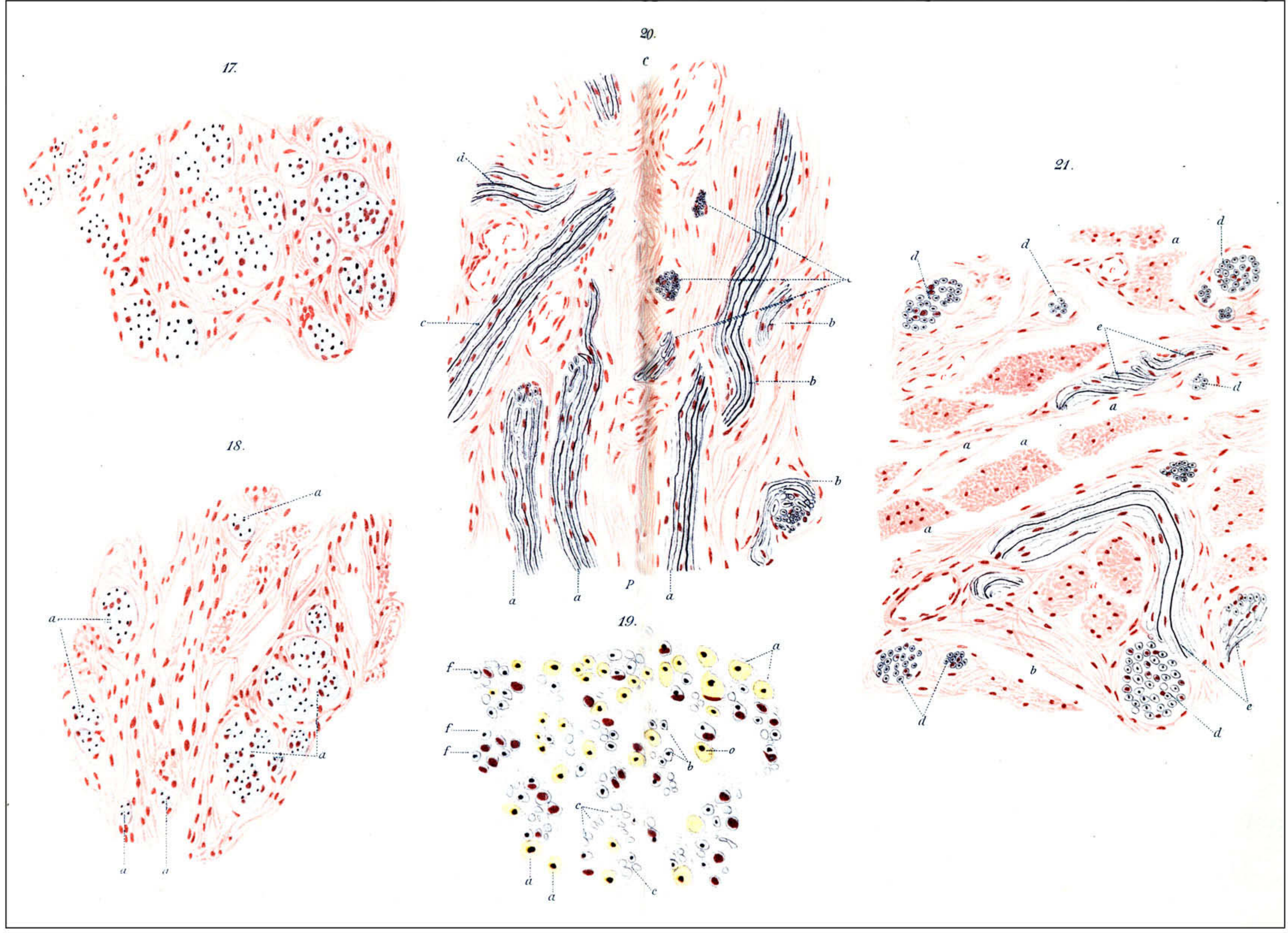

